André Iasi Moura

\title{
WBLS: um sistema de localização de dispositivos móveis em redes $\mathrm{Wi}$-Fi
}

Dissertação apresentada à Escola

Politécnica da Universidade de São

Paulo para a obtenção do Título de Mestre em Engenharia Elétrica. 
André Iasi Moura

\section{WBLS: um sistema de localização de dispositivos móveis em redes $\mathrm{Wi}$-Fi}

Dissertação apresentada à Escola

Politécnica da Universidade de São

Paulo para a obtenção do Título de

Mestre em Engenharia Elétrica.

Área de concentração:

Sistemas Digitais

Orientadora: Profa. Livre Docente

Anna Helena Reali Costa 


\section{Ficha Catalográfica}

Moura, André Iasi

WBLS: um sistema de localização de dispositivos móveis em redes Wi-Fi / A. I. Moura. - São Paulo, 2007.

120 p.

Dissertação (Mestrado) — Escola Politécnica da Universidade de São Paulo. Departamento de Engenharia de Computação e Sistemas Digitais.

1. Redes locais de computadores 2. Radionavegação 3. Processamento digital de sinais 4. Sistema de posicionamento global I. Universidade de São Paulo. Escola Politécnica. Departamento de Engenharia de Computação e Sistemas Digitais. II. t. 


\section{Resumo}

A proliferação de dispositivos móveis e de redes sem fio tem encorajado um crescente interesse em sistemas e serviços baseados na localização de dispositivos portáteis, especialmente em ambientes internos, como edifícios e residências. A localização de um dispositivo portátil é um parâmetro crítico em aplicações baseadas no contexto, as quais requerem grande precisão na estimativa de localização. Entretanto, projetar e desenvolver sistemas de localização em interiores, com crescente precisão na estimação e decrescente custo de instalação, é um problema desafiador. Uma abordagem bastante interessante para satisfazer os requisitos de baixo custo consiste em utilizar as infra-estruturas existentes de redes locais sem fio (WLAN) no padrão IEEE 802.11, que já estão instaladas em muitos ambientes. A maioria das abordagens para localização usando WLAN propostas na literatura é baseada em técnicas probabilísticas, que apresentam bom desempenho e estão cada vez mais populares. Estas técnicas usam um mapa com a informação da potência recebida do sinal (RSSI) juntamente com a freqüência de presença de sinal coletada de múltiplos pontos de acesso Wi-Fi, em diferentes localizações físicas no ambiente. Porém, a informação sobre freqüência de presença de sinal pode ser muito ruidosa devido à natureza imprevisível das falhas de transmissão, as quais podem ocorrer decorrentes de diversos fatores. Este trabalho propõe um novo sistema de localização Wi-Fi, o WBLS (Wireless Based Location System), que não considera a informação sobre freqüência de presença de sinal no processo de estimação, visando eliminar os ruídos a ela associados. O WBLS explora o fato da potência do sinal Wi-Fi variar com a localização e usa um HMM descrito em um grafo onde os nós representam as localizações e as arestas, as probabilidades de transição em função da topologia do ambiente e das velocidades esperadas de um pedestre portando um dispositivo móvel. Investiga-se em que situações a eliminação da informação sobre freqüência de presença de sinal devido a seus ruídos associados aumenta a exatidão da estimativa de localização, apesar do descarte da informação em si. Os experimentos realizados demonstram que a característica mais importante do WBLS é uma particular robustez ao lidar com desligamentos de pontos de acesso, os quais podem ocorrer sem nenhum aviso ou previsão em um ambiente onde pouco controle se tem sobre sua infra-estrutura. 


\section{Abstract}

The proliferation of mobile computing devices and wireless networks has fostered a growing interest in location-based systems and services for Portable Wireless Devices, specially in indoor environments. The location of a handheld device is a critical parameter in context-aware applications, which require high degree of accuracy of location estimation. However, designing and developing indoor location systems with increasing estimation accuracy and decreasing cost installation is a challenging problem. A very interesting approach to reach low-cost requirements consists in using the pre-existing IEEE 802.11 wireless local area network (WLAN) infrastructure that is already installed in many places. Most of the WLAN indoor location approaches proposed in the literature are based on probabilistic techniques which show good performance and are becoming increasingly popular. Such approaches use a map of received signal strength information and signal presence frequency collected from multiple Wi-Fi access points at different physical locations in the environment. However, the signal presence frequency information can be very noisy due to the unpredictable nature of transmissions failures, which can be caused by several factors. This work proposes a new probabilistic-based Wi-Fi location system, WBLS (Wireless Based Location System), which doesn't take the signal presence frequency information into account in the estimation process, in an attempt to eliminate its associated noise. WBLS exploits the fact that Wi-Fi signal strength vary with location, and uses an HMM on a graph of location nodes whose transition probabilities are a function of the building's floor plan and expected speeds of a pedestrian holding a portable device. We investigate if eliminating signal presence frequency information due to its associated noise increases the accuracy of the location estimation, despite the amount of information about the signal presence that is discarded. Experiments show that the most important feature of WBLS is a particular robustness while dealing with access points shutdowns that may happen without any warning in an environment where there is little control over the infrastructure. 


\section{Lista de Figuras}

2.1 Características da RSSI observada em redes Wi-Fi . . . . . . . . . . . 16

2.2 Técnica de triangulação que utiliza a informação do ângulo do sinal. . . . . 17

2.3 Técnica de triangulação que utiliza a informação da distância entre emissor e receptor. . . . . . . . . . . . . . . . . . . . . . 18

3.1 Representação de uma cadeia de Markov. . . . . . . . . . . . . . . . . . . . 41

3.2 Esquema do algoritmo de localização completo. . . . . . . . . . . . . . 45

4.1 Distribuições de probabilidade do estado calculadas pelo algoritmo de localização . . . . . . . . . . . . . . . . . . . . . . 50

4.2 Distribuição das probabilidades de observação em dois instantes consecutivos 52

4.3 Distribuição da RSSI de um sinal . . . . . . . . . . . . . . . . . . 53

5.1 Planta da área onde foram realizados os experimentos. . . . . . . . . . . 61

5.2 Caminhos percorridos nos experimentos de localização com o dispositivo em movimento. . . . . . . . . . . . . . . . . . 63

5.3 Desempenho de sistemas propostos na literatura em termos dos erros médios obtidos em função da combinação de PAs presentes. . . . . . . . . . . 68

5.4 Desempenho do sistema básico com dados simulados variando o coeficiente de correlação $\alpha \ldots \ldots$. . . . . . . . . . . . . . . . . 70

5.5 Desempenho do WBLS com dados simulados variando o coeficiente de cor-

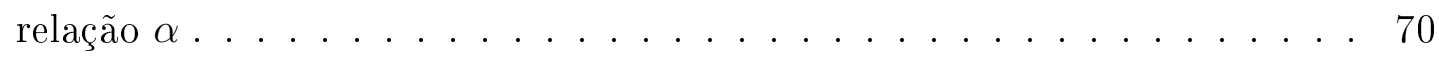

5.6 Comparação de desempenho entre o WBLS e o sistema básico em três grupos de dados simulados . . . . . . . . . . . . . . . . . 71

5.7 Comparação de desempenho entre o WBLS e o sistema básico com dados de percursos realizados em ambiente real . . . . . . . . . . . . 72 
5.8 Comparação de desempenho entre o WBLS e o sistema básico desconsiderando PA com falha. . . . . . . . . . . . . . . . . . . . . 73

5.9 Comparação de desempenho entre o WBLS e o sistema básico com simulação de desligamento de certos PAs durante os percursos . . . . . . . . . . 75

A.1 Arquitetura distribuída para um serviço de localização Wi-Fi. . . . . . . . . 89

A.2 Camadas inferiores de um modelo de interconexão de um dispositivo que implementa a especificação 802.11. . . . . . . . . . . . . . . . . . . . . 90

A.3 Canais de transmissão para redes Wi-Fi. . . . . . . . . . . . . . . . 95

A.4 Configuração ideal para implementação de redes vizinhas. . . . . . . . . . . . 96

A.5 Utilização de mesmo canal no mesmo espaço físico. . . . . . . . . . . . . . 97

A.6 Distribuições da RSSI de sinais que se aproximam da sensibilidade . . . . . 107

A.7 Sensibilidade do aparelho usado nos experimentos. . . . . . . . . . . . . . 108

B.1 Comparação de desempenho entre sistemas propostos na literatura em função de diferentes medidas . . . . . . . . . . . . . . . . . . . . . . . . . 110

B.2 Desempenho do sistema básico com dados simulados variando o coeficiente de correlação $\alpha$ em função de diferentes medidas . . . . . . . . . . . . . . . . 111

B.3 Desempenho do WBLS com dados simulados variando o coeficiente de correlação $\alpha$ em função de diferentes medidas . . . . . . . . . . . . . . . . . . 112

B.4 Comparação de desempenho entre o WBLS e o sistema básico em caminhadas simuladas com $\alpha=1$, em função de diferentes medidas . . . . . . . 113

B.5 Comparação de desempenho entre o WBLS e o sistema básico em caminhadas simuladas com $\alpha=0,8$, em função de diferentes medidas . . . . . . 114

B.6 Comparação de desempenho entre o WBLS e o sistema básico em caminhadas simuladas com $\alpha=0,6$, em função de diferentes medidas . . . . . . 115

B.7 Comparação de desempenho entre o WBLS e o sistema básico com dados de percursos realizados em ambiente real, em função de diferentes medidas 116

B.8 Comparação de desempenho entre o WBLS e o sistema básico desconsiderando PA com falha, em função de diferentes medidas . . . . . . . . . . . . 117

B.9 Comparação de desempenho entre o WBLS e o sistema básico com simulação do desligamento de um PA com baixa presença . . . . . . . . . . . 118 
B.10 Comparação de desempenho entre o WBLS e o sistema básico com simulação do desligamento de um PA com alta presença . . . . . . . . . . . . . 119

B.11 Comparação de desempenho entre o WBLS e o sistema básico com simulação de desligamento de dois PAs . . . . . . . . . . . . . . . . . . . . 120 


\section{Lista de Tabelas}

2.1 Variação de RSSI médio observado em função da distância do PA. . . . . . 15

2.3 Características dos principais trabalhos de localização Wi-Fi. . . . . . . . . 30

4.1 Freqüência de presença e RSSI de sinais em uma mesma sala. . . . . . . . . 54

5.1 Teste $\mathrm{T}$ para o primeiro experimento em ambiente real (figura 5.7). . . . . 73

5.2 Teste $\mathrm{T}$ para o segundo experimento em ambiente real (figura 5.8). . . . . 73

5.3 Teste $\mathrm{T}$ para o primeiro experimento com perda de sinal. . . . . . . . . . 76

5.4 Teste $\mathrm{T}$ para o segundo experimento com perda de sinal. . . . . . . . . . 76

5.5 Teste $\mathrm{T}$ para o terceiro experimento com perda de sinal. . . . . . . . . 76

A.1 Trechos de seqüências de RSSIs observadas no Linux e no Windows. . . . . 106 


\title{
Lista de Abreviaturas e Siglas
}

\author{
ACK Acknowledge \\ AOA Angle Of Arrival \\ CM Cadeia de Markov \\ CSMA/CA Carrier Sense Media Access / Collision Avoidance \\ CTS Clear To Send
}

DGPS Diferential Global Positioning System

GPS Global Positioning System

HMM Hidden Markov Model

k-NNSS K-Nearest Neighbor in Signal Space

LME Layer Manegement Entity

LOS Line of Sight

LSA Limiar de Sensibilidade Absoluta

MAC Media Access Control

MLP Multi-Layer Perceptron

NDIS Network Driver Interface Specification

NLOS Non Line of Sight

OFDM Ortogonal Frequency Division Multiplexing

OSI Open System Intereconnection

PA Ponto de Acesso

PDA Personal Digital Assistent 
PHY Physical Layer

PLCP Physical Layer Convergence Protocol

PM Ponto de Medida

PMD Physical Medium Dependent

RSSI Received Signal Strength Indication

RTS Request To Send

TDOA Time Diference of Arrival

TOA Time Of Arrival

WBLS Wireless Based Location System

Wi-Fi Wireless Fidelity

WLAN Wireless Local Area Network 


\section{Lista de Símbolos}

Conjuntos, Tuplas e Vetores

- $A$ - conjunto de pontos de acesso

- $C_{i}$ - vetor de características armazenado no registro $i$ do mapa de RSSI

- $E$ - conjunto de estados

- $O_{t}$ - vetor de observações no instante $t$

- $R_{i}-\left(e_{i}, C_{i}\right)$, tupla que representa as informações armazenadas no registro $i$ do mapa de RSSI

- $R s s i_{i, a}$ - conjunto de parâmetros que descreve a distribuição de probabilidade de RSSI do PA a no PM correspondente ao registro $i$ do mapa de RSSI

\section{Elementos}

- $b_{i, a, n}$ - altura da barra $n$ do histograma do PA a no registro $i$ do mapa de distribuição de RSSI

- $e_{i}$ - estado de localização $i$

- $l_{t}$ - localização do dispositivo no instante $t$

- $o_{a, t}$ - observação da RSSI do PA $a$ feita no instante $t$

- $p_{a}$ - ponto de acesso $a$

- rssi - valor da observação da RSSI de um PA

\section{PARÂMETROS}

- $f_{a, i}$ - freqüência de presença do sinal do PA $a$ no registro $i$ do mapa de distribuição de RSSI 
- $x, y$ - coordenadas de um estado de localização

- $z_{t}$ - número de sinais presentes na observação $O_{t}$

- $\alpha$ - coeficiente de correlação entre as freqüências de presença dos sinais gravadas no mapa de RSSI e as freqüências de presença dos sinais durante um percurso simulado

- $\eta, \eta^{\prime}$ - fatores de normalização

- $\eta_{a, i}$ - fator de normalização de $G_{a, i}(r s s i)$

- $\mu_{i, a}$ - média da função de distribuição de RSSI do PA a no registro $i$ do mapa de distribuição de RSSI

- $\sigma_{i, a}$ - variância da função de distribuição de RSSI do PA a no registro $i$ do mapa de distribuição de RSSI

- $v$ - um número aleatório entre 0 e 1

VARiáveis Aleatórias e Proposições

- $\mathbf{o}_{a}-\mathrm{RSSI}$ observada do PA $a$

- $\mathbf{q}$ - variável de estado

- $\mathbf{q}_{t}$ - variável de estado no instante $t$

- $\mathbf{S}_{a}$ - proposição que afirma presença de sinal do PA $a$, equivalente a $\mathbf{o}_{a} \geq \mathcal{R}$ min.

\section{ÍNDICES}

- $a$ - índice de PA

- $g$ - índice genérico

- $i, j$ - índices de estado

- $n$ - índice de uma barra em um histograma

- $t$ - índice de tempo discreto 
- $\mathcal{A}$ - número de PAs

- $\mathcal{I}$ - número de estados

- $\mathcal{N}$ - número de barras em um histograma

- Rmin - valor mínimo de RSSI

- $\mathcal{R} \max$ - valor máximo de RSSI

FunÇÕES E Probabilidades

- $G_{a, i}(r s s i)$ - função que discretiza a gaussiana que representa a distribuição de RSSI do PA a no PM correspondente ao registro $i$ do mapa de distribuição de RSSI

- $K\left(e_{i}\right)$ - função de núcleo usada na interpolação do mapa de RSSI

- $\mathbf{P}(\mathbf{x})$ - distribuição de probabilidade dos valores de uma variável aleatória $\mathbf{x}$

- $P(\chi)$ - probabilidade de $\chi$ ocorrer

- $P(\chi \mid \phi)$ - probabilidade de $\chi$ ocorrer dado que $\phi$ é verdadeiro

- $P_{\text {trans }}\left(e_{j}, e_{i}\right)$ - representação de $P\left(\mathbf{q}_{t+1}=e_{i} \mid \mathbf{q}_{t}=e_{j}\right)$, probabilidade de ocorrer a transição do estado $e_{j}$ para o estado $e_{i}$ 


\section{Sumário}

1 Introdução 4

1.1 Localização Wi-Fi . . . . . . . . . . . . . . . . . . . . . . 6

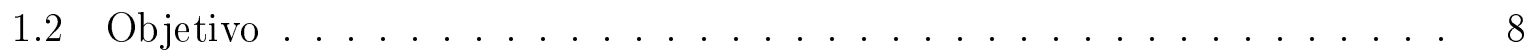

1.3 Organização do trabalho . . . . . . . . . . . . . . . . . 10

2 Localização em redes Wi-Fi $\quad 12$

2.1 Características do problema de localização em redes Wi-Fi $\quad \ldots . . .12$

2.2 Técnicas de localização com sinais de rádio-freqüência . . . . . . . . . . . . 16

2.2.1 Técnicas que utilizam triangulação . . . . . . . . . . . . . . . 17

2.2.2 Técnicas que utilizam um modelo discreto do ambiente . . . . . . . 20

2.2.3 Técnicas que utilizam redes neurais . . . . . . . . . . . 25

2.3 Comparação e análise dos trabalhos sobre localização Wi-Fi $\quad$. . . . . . . 27

2.3.1 Histórico dos trabalhos realizados em localização Wi-Fi . . . . . . . 27

2.3.2 Questões relacionadas à metodologia da parte experimental . . . . . 31

2.3.3 Análise do desempenho das técnicas com base nos trabalhos apre-

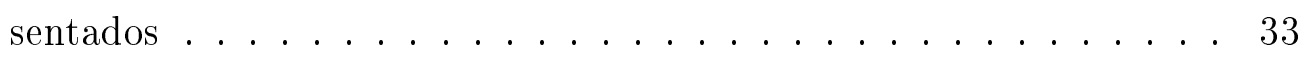

2.3.4 Adaptabilidade a variações no ambiente . . . . . . . . . . . 35

3 Um sistema básico de localização Wi-Fi 37

3.1 A fase de treinamento: construção do mapa de RSSI . . . . . . . . . . . 37

3.1 .1 Realização das medidas de observação . . . . . . . . . . . . . . 38

3.1.2 O armazenamento da informação obtida . . . . . . . . . . . . 39

3.2 A fase de execução: localização markoviana em redes Wi-Fi . . . . . . . . . 40 
3.2.1 O modelo de estados ocultos de Markov - HMM . . . . . . . . . . . 41

3.2 .2 O algoritmo de localização . . . . . . . . . . . . . . . . . . . 44

3.3 Especificações do sistema básico de localização Wi-Fi . . . . . . . . . . . . 46

4 WBLS: o sistema de localização proposto 49

4.1 Definição do foco de desenvolvimento da proposta . . . . . . . . . . . . . . . 49

4.1 .1 Análise crítica do sistema básico . . . . . . . . . . . . . . . . . . 49

4.1.2 Análise do ruído característico da informação . . . . . . . . . . . . 52

4.2 Descrição do WBLS . . . . . . . . . . . . . . . . . . . . . 54

4.2.1 A alteração proposta no sistema básico . . . . . . . . . . . . . 55

4.2 .2 Análise matemática da proposta . . . . . . . . . . . . 56

4.3 Discussão sobre implicações da proposta . . . . . . . . . . . . . . . 58

$\begin{array}{llr}5 & \text { Parte experimental } & 60\end{array}$

5.1 O ambiente de testes . . . . . . . . . . . . . . . 60

5.2 Metodologias para realização dos experimentos . . . . . . . . . . . . . . 61

5.2.1 Captura das seqüências de observações dos caminhos . . . . . . . . 62

5.2.2 O simulador de um dispositivo em movimento . . . . . . . . . . . . 64

5.2.3 Realização dos experimentos . . . . . . . . . . . . . . . . 65

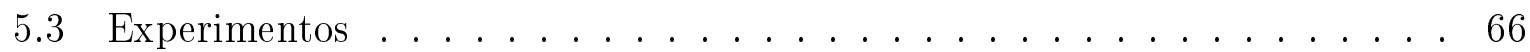

5.3 .1 Testes preliminares . . . . . . . . . . . . . 67

5.3.2 Análise de desempenho sem perda de sinal . . . . . . . . . . . 68

5.3.3 Análise de desempenho com perda de sinal de um PA . . . . . . . . 74

5.3 .4 Discussão dos resultados . . . . . . . . . . . . . . . 76

$\begin{array}{llr}6 & \text { Conclusão } & 78\end{array}$

6.1 Contribuições do trabalho . . . . . . . . . . . . . . . . 78

6.2 Trabalhos futuros . . . . . . . . . . . . . . . . . . . . . 79 
6.3 Considerações finais . . . . . . . . . . . . . . . . . . . . 80

$\begin{array}{ll}\text { Referências } & 81\end{array}$

Apêndice A - Questões técnicas sobre infra-estrutura para localização Wi-

$\begin{array}{ll}\text { Fi } & 87\end{array}$

A.1 Arquiteturas para um serviço de localização Wi-Fi . . . . . . . . . . . . . 87

A.2 Especificação 802.11 para redes Wi-Fi . . . . . . . . . . . . . . . . . . 90

A.2.1 A sub-camada MAC . . . . . . . . . . . . . . . 90

A.2.2 A camada PHY . . . . . . . . . . . . . . . . . . . 94

A.3 Hardware e Drivers . . . . . . . . . . . . . . . . . . . . . . . . . . . 101

A.3.1 A rede sem fio no Windows . . . . . . . . . . . . . . . . 102

A.3.2 A rede sem fio no Linux . . . . . . . . . . . . . . . . . 103

A.3.3 Comparação entre plataformas para a realização de experimentos . 105

A.3.4 Análise da sensibilidade do aparelho utilizado nos experimentos . . 106

Apêndice B - Resultados completos dos experimentos realizados $\quad 109$

B.1 Testes preliminares . . . . . . . . . . . . . . . . 110

B.2 Experimentos com dados simulados . . . . . . . . . . . . . . . 111

B.3 Experimentos em ambiente real . . . . . . . . . . . . . . . 116

B.4 Experimentos com perda de sinal . . . . . . . . . . . . . . . 118 


\section{Introdução}

Tem sido visto nos últimos anos um crescimento acentuado na utilização de dispositivos portáteis com processadores de alto desempenho, como lap-tops e PDAs (Personal Digital Assistent), ao ponto de tais dispositivos passarem a fazer parte do cotidiano das pessoas. Essa nova condição traz uma série de possibilidades a serem exploradas e tem influências em diversas áreas de pesquisa. Uma das áreas que tem atraído bastante interesse nos últimos anos, por estar vinculada ao aumento da capacidade dos processadores existentes no mercado, é a de aplicativos que consideram o contexto em que estão inseridos. Aplicativos orientados a contexto podem escolher a forma e o momento de se comunicar com o usuário, fornecendo informações relevantes e úteis, em função da situação em que o dispositivo e o usuário se encontram, das ações do usuário e de sua história pregressa. Tais aplicativos geralmente possuem mecanismos de inferência sobre os tipos de atividade e os objetivos que o usuário busca alcançar. Quando um aplicativo orientado a contexto é executado em um dispositivo móvel, uma informação que pode ser importante para esse processo é a localização deste dispositivo no ambiente em que ele se encontra.

Uma série de trabalhos com foco em aplicativos orientados a contexto e que fazem uso da informação de localização do dispositivo vem sendo apresentada nos últimos anos. Sparacino (2003) e Abowd et al. (1997), por exemplo, propõem guias para museus ou escolas na forma de dispositivos portáteis que podem fornecer a seus usuários informações sobre as obras que o cercam, sugestões de seções a visitar em função de uma análise dos lugares já visitados, ou ajudá-los a encontrar o que procuram partindo da posição em se encontram, tarefas que dependem fundamentalmente de um serviço de localização.

Outros exemplos interessantes são os projetos de casas inteligentes (BRUMITT et al., 2000; DEY; ABOWD; SALBER, 1999). Em tais projetos, todos os dispositivos dentro de uma residência planejada estão integrados e se comunicam com um sistema central. O sistema costuma analisar o comportamento e as ações dos usuários da casa e pode controlar automaticamente o acendimento de lâmpadas, o acionamento do ar condicionado, o acesso a determinados ambientes, ou fornecer informações que ajudem aos usuários da 
casa na utilização de seus equipamentos de forma a otimizar a eficiência do consumo de energia e maximizar o conforto dos usuários, entre outras coisas. Nestes trabalhos, serviços de localização para dispositivos portáteis servem para fornecer dados importantes sobre o comportamento de seus usuários, além de fornecer informação de contexto para os aplicativos executados em tais dispositivos quando se comunicam com o sistema central da casa.

Aplicativos orientados a contexto representam uma parcela importante da demanda por serviços de localização; no entanto, diversos tipos de aplicativo de roteamento, de busca, de geração de informação contextual, de auxílio a deficientes físicos, de alocação de recursos, entre outros, podem ser beneficiados pela existência de um serviço de localização eficiente e confiável. Dessa forma, é fácil imaginar que esse tipo de serviço tende a se tornar componente integrante dos aparelhos portáteis e, por isso, muito se tem estudado e escrito sobre o tema.

Quando se trata de sistemas de localização, sem dúvida o mais conhecido de todos é o GPS (Global Positioning System) (LONGSDON, 1995). O GPS é um sistema de geolocalização que cobre toda a superfície do globo terrestre oferecendo um erro de estimativa máximo de 10 metros em áreas abertas. Esse erro pode ainda ser reduzido para a ordem de centímetros fazendo-se uso de uma estação de referência, num sistema que é chamado de DGPS (Diferential Global Positioning System) (WüBBENA et al., 1996). Ambos os sistemas - GPS e DGPS - utilizam sinais enviados por satélites para que os dispositivos possam estimar sua localização, o que resulta em um problema: para um dispositivo realizar sua estimativa é necessário que os sinais de um número mínimo de satélites sejam recebidos por ele. Conseqüentemente, estes sistemas não funcionam adequadamente dentro de ambientes fechados como edifícios ou casas, ou mesmo em espaços urbanos cercados de construções muito altas e, assim, não podem ser utilizados em determinadas aplicações.

As companhias de telefonia celular têm sistemas de localização que utilizam como referência os sinais recebidos dos aparelhos celulares pelas suas antenas, podendo analisar o tempo de viagem, a potência ou o ângulo com que o sinal de cada aparelho chega à antena ou simplesmente reportar a posição da antena à qual cada aparelho está associado. Estes sistemas fornecem informações de localização inclusive quando os aparelhos se encontram dentro de edifícios, mas a complexidade da propagação das ondas eletromagnéticas próximas ao chão (NESKOVIC; NESKOVIC; PAUNOVIC, 2000) e a quantidade imprevisível de obstáculos como paredes, objetos e pessoas, afetam seu desempenho ${ }^{1}$. Além disso, há a

\footnotetext{
${ }^{1}$ Neste trabalho, o termo desempenho, quando usado para caracterizar um sistema de localização, está relacionado principalmente à qualidade das estimativas e não à eficiência computacional dos sistemas.
} 
questão do freqüente baixo número de antenas presentes no raio de alcance do aparelho, situação agravada pela política de controle da potência do sinal, cujo objetivo é evitar interferências entre os sinais de aparelhos localizados na mesma célula (CAFFERY; STüBER, 1998; BALBACH, 2000).

Nos Estados Unidos há uma legislação que requer que as companhias de celular sejam capazes de localizar aparelhos conectados à sua rede com um erro de estimativa máximo de $125 \mathrm{~m}$ em pelo menos $67 \%$ das vezes (FCC, 1996). De fato, as estimativas de sistemas de localização utilizando as antenas de celular - seja empregando tecnologia GSM ou CDMA - dificilmente devem superar essa ordem de grandeza em termos de precisão e exatidão (CAFFERY; STüBER, 1998; BALBACH, 2000). Os melhores resultados de que se tem notícia nos dias de hoje são anunciados por alguns sistemas comerciais que prometem um erro médio de 10m, mas apenas em regiões onde a densidade de antenas é muito grande.

Alguns sistemas de alta precisão foram desenvolvidos para localização em ambientes fechados. Dentre estes, pode-se citar sistemas que usam sinais de ultra-som (HAZAS, 2002) e infra-vermelho (KRUMM; WILLIAMS; SMITH, 2002), os quais chegam a apresentar erro de estimativa máximo de apenas poucos centímetros, mas que possuem um custo de implantação proibitivo, já que o ambiente teria que ser todo coberto por sensores para que pudesse ser completamente monitorado e os sistemas apresentassem um bom desempenho.

\subsection{Localização Wi-Fi}

Uma idéia alternativa aos sistemas baseados em sinais de ultra-som, de infra-vermelho, de antenas de celular e de satélites para resolver o problema de localização em ambientes fechados é estabelecer um compromisso entre o tamanho das células de cobertura e o custo do investimento em infra-estrutura. Essa alternativa tem se concretizado através da exploração dos sinais das redes Wi-Fi.

Wi-Fi (Wireless Fidelity) é um termo que identifica redes e dispositivos que implementam a especificação IEEE 802.11 para redes sem fio (ANSI/IEEE, 1999). Uma rede Wi-Fi estruturada, que é o objeto de estudo deste trabalho, é composta por dispositivos que se comunicam por sinais de rádio-freqüência dentre os quais um ou mais são Pontos de Acesso (PA). PAs são dispositivos que, por um lado, conectam-se à rede cabeada e, por outro, comunicam-se com os outros dispositivos Wi-Fi através de sinais de rádio-freqüência, servindo como ponte para que tais dispositivos acessem a rede ${ }^{2}$.

\footnotetext{
${ }^{2} \mathrm{~A}$ especificação IEEE 802.11 descreve também redes $a d$-hoc, onde não existem PAs, mas como elas não são de interesse para o presente trabalho, sempre que aqui se usar a expressão "rede Wi-Fi" estar-se-á
} 
Com o aumento da utilização de lap-tops e PDAs e considerando que a implantação de uma rede cabeada pode ser complicada dependendo da estrutura física do ambiente, cada vez mais se opta pela utilização de redes Wi-Fi. Muitos edifícios como shopping centers, escolas, escritórios, fábricas e outros já possuem vários PAs em funcionamento, fornecendo acesso às suas respectivas redes. Essa infra-estrutura pode ser utilizada por um sistema de localização que analise os sinais das redes para inferir coordenadas de posição dos dispositivos no ambiente. À primeira vista, apesar de sofrer dos mesmos problemas de imprevisibilidade da forma de propagação do sinal que os sistemas que usam antenas de celular sofrem, o fato de as células de cobertura das redes Wi-Fi serem menores, por si só, já implicam maior precisão e exatidão.

Como um dos principais objetivos do estudo de localização de dispositivos móveis em redes Wi-Fi - chamada daqui para frente apenas de localização Wi-Fi - é a utilização de uma infra-estrutura já existente, minimizando ou, se possível, eliminando a necessidade de instalações de novos aparelhos ou mesmo de alterações nos aparelhos existentes, a informação que costuma ser usada para efetuar as estimativas de localização é a potência do sinal recebido, também conhecida como RSSI (Received Signal Strength Indication). A RSSI é uma informação que os drivers da rede Wi-Fi sempre fornecem, já que é uma informação útil para a escolha de associação entre possíveis redes disponíveis.

Na maioria dos trabalhos reportados na literatura sobre localização Wi-Fi (BAHL; PADMANBHAM, 2000; BERNA et al., 2003; BRUNATO; KALLó, 2002; ELNAHRAWY; LI; MARTIN, 2004; HAEBERLEN et al., 2004; HOWARD; SIDDIQI; SUKHATME, 2003; KRUMM; HORVITZ, 2004; LADD et al., 2002; ROOS et al., 2002; SAHA et al., 2003; TAO et al., 2003; XIANG et al., 2004; YOUSSEF; AGRAWALA, 2005), o processo de localização é feito em duas fases. Na primeira, é construído um banco de dados que armazena a informação das RSSIs e das freqüências de presença dos sinais provenientes dos diversos PAs que se encontram no ambiente, informação esta que é obtida por um dispositivo móvel que realiza observações em diferentes localizações físicas do ambiente. Esse banco de dados costuma ser chamado de mapa de RSSI.

Na segunda fase, esse mapa é então usado como referência para determinar a qual das posições gravadas o conjunto de valores de RSSI que um dispositivo observa num determinado momento deve corresponder, possibilitando assim a estimativa de localização. A forma como isso é feito varia de trabalho para trabalho, mas um grande número deles utiliza métodos probabilísticos (ELNAHRAWY; LI; MARTIN, 2004; KRUMM; HORVITZ, 2004; HAEBERLEN et al., 2004; LADD et al., 2002; ROOS et al., 2002; YOUSSEF; AGRAWALA, 
2005; BERNA et al., 2003; XIANG et al., 2004), pois são esses os que apresentam melhores resultados práticos. Esses métodos possuem dois componentes básicos: um módulo para o cálculo da probabilidade de obtenção das RSSIs medidas em um determinado momento - a chamada probabilidade de observação -; e um módulo para o cálculo da probabilidade de transição entre localizações consecutivas do dispositivo - a chamada probabilidade de transição. A combinação dos resultados dos cálculos realizados em cada módulo define uma distribuição de probabilidade no universo de estados de localização, estados estes que correspondem a posições pré-definidas no ambiente. Com base nesta distribuição, estima-se então a localização do dispositivo.

Apesar de um grande número de trabalhos sobre localização Wi-Fi ser encontrado na literatura, apenas uma pequena parcela deles apresenta uma análise do desempenho dos sistemas quando estes estimam a localização de dispositivos em movimento. Esse tipo de situação - que deve ser a mais comum em diversas classes de aplicações (ABOWD et al., 1997; ASTHANA; CRAVATTS; KRZYZANOWSKI, 1994; SPARACINO, 2003) - tem características particulares que implicam maiores dificuldades para um sistema de localização. Quando os trabalhos comparam os resultados de experimentos realizados com dispositivos em movimento aos resultados de experimentos realizados com dispositivos parados, os primeiros costumam se mostrar consideravelmente piores (BAHL; PADMANBHAM, 2000; LADD et al., 2005), o que deixa claro que eles constituem um caso crítico e que devem ser analisados mais a fundo.

\subsection{Objetivo}

O foco deste trabalho é o estudo de sistemas de localização em redes Wi-Fi em um contexto onde os dispositivos a serem localizados freqüentemente se encontram em movimento, em ambientes fechados que oferecem pouco ou nenhum controle sobre sua infra-estrutura de redes sem fio.

As principais dificuldades que este tipo de sistema enfrenta estão relacionadas com o fato de ter que lidar com uma informação muito ruidosa. A característica da propagação de ondas eletromagnéticas (como os sinais Wi-Fi) em ambientes internos e as interferências causadas pelas pessoas que transitam por ele, entre outras coisas, faz com as RSSIs apresentem variações relativamente grandes e de difícil previsibilidade.

Uma conseqüência disso, e fonte certa de ruído na informação que o sistema recebe, é o fato de a presença do sinal de determinados PAs não apresentar uma freqüência constante. 
Uma análise dos algoritmos probabilísticos utilizados nos sistemas propostos para resolver este problema sugere que isso pode ser uma importante fonte de erro, já que os sistemas baseiam-se, em boa parte, nesta informação de freqüência de presença de sinal.

A proposta do presente trabalho é apresentar um sistema - o WBLS (Wireless Based Location System) - que realiza suas estimativas de localização utilizando um sistema básico com abordagem probabilística, porém ignorando a informação de freqüência de presença do sinal, dando assim um maior peso às RSSIs de fato observadas pelo dispositivo que está sendo localizado.

Um sistema de localização Wi-Fi deve lidar com um ambiente sobre o qual se tem pouco ou nenhum controle e, muitas vezes, sequer conhecimento detalhado a priori. Como se pretende que um sistema funcione bem utilizando uma infra-estrutura que já existe, é imperativo que este sistema tenha a capacidade de adaptar-se a alterações que podem acontecer sem qualquer aviso nesta infra-estrutura. A queda de algum PA, seu desligamento permanente ou falhas na sua transmissão são cenários que podem ocorrer de fato. Ao deixar de considerar a informação da freqüência de presença do sinal, o sistema localização proposto se mostrou robusto para lidar com este tipo de situação.

Uma parte importante do trabalho apresentado aqui consiste na realização de experimentos que forneçam os dados para a análise do comportamento do WBLS. No entanto, definir uma metodologia confiável para a análise do desempenho de um sistema de localização Wi-Fi no contexto proposto apresenta seus desafios. O primeiro problema a resolver é definir como obter seqüências de observações correspondentes a caminhadas por um ambiente de testes, determinando ao mesmo tempo a posição real do dispositivo em cada um dos instantes de observação. Em trabalhos encontrados na literatura, poucas referências apresentam uma boa solução para este problema (BERNA et al., 2003; KRUMM; HORVITZ, 2004) apresentando, assim, uma análise de qualidade dos sistemas de localização Wi-Fi quando se trata de realizar estimativas de localização de dispositivos em movimento.

Outro problema encontrado é obter conclusões que possam ser generalizadas, já que cada ambiente de testes tem particularidades que afetam o desempenho dos sistemas, o que torna muito difícil a comparação entre eles. A existência de uma ferramenta que dê suporte à execução dos sistemas, simulando condições que possam ser reproduzidas em novos testes, é uma carência dessa área de pesquisa. A metodologia proposta aqui é um passo no sentido da solução desses problemas e faz parte das contribuições deste trabalho. 


\subsection{Organização do trabalho}

Este trabalho está organizado da forma descrita a seguir.

O capítulo 2 descreve o contexto de localização Wi-Fi. Primeiramente são apresentadas as características do problema de localizar um dispositivo móvel utilizando os sinais das redes de um determinado ambiente, o que ajuda a definir quais são os principais desafios encontrados. Em seguida, técnicas de localização com sinais de rádio-freqüência são descritas com o objetivo de ajudar na compreensão das propostas existentes para a solução do problema. Por fim, uma análise dessas propostas é apresentada para definir o modelo de sistema que se adapta melhor ao contexto e estabelecer quais problemas ainda carecem de uma abordagem mais profunda.

No capítulo 3 apresenta-se um sistema de localização baseado no modelo definido no capítulo anterior, que servirá como base para a proposta apresentada e como referência na análise de desempenho. Neste capítulo são descritos em detalhes a construção do mapa de RSSI e o funcionamento do processo de estimativa de localização de um dispositivo móvel através do método chamado localização markoviana.

No capítulo 4 é proposto o sistema WBLS (Wireless Based Location System). O capítulo inicia com uma análise dos pontos que podem ser alterados no sistema básico, apresentado no capítulo anterior, para se conseguir um desempenho melhor. Segue-se então uma análise das características do ruído presente na informação com a qual o sistema lida. Essas duas análises apresentam as idéias que dão suporte à alteração proposta no algoritmo do sistema básico, gerando o WBLS. Esta alteração é então detalhada e, por fim, é apresentada uma análise matemática da proposta.

No capítulo 5 são descritos os experimentos realizados neste trabalho para validar a proposta. Primeiramente, o ambiente de testes e o hardware utilizado são apresentados. Segue-se então uma descrição da metodologia utilizada para a captura das observações de um dispositivo - real e virtual - que se movimenta no ambiente. Os experimentos são então apresentados e seus resultados, discutidos.

No capítulo 6, as conclusões são apresentadas. Primeiramente discutem-se as contribuições do trabalho, em seguida, são listados os possíveis caminhos a serem explorados em trabalhos futuros e, por fim, são feitas as considerações finais.

O apêndice A tem como objetivo apresentar análises mais profundas de alguns dos argumentos utilizados no trabalho. Ele inicia com algumas considerações sobre arquiteturas para a implementação de um serviço de localização Wi-Fi. Em seguida descreve-se a espe- 
cificação IEEE 802.11 para redes sem fio. Vários detalhes de funcionamento que ajudam a compreender mais profundamente o contexto de localização Wi-Fi são apresentados. Particularmente, a seção sobre a camada PHY responde a questões importantes levantadas no texto sobre a variação da freqüência da presença de sinais dos aparelhos Wi-Fi e dá suporte à análise dos dados realizada no capítulo 4. Por fim, são feitas considerações sobre o hardware e os drivers envolvidos.

O apêndice B apresenta o conjunto completo de resultados dos experimentos realizados neste trabalho, cuja descrição e discussão é apresentada no capítulo 5. 


\section{Localização em redes $\mathrm{Wi}$-Fi}

Uma compreensão das características de um problema é essencial para a obtenção de sua solução. A primeira seção deste capítulo descreve as características do problema de localização de dispositivos móveis fazendo uso dos sinais emitidos pelos PAs de redes Wi-Fi em ambientes fechados, indicando quais são suas possibilidades e limitações. São então descritas técnicas de localização baseadas em sinais de rádio-freqüência que podem ser usadas para o desenvolvimento de sistemas de localização Wi-Fi e, por fim, é apresentada uma comparação entre trabalhos encontrados na literatura em termos das técnicas empregadas, metodologias e resultados.

\subsection{Características do problema de localização em re- des Wi-Fi}

Quando uma pessoa caminha por uma rua, ela estima sua localização identificando pontos de referência e calculando sua distância a cada um deles, o ângulo em que os percebe, ou meramente estabelecendo quais referências estão em seu campo de visão. A pessoa faz isso simplesmente analisando as imagens formadas em sua retina. O mesmo princípio está por trás de qualquer sistema de localização. Um dispositivo que deseja se localizar deve possuir um ou mais sensores (que correspondem aos olhos da pessoa) que captam informações de pontos de referência no ambiente. Em localização em redes Wi-Fi, os pontos de referência são os PAs que fornecem acesso à rede, e os sensores são as próprias placas de rede Wi-Fi que recebem sinais de rádio-freqüência provenientes dos PAs. Estes são os sinais que carregam as informações dos quadros da rede. Para detalhes sobre o funcionamento de redes Wi-Fi, veja o item A.2 do apêndice.

Sinais de rádio-freqüência captados por um aparelho receptor possuem basicamente três atributos que representam informações relevantes para localização: o ângulo em que o sinal chega; o instante em que o sinal chega (informação que pode ser usada para estimar o tempo de percurso entre a antena emissora e receptora); e a potência com que 
esse sinal é recebido (em sistemas de localização Wi-Fi essa informação é chamada de RSSI - Received Signal Strength Indication). Quanto mais exata a informação, melhor a qualidade das estimativas de localização.

Sendo assim, a forma como o sinal de rádio-freqüência se propaga tem grande influência no funcionamento do sistema de localização. Como já foi discutido na introdução, sistemas de localização Wi-Fi têm como foco ambientes fechados, como prédios, casas, shopping centers, universidades. Esses ambientes têm como característica o fato de que os sinais de rádio-freqüência se propagam por múltiplos caminhos, caminhos estes que quase sempre correspondem a uma propagação NLOS (Non Line Of Sight), ou seja, que não inclui o caminho em linha reta entre as antenas (PAHLAVAN; LI; MAKELA, 2002; HIGHTOWER; BORRIELLO, 2001). Isso torna muito mais difícil e imprecisa a interpretação das informações provenientes dos sinais que chegam aos dispositivos. Além disso, os sinais sofrem influências de agentes e condições não estacionários do ambiente, os primeiros representados por pessoas, objetos e outros emissores de rádio-freqüência - principalmente fornos de micro-ondas (WISOCKI; ZEPERNICK, 2000) - e os últimos, pelas condições climáticas como umidade e temperatura.

Outra característica importante da localização Wi-Fi é a possibilidade da utilização de uma infra-estrutura já existente no ambiente, o que reduz consideravelmente o custo de implantação do sistema. Mas utilizar uma infra-estrutura já existente pode ter implicações que complicam o problema de localização de dispositivos, principalmente porque isso implica, na maioria das vezes, utilizar sinais de aparelhos sobre os quais não se tem qualquer controle. Como os aparelhos têm diferentes proprietários, nunca se sabe quando qualquer um deles será desligado para manutenção, trocado de posição ou simplesmente desabilitado indefinidamente.

A falta de controle não apenas sobre os aparelhos, mas sobre a implantação da rede em si, é outro fator complicador. A instalação de PAs Wi-Fi é muito simples e pode ser feita por qualquer pessoa que deseja ter uma rede sem-fio própria em funcionamento. No entanto, em uma área onde há várias redes instaladas sem um controle centralizador, é muito provável que PAs ocupem canais vizinhos, que interferem entre si, ou até o mesmo canal. Como conseqüência, as redes passam a ser menos confiáveis, o que prejudica o processo de localização (no item A.2.2 do apêndice há uma explicação detalhada das possíveis conseqüências de diferentes configurações de redes Wi-Fi).

Por fim, a falta de controle é problemática também quando se trata da estrutura física do ambiente. A construção de uma parede ou a instalação de um biombo, por exemplo, 
podem alterar a forma de propagação de um sinal e, se o sistema de localização não for informado dessa mudança estrutural, ele não será capaz de interpretar corretamente a informação que recebe.

O raio de alcance do sinal de um PA é outra característica interessante do problema. É possível ter uma idéia da grandeza desse raio ao serem feitas algumas considerações. Primeiramente, considere que a potência de saída de um PA costuma ser cerca de $20 \mathrm{dBm}$ - valor correspondente à potência do sinal percebida, em decibéis de miliwatt, a uma polegada de distância da antena, o que implica uma potência de $-10 \mathrm{dBm}$ a um metro da antena (BARDWELL, 2007) - e o sinal pode ser percebido enquanto sua potência permanecer superior a aproximadamente $-100 \mathrm{dBm}$ - esse valor, chamado de sensibilidade, varia de aparelho para aparelho, mas costuma ficar em torno disso, conforme demonstram as descrições apresentadas por Langfeldt (2007). Assim, o sinal varia cerca de 90dBm entre a distância de um metro da antena emissora e o ponto mais distante em que o sinal ainda é percebido por um aparelho receptor.

Segundo Hashemi (1993), um dos principais modelos utilizados para caracterizar a propagação de sinais de rádio-freqüência em ambientes fechados sugere uma relação linear entre a potência do sinal recebido medida em dBm's e a distância entre as antenas emissora e receptora. Para se ter uma idéia da magnitude dessa relação, realizou-se um pequeno experimento. Foram feitas medidas da RSSI do sinal de um determinado PA em três posições de um corredor com um espaçamento de aproximadamente $3 \mathrm{~m}$ entre elas. A tabela 2.1 apresenta a média de 300 medidas em cada uma dessas posições. Fazendo-se uma interpolação com mínimos quadrados, o coeficiente de perda de potência por distância que se encontra neste experimento é de cerca de $2.4 \mathrm{dBm} / \mathrm{m}$. Os trabalhos de Brunato e Kalló (2002) e Smailagic, Small e Siewiorek (2000) mostram resultados semelhantes para esse mesmo coeficiente - cerca de $2 \mathrm{dBm} / \mathrm{m}$ para o primeiro e $1.7 \mathrm{dBm} / \mathrm{m}$ para o último. Isso dá uma idéia de que o raio de alcance de um PA deve ficar entre 40m e 60m. Como essa relação entre potência e distância depende muito da configuração do ambiente (principalmente de quantos elementos de absorção e dispersão existem no caminho do sinal), esse valor pode variar bastante - utilizando o modelo de propagação em espaço livre de obstáculos (HALLIDAY; RESNICK; WALKER, 2000), que diz que a potência (em Watts) decai com o quadrado da distância, esse raio seria maior que $10 \mathrm{Km}$, o que indica como esse valor pode variar. No entanto, na prática, é difícil encontrar uma rede Wi-Fi com um alcance maior que $100 \mathrm{~m}$. 
Tabela 2.1: Variação de RSSI médio observado em função da distância do PA.

\begin{tabular}{|c|c|c|}
\hline & distância do PA $(\mathrm{m})$ & RSSI médio $(\mathrm{dBm})$ \\
\hline \hline PM-1 & 4.2 & -57.7972 \\
\hline PM-2 & 7.3 & $-64,0417$ \\
\hline PM-3 & 9.9 & $-74,6778$ \\
\hline
\end{tabular}

O tamanho do raio de alcance indica a distância máxima que um dispositivo pode estar de um determinado PA e ainda conseguir perceber o sinal proveniente dele. Um sinal que atravessa uma distância menor está sujeito a menos fontes de interferência e obviamente produz uma informação mais confiável para o sistema de localização. Por isso, o fato do raio de alcance de $100 \mathrm{~m}$ ser relativamente pequeno se comparado, por exemplo, ao tamanho das células de cobertura das redes de telefonia celular - as quais chegam a ter raio de alguns quilômetros (CAFFERY; STüBER, 1998) - é uma das qualidades dos sistemas de localização Wi-Fi. Por outro lado, esse alcance permite que, com um número razoável de PAs, seja possível cobrir áreas de um bom tamanho.

Por uma série de motivos que serão explicados nas próximas seções, a potência percebida do sinal recebido, a RSSI, é a informação que se costuma usar como referência em sistemas de localização Wi-Fi. Por isso, é importante salientar alguns detalhes das características da RSSI do sinal Wi-Fi. A figura 2.1-a mostra uma comparação entre as médias das medidas de RSSI de um determinado PA obtidas por um dispositivo móvel em uma mesma posição mas com quatro orientações diferentes. Fica claro que a orientação tem grande influência na característica da distribuição do sinal observado e pode fazer variar a média da distribuição em até $10 \mathrm{dBm}$. A principal razão disso é a posição do corpo do usuário e da própria máquina em relação à antena, ambos agentes que interferem no sinal - no caso do usuário, o corpo absorve parte do sinal, no caso da máquina, o metal que a constitui tem propriedades de reflexão e dispersão do sinal (HASHEMI, 1993).

Outra característica importante pode ser visualizada na figura 2.1-b, que mostra a variação da RSSI de um determinado PA observada durante mais de 2 horas por um dispositivo parado em um ponto fixo. A primeira observação que se pode fazer é que a amplitude da variação do sinal chega a mais de $15 \mathrm{dBm}$, o que mostra uma grande incerteza relacionada com cada observação isolada. A segunda observação é que há o que se pode chamar de uma incerteza sobre essa incerteza pois, dependendo da região analisada do gráfico, a média pode estar deslocada para cima ou para baixo, variando - a média em 
si - em cerca de $7 \mathrm{dBm}$. Essa variação está relacionada à presença dos elementos não estacionários do ambiente e é um exemplo do ruído que eles introduzem.

Esses dados mostram que o tipo de variação relacionado à orientação $(10 \mathrm{dBm}$, como mostra a figura 2.1-a), por exemplo, pode causar uma variação de cerca de $3 \mathrm{~m}$ a $5 \mathrm{~m}$ no raio de propagação do sinal considerado por um sistema de localização, e a observação de dois sinais extremos de um mesmo PA (com diferença de pouco mais de $15 \mathrm{dBm}$ na figura 2.1-b) pode causar uma variação de até $7 \mathrm{~m}$ desse raio. Isso dá uma idéia do grau de incerteza relacionado com o tipo de entrada, característico de um sistema de localização Wi-Fi.

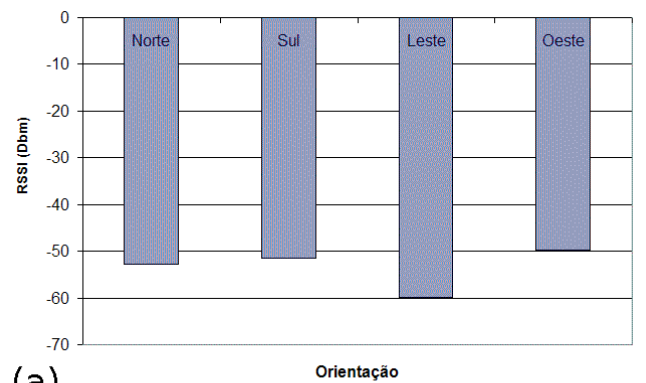

(a)

Orientação (b)

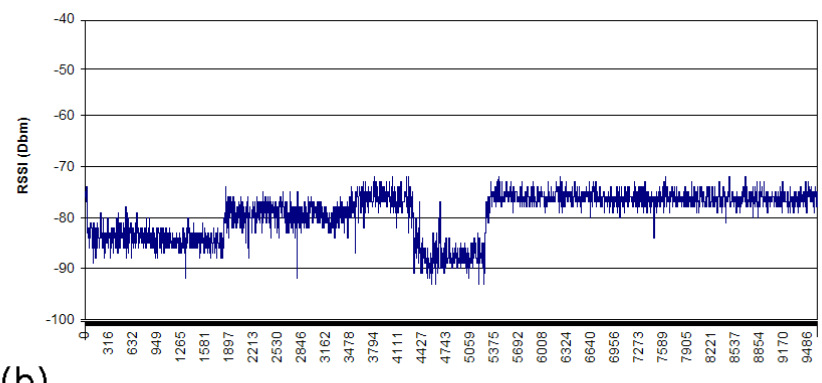

tempo (seg.)

Figura 2.1: Características da RSSI observada em redes Wi-Fi: (a) média da RSSI observada com o dispositivo posicionado em quatro diferentes orientações; e (b) RSSIs observadas durante um longo período de tempo com o dispositivo parado.

Tendo em vista as características descritas, os principais desafios para o desenvolvimento de um sistema de localização Wi-Fi estão na criação (ou definição) de um modelo que: represente corretamente a propagação dos sinais Wi-Fi em um ambiente que possui uma alta complexidade estrutural; adapte-se às condições imprevisíveis da parte não estacionária do ambiente; e seja robusto para lidar com as modificações de uma infra-estrutura sobre a qual não se tem controle.

\subsection{Técnicas de localização com sinais de rádio-freqüência}

Existem diversas técnicas que podem ser empregadas quando se procura estimar localização utilizando sinais de rádio-freqüência. Cada uma delas tem suas vantagens e desvantagens, adequando-se melhor a um ou outro contexto. Para que se possa definir qual técnica melhor se adequa ao contexto de localização Wi-Fi é importante conhecê-las. Por isso, neste capítulo estas técnicas serão descritas e suas características, comentadas. Para maior facilidade de compreensão, as técnicas foram agrupadas em três categorias: técni- 
cas que utilizam triangulação; técnicas que utilizam um modelo discreto do ambiente; e técnicas que empregam redes neurais.

\subsubsection{Técnicas que utilizam triangulação}

Muitas técnicas empregadas para localização com sinais de rádio-freqüência consistem na realização de alguma forma de triangulação. As técnicas de triangulação têm algumas particularidades que variam de acordo com o tipo de informação que é usada no sistema de localização. Por exemplo, para os casos em que a informação a ser considerada é o ângulo de chegada, tal informação costuma ser obtida nos pontos de referência que, para isso, recebem sinais vindos do dispositivo. Neste contexto, com apenas dois pontos de referência é possível realizar o processo de localização em um espaço de duas dimensões, já que é necessária apenas a definição de dois ângulos - cujo tamanho da aresta adjacente a ambos seja conhecido - para que se possa definir um triângulo. A figura 2.2 ilustra o processo. Essa técnica é conhecida como AOA (Angle Of Arrival) (HIGHTOWER; BORRIELLO, 2001; RUSSEL, 2003).

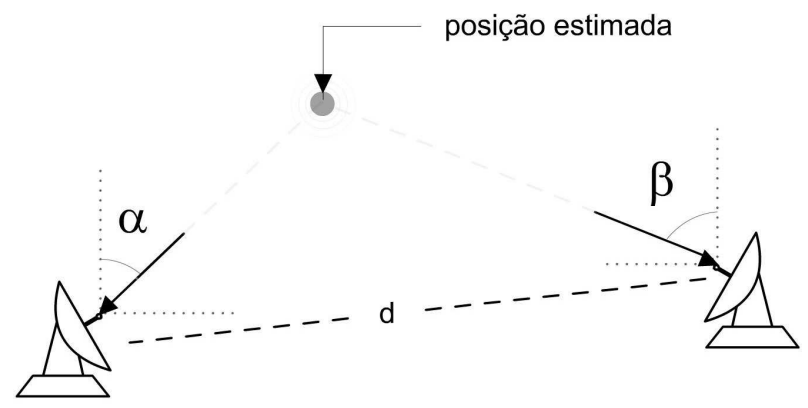

Figura 2.2: Técnica de triangulação que utiliza a informação do ângulo do sinal.

Já para os casos em que se utiliza a informação de tempo de chegada do sinal ou de potência, parte-se de um modelo matemático que descreve o comportamento do sinal no ambiente para se determinar a distância entre cada ponto de referência e o dispositivo. Aqui, quem recebe o sinal tanto pode ser o ponto de referência como o próprio dispositivo que está sendo localizado, e é preciso que se conheça a posição de três pontos de referência que estejam dentro do raio de alcance do dispositivo para que a estimativa seja feita. Conhecendo-se o tamanho das arestas dos triângulos formados por pares de pontos de referência e pelo dispositivo, pode-se determinar a posição do vértice que corresponde à 
sua localização. O procedimento usual para essa determinação consiste em traçar circunferências em torno de cada um dos pontos de referência. Os raios de tais circunferências devem ser as distâncias calculadas entre os respectivos pontos de referência e o dispositivo, e a intersecção delas corresponde à localização do dispositivo. A figura 2.3 ilustra o procedimento. Como a informação sempre possui uma imprecisão característica, é comumente realizada alguma forma de média entre as possíveis posições estimadas (GWON; JAIN; KAWAHARA, 2004; CAFFERY; STüBER, 1998).

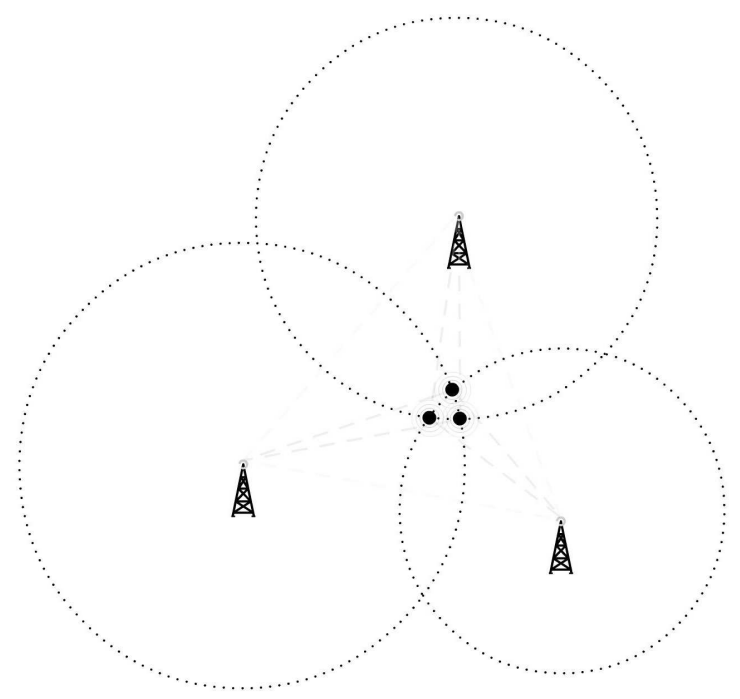

Figura 2.3: Técnica de triangulação que utiliza a informação da distância entre emissor e receptor.

No caso da informação ser a potência do sinal recebido - a RSSI - o modelo matemático usado para propagação em espaço livre de obstáculos é aquele que diz que a potência do sinal varia de forma inversa ao quadrado da distância da antena transmissora. Para o caso da propagação em ambientes fechados, que corresponde mais diretamente ao contexto do presente trabalho, alguns modelos foram propostos na literatura. Pode-se encontrar boas seleções deles nos trabalhos de Hashemi (1993) e de Neskovic, Neskovic e Paunovic (2000).

No caso da informação ser o tempo de chegada do sinal, a situação é um pouco mais complexa. A informação de fato necessária não é simplesmente o instante de chegada, mas o tempo de percurso do sinal entre a antena emissora e a receptora. Por isso, não basta que se conheça o instante de chegada do sinal, mas é preciso saber também o tempo em que o sinal partiu da antena emissora. O sinal pode conter uma marca desse tempo (timestamp), mas é preciso que os relógios do aparelho emissor (ou seja, de um dos pontos de referência) e do receptor estejam sincronizados para que a diferença entre o tempo de chegada do sinal, marcado pelo receptor, e o tempo de partida do sinal, marcado pelo 
emissor, corresponda ao tempo de viagem. Essa técnica é conhecida como TOA (Time Of Arrival). Como muitas vezes não é possível que os relógios dos pontos de referências estejam sincronizados com o relógio do dispositivo, uma solução é utilizar um ponto de referência a mais, sincronizar apenas os relógios dos pontos de referência (emissores) e trabalhar com o tempo relativo de viagem do sinal em lugar do absoluto. É o que é feito, por exemplo, no GPS (LONGSDON, 1995). Essa técnica é chamada de TDOA (Time Diference Of Arrival).

Sistemas que utilizam o AOA não servem para ambientes fechados devido aos múltiplos caminhos de propagação NLOS que um sinal pode percorrer até ser captado pela antena do aparelho receptor. Além disso, a implementação de um sistema que utiliza AOA necessita de antenas direcionais nos receptores, o que não é viável para localização Wi-Fi.

Em relação aos sistemas que se baseiam na informação de RSSI, o problema que se encontra é que os modelos matemáticos empregados raramente se aproximam suficientemente da realidade para que os resultados alcançados com essa técnica sejam expressivos. Duas são as principais razões disso: a interferência entre múltiplos caminhos gera uma variação muito grande de RSSI em espaços muitos pequenos; e o efeito exato dos diversos obstáculos que compõem um ambiente interno sobre um sinal é muito difícil de ser captado por um modelo matemático. Neskovic, Neskovic e Paunovic (2000) argumentam que mesmo modelos complexos acabam sendo imprecisos devido à influência da parte não estacionária do ambiente.

TOA e TDOA costumam ser técnicas muito eficientes quando existe propagação LOS (Line Of Sight). No entanto, em ambientes fechados esse tipo de propagação não acontece, ou chega muito atenuada em relação à propagação feita por outros caminhos. É possível, com algumas técnicas de super resolução, recuperar o instante da chegada da primeira propagação (PAHLAVAN; LI; MAKELA, 2002) mas não é possível garantir que essa primeira propagação seja LOS. Além disso, o hardware para realizar essa operação é um hardware específico (KRIZMAN; BIEDMAN; RAPPAPORT, 1997). Outra dificuldade na implementação de TOA ou TDOA é que elas necessitam de uma sincronização muito fina entre os relógios dos pontos de referência, os quais devem ser, além de tudo, extremamente precisos (YAMASAKI et al., 2005; BALBACH, 2000). 


\subsubsection{Técnicas que utilizam um modelo discreto do ambiente}

Uma alternativa ao raciocínio geométrico representado pelas triangulações é a utilização de um modelo discreto do ambiente, onde registros de padrões de variação de determinados atributos servem como referência para o sistema de localização. Na teoria, quaisquer dos atributos dos sinais podem ser considerados, mas na prática o atributo escolhido costuma ser a RSSI. Isso porque, se a informação sobre o ângulo de chegada do sinal ou sobre o tempo de percurso do sinal for a informação mais confiável e simples de ser obtida em um determinado contexto, costuma-se utilizar a técnica de triangulação, que se adapta bem a esse tipo de informação e não necessita de uma discretização do ambiente.

As técnicas que se baseiam em um modelo discreto costumam consistir de duas fases: a fase de treinamento, onde se cria um banco de dados que armazena o padrão de variação de um ou mais atributos em diversas posições no ambiente; e a fase de execução do localizador, onde as estimativas de localização são efetivamente realizadas.

A informação armazenada no banco de dados - que, no caso específico de localização Wi-Fi, é comumente chamado de mapa de RSSI - pode ser obtida experimentalmente, ou seja, através de medições feitas em posições do ambiente, ou através de um modelo matemático que descreve o comportamento do sinal. Como a etapa de criação do banco de dados é anterior à execução do localizador, é possível utilizar modelos matemáticos bastante complexos e que consomem um tempo de processamento alto, o que seria proibitivo se fossem executados durante o processo de localização propriamente dito.

A maior desvantagem dessa técnica é que a construção desse banco de dados - no caso dos padrões obtidos experimentalmente, que é o método mais usado - implica um trabalho exaustivo, onde todo o ambiente que será atendido pelo sistema de localização deve ser coberto.

$\mathrm{Na}$ fase de execução, os atributos dos sinais recebidos pelo dispositivo são comparados com os padrões das diversas posições gravadas no banco de dados e, a partir dessa comparação, realiza-se a estimativa de localização do dispositivo. O método usado para a comparação de atributos e para a realização das estimativas de localização é o que define cada sistema específico. Pode-se separar os métodos existentes em dois grupos (YOUSSEF; AGRAWALA, 2005): métodos deterministas e métodos probabilísticos. 


\section{Métodos deterministas}

Os métodos deterministas são aqueles cujos algoritmos trabalham com variáveis deterministas em toda sua cadeia (diferentemente dos métodos probabilísticos, que trabalham com variáveis aleatórias e distribuições de probabilidade).

O primeiro método que foi apresentado para localização Wi-Fi (BAHL; PADMANBHAM, 2000) era determinista e bastante simples. Segundo este método, as RSSIs dos sinais de cada um dos PAs de um ambiente, observadas pelo dispositivo que deve ser localizado, formam um vetor de atributos. No mapa de RSSI, cada posição é representada por um vetor semelhante a esse, gerado através das médias de um conjunto de medidas realizadas naquela posição. Calculam-se as distâncias euclidianas entre o vetor de atributos observado e cada um dos vetores das diferentes posições que constituem o mapa de RSSI. A estimativa do sistema é então a posição cuja distância calculada tenha sido a menor. Este método é chamado de NNSS (Nearest Neighbour in Signal Space).

Um extensão deste método é o chamado k-NNSS (apresentado pela primeira vez também por Bahl e Padmanbham (2000)), no qual o localizador determina, a cada iteração, um conjunto das k posições cujos vetores de atributos são os mais próximos do vetor de atributos observado, e a média das coordenadas dessas posições é o valor estimado para a localização do dispositivo.

Outros métodos deterministas foram propostos na literatura (GWON; JAIN; KAWAHARA, 2004; ELNAHRAWY; LI; MARTIN, 2004; KRUMM; PLATT, 2003) mas como não apresentam resultados especialmente significativos, foge ao escopo deste trabalho entrar em detalhes sobre eles.

Métodos deterministas são de simples compreensão e implementação, mas não levam em consideração informações sobre as estatísticas das variações de RSSI. Além disso, eles não incorporam naturalmente a relação de dependência entre estimativas consecutivas de localização. Existem alguns trabalhos em localização Wi-Fi que utilizam métodos deterministas e que procuram modelar de alguma forma essa relação (BAHL; PADMANBHAM, 2000; GWON; JAIN; KAWAHARA, 2004) mas seus resultados foram apenas moderados quando comparados a outros métodos, como será visto na próxima seção.

\section{Métodos probabilísticos}

A característica estocástica das RSSIs observadas por um dispositivo em uma rede Wi-Fi leva a crer que métodos probabilísticos devem constituir o tipo de ferramenta indicado 
para realizar a tarefa de estimar localização em ambientes fechados. A área de robótica móvel, que tem na localização um dos seus problemas mais importantes (DUDEK; JENKIN, 2000), desenvolveu diversos estudos utilizando esse tipo de abordagem. Segundo Fox et al. (1999), os principais métodos utilizados em robótica são: o filtro de Kalman (e suas variações), o filtro multi-hipóteses, o filtro de partículas, a localização em grade e a localização topológica.

Pode-se encontrar na literatura comparações entre estes métodos quando aplicados à localização de robôs (FOX et al., 2003; NEHMZOW, 2003), mas algumas características deste problema diferem fundamentalmente das características da localização de dispositivos móveis, o que indica que cada método deve ser analisado à luz dessas diferenças. Quais seriam elas? Primeiramente, robôs possuem sensores proprioceptivos, como odômetros, que os permite utilizar modelos de movimento relativamente precisos. No caso da localização Wi-Fi, por exemplo, é muito difícil prever com segurança, entre uma observação e outra, para onde um dispositivo está se deslocando e se de fato há o objetivo de atingir algum lugar ou não. Segundo, a informação dada pelos sensores dos robôs corresponde, na localização de dispositivos móveis, à informação das RSSIs dos sinais provenientes dos pontos de referência, o que, em ambientes fechados, costuma ser uma informação muito mais ruidosa que aquela dada pelos sensores dos robôs.

Assim, o filtro de Kalman, que é muito interessante para uso na localização de robôs por ser computacionalmente eficiente (FOX et al., 2003), não é recomendável para localização Wi-Fi de dispositivos móveis em ambientes fechados. Simplificadamente, o filtro de Kalman consiste de duas fases: na primeira, a fase de predição, utiliza-se a estimativa da postura $^{1}$ do robô em um instante anterior e o modelo de movimento - derivado, no caso dos robôs, dos sensores proprioceptivos - para prever a postura esperada, e então, fazendo uso de um modelo de observação - derivado dos sensores exteroceptivos -, determina-se uma previsão do sinal que será observado; na segunda fase, o sinal de fato observado é comparado com a previsão, a diferença entre eles é calculada e a estimativa de postura é colocada entre a postura esperada e aquela que corresponderia à observação, de forma a ficar mais próxima da postura prevista na primeira fase, se o modelo de movimento for mais preciso, ou à correspondente à observação dos sensores, se mais preciso for o modelo de observação (detalhes sobre o filtro de Kalman são descritos por Bozic (1979) e por Gelb et al. ()). Esse filtro apóia-se substancialmente em dois pontos: na existência de modelos cuja incerteza seja representada por um ruído branco (um ruído representado

\footnotetext{
${ }^{1}$ Postura é um termo empregado em localização de robôs e que está sendo utilizado aqui por estar se tratando de métodos utilizados primordialmente nesse contexto. Ela corresponde à informação de posição e de orientação do objeto quando se refere à localização em um plano de movimento.
} 
por uma distribuição gaussiana em torno de um valor nulo), tanto no caso do modelo de movimento quanto no de observação; e em modelos que sejam representados por funções lineares ou que possam ser aproximadas por funções lineares (através da derivação da função original) na região da incerteza. Quando se trata de localização de dispositivos móveis em redes Wi-Fi dentro de ambientes fechados, as incertezas - do modelo de movimento e da observação - são muito grandes e o modelo de observação muito complexo, o que indica que filtros de Kalman não se apresentam como uma boa solução.

O filtro multi-hipóteses consiste da implementação de múltiplos filtros de Kalman, um para cada hipótese de postura do robô. Cada hipótese recebe um peso, que pode ser igual para todas elas, inicialmente. Quando o filtro de Kalman é executado, a cada iteração, além de fazer a estimativa de localização, o filtro calcula uma matriz de co-variância, que pode ser vista como uma medida da incerteza da estimativa. Essa informação pode ser usada para corrigir os pesos das hipóteses. Apesar de ser mais flexível, continua modelando a incerteza com ruído branco, é computacionalmente mais custoso e necessita de heurísticas sofisticadas para determinar quando se deve adicionar ou dispensar hipóteses (FOX et al., 2003). Dada a complexidade da localização de dispositivos móveis em redes Wi-Fi dentro de ambientes fechados, esse tipo de filtro deixa de ser recomendável.

O filtro de partículas (THRUN et al., 2000) consiste de um método que utiliza partículas para representar uma distribuição de probabilidade da postura do objeto que está sendo localizado. Já a localização em grade e a localização topológica são variações do método mais genérico chamado localização markoviana (FOX; BURGARD; THRUN., 1999). A localização markoviana utiliza um modelo de estados ocultos de Markov - também conhecido como HMM (Hidden Markov Model) - e a distribuição de probabilidade da postura do objeto é dada sobre um universo discreto representado pelo conjunto de estados do modelo (no próximo capítulo, o método de localização markoviana será descrito em detalhes).

Ambos os métodos - o filtro de partículas e a localização markoviana - apóiam-se no princípio markoviano, que diz que o estado (no caso, a postura do objeto a ser localizado) em um determinado instante é dependente apenas do estado no instante imediatamente anterior e da ação executada. Assim, a cada iteração, o algoritmo de localização - em ambos os métodos - calcula uma nova distribuição de probabilidade da postura do objeto em função da distribuição estimada no instante anterior. Essa modelagem explícita da relação de dependência de estimativas em instantes consecutivos é uma das grandes forças destes métodos, principalmente quando se trata de localizar um dispositivo que está de fato se movimentando. Uma diferença importante entre o filtro de partículas e a localização markoviana é que o primeiro concentra a informação de distribuição de probabilidade 
do estado de localização na região próxima de onde se espera que o dispositivo se encontre, podendo assim armazenar mais detalhes sobre essa região e desprezar regiões onde o processamento seria inócuo, e a localização markoviana mantém a informação de distribuição de probabilidade do estado de localização no ambiente inteiro, perdendo assim o poder de detalhar regiões muito específicas.

Ambos os métodos são flexíveis para lidar com um modelo de observação complexo derivado do mapa de RSSI. No entanto, o filtro de partículas - que é uma ferramenta que se encaixa perfeitamente ao contexto de localização de robôs - necessita de alguns ajustes para ser adaptado ao contexto de localização de dispositivos móveis e algumas questões podem ser levantadas quanto a sua praticidade - devido à necessidade de tais adaptações - e mesmo ao seu desempenho - devido às grandes incertezas encontradas nos modelos de observação e movimento. Já a localização markoviana é o método que se encaixa melhor no contexto de localização de dispositivos móveis em ambientes fechados devido à correspondência entre os estados do HMM e os registros do mapa de RSSI.

Até aqui foram comentados métodos probabilísticos que levam em consideração a relação de dependência entre estimativas consecutivas. Há, no entanto, uma série de métodos mais simples que se baseiam apenas no conceito de probabilidades condicionais de Bayes (BAYES, 1763), que quando se trata de localização com sinais de rádio-freqüência pode ser expresso pela fórmula:

$$
P(e \mid O)=\frac{P(O \mid e) P(e)}{P(O)}
$$

onde $P(e \mid O)$ representa a probabilidade do estado de localização $e$ dado que se observou $O, P(O \mid e)$ representa a probabilidade de se observar $O$ dado que se está no estado $e, P(e)$ representa a probabilidade do estado e e $P(O)$ representa a probabilidade de se observar $O$.

Estes métodos - que neste trabalho serão chamados de filtros bayesianos simples costumam considerar a distribuição de probabilidade a priori para o universo de estados de localização, $\mathbf{P}(\mathbf{e})$, como sendo uniforme, o que deixa a estimativa dependente apenas da comparação do vetor de característica observado com os vetores de características que compõem o mapa de RSSI (comparação esta representada na fórmula pelo fator $P(O \mid e))$. Em relação aos métodos deterministas, a única diferença substancial está no fato de considerarem também a forma da distribuição de probabilidade dos valores de RSSI medidos em cada posição, em vez de apenas a média. Como os filtros bayesianos simples não modelam a relação de dependência entre estimativas consecutivas, seu desempenho é 
questionável quando se trata de localizar dispositivos que realmente estão em movimento. De fato, como será visto na próxima seção, os trabalhos encontrados na literatura com este tipo de método ou não apresentam resultados para este tipo de localização, ou apresentam resultados relativamente fracos.

Os métodos probabilísticos em geral levam vantagem em relação aos deterministas porque eles incorporam mais informação, o que inclui as distribuições de probabilidade dos valores de RSSI dos diferentes pontos de referência em diferentes posições do ambiente, além da relação de dependência entre estimativas consecutivas de localização (esta última, exceto para os métodos bayesianos simples). Essa é a razão de os melhores resultados encontrados na literatura sobre localização Wi-Fi utilizarem métodos probabilísticos. Dentre os trabalhos que utilizam outras técnicas, os únicos que apresentam resultados comparáveis a eles são os que empregam redes neurais. Técnicas com redes neurais serão descritas a seguir.

\subsubsection{Técnicas que utilizam redes neurais}

Um sistema de localização pode ser visto simplesmente como uma função que tem como entrada um vetor de atributos observado e como saída a posição do objeto a ser localizado em termos de coordenadas de posição ou em termos da célula em que se encontra - neste trabalho, células correspondem a pequenas áreas que não se sobrepõem e que, unidas, formam a área total do ambiente. Essa função deve lidar com entradas ruidosas e, para sua construção, deve-se levar em consideração exemplos de vetores de atributos obtidos através de medidas realizadas em posições conhecidas do ambiente. Um tipo de função que é conhecida por lidar bem com entradas ruidosas e que tem boa capacidade de aprender através de exemplos são as redes neurais de alimentação direta² (RUSSEL; NORVIG, 2003).

O desenvolvimento de redes neurais teve origem a partir da intuição de que as redes de neurônios cerebrais apresentavam grande capacidade de processamento de informações (MCCULLOCH; PITTS, 1943). Uma rede neural consiste de um conjunto de neurônios artificiais interconectados, onde as saídas de alguns neurônios alimentam as entradas de outros (SAHA et al., 2003). Em uma rede neural de alimentação direta, as entradas de cada neurônio artificial são multiplicadas, cada uma, por um peso específico. Dessa forma, a estrutura e o conjunto dos pesos da rede definem a função que ela representa.

A maneira mais comum de se organizar uma rede neural de alimentação direta é dis-

\footnotetext{
${ }^{2} \mathrm{~A}$ outra categoria de redes neurais que existe são as chamadas redes recorrentes. Elas não são abordadas neste trabalho, mas uma leitura sobre o assunto pode ser encontrada na obra de Bishop (1995).
} 
por os neurônios em camadas, com as saídas dos neurônios de uma determinada camada alimentando apenas neurônios da camada seguinte. Estas são as chamadas redes neurais do tipo MLP (Multi-Layer Perceptron). Considerando que se tenha um conjunto de exemplos rotulados, pode-se utilizar algoritmos de retropropagação de erro para o aprendizado do conjunto de pesos de uma rede neural MLP com uma estrutura pré-definida (RUSSEL; NORVIG, 2003).

Os casos encontrados na literatura que utilizam redes neurais em localização Wi-Fi (BATTITI; NHAT; VILLANI, 2002; SAHA et al., 2003) empregam redes MLP com apenas uma camada intermediária. Dois são os tipos de redes encontrados: redes cujas saídas representam coordenadas de posição; e redes cujas saídas representam as probabilidades de cada uma das células de um ambiente corresponder à localização verdadeira do dispositivo. A estrutura de uma rede MLP pode ser representada por um vetor composto pelo número de entradas da rede seguido do número de neurônios em cada camada. Para o primeiro tipo, uma estrutura típica seria $[\mathrm{E}, \mathrm{N}, 2]$, onde $\mathrm{E}$ representa o número de elementos do vetor de atributos e $\mathrm{N}$ um número definido experimentalmente. Os dois neurônios da camada de saída representam as coordenadas de posição. Para o segundo tipo, a estrutura difere na última camada, podendo ser representada por [E, N, C], onde $\mathrm{C}$ representa o número de células em que foi dividido o ambiente. A saída de cada um dos $\mathrm{C}$ neurônios pode ser interpretada como a probabilidade da célula correspondente ser a estimativa correta de posição.

Os métodos probabilísticos assumem uma premissa de independência condicional das probabilidades de cada um dos elementos do vetor de atributos, dada uma posição específica. Essa suposição é necessária para que o método não se torne complexo demais e, portanto, inviável. A grande vantagem das redes neurais MLP em relação aos métodos probabilísticos é que elas não precisam fazer qualquer suposição. Dessa forma elas podem captar qualquer dependência condicional que possa existir entre os elementos do vetor de características. No entanto, como se trata de um método empírico, nada garante que tais dependências sejam capturadas, nem mesmo que o comportamento estocástico das RSSIs seja representado tão bem quanto nos métodos probabilísticos.

Além disso, como acontece com os métodos deterministas, as redes neurais apresentadas na literatura para localização Wi-Fi não levam em consideração a dependência entre estimativas consecutivas de localização. Isso poderia ser implementado incluindo uma ou mais entradas na rede - que corresponderiam à estimativa do instante anterior - ou utilizando um esquema misto de localização markoviana e rede neural. Estas propostas, no entanto, ainda precisam ser melhor estudadas e aplicadas no contexto de localização 
Wi-Fi para que suas propriedades e características sejam conhecidas de fato.

\subsection{Comparação e análise dos trabalhos sobre localiza- ção Wi-Fi}

Esta seção tem como objetivo dar um panorama geral daquilo que se tem apresentado sobre sistemas de localização Wi-Fi. O que se pretende é apresentar uma análise crítica dos trabalhos de forma a esclarecer o que vem sendo feito, o que ainda está por fazer e quais caminhos parecem mais promissores. Primeiramente é apresentado um breve histórico dos trabalhos encontrados na literatura sobre localização Wi-Fi, o que dá uma idéia de quais áreas vêm sendo exploradas. Alguns esclarecimentos então são feitos sobre a metodologia dos experimentos, de forma a definir em que termos os trabalhos podem ser comparados. Em seguida é apresentada uma análise do desempenho das técnicas empregadas com base nos trabalhos citados. Por fim, algumas questões são levantadas sobre o que se tem feito para que os sistemas sejam mais robustos em relação a um ambiente que, a princípio, não é controlável.

\subsubsection{Histórico dos trabalhos realizados em localização Wi-Fi}

O primeiro trabalho encontrado na literatura a tratar especificamente do tema de localização Wi-Fi (BAHL; PADMANBHAM, 2000) propôs um sistema chamado RADAR que introduziu dois métodos: um que se baseia em um mapa de RSSI obtido experimentalmente, e outro que utiliza um modelo matemático de propagação de sinais de rádio-freqüência para a construção desse mapa. O primeiro mostrou ter um desempenho consideravelmente melhor e influenciou trabalhos que vieram depois a descartarem o uso de modelos matemáticos. Seu sistema de localização usa o método determinista que recebeu o nome de k-NNSS. Alguns trabalhos que vieram depois apresentaram também estudos sobre esse método (BRUNATO; KALLó, 2002; SAHA et al., 2003; BAHL; PADMANABHAN, 2000; SMAILAGIC et al., 2002).

Outro trabalho pioneiro na área e muito referenciado nos trabalhos subseqüentes é o trabalho de Smailagic, Small e Siewiorek (2000). Nele encontra-se um primeiro estudo das possibilidades e limitações de sistemas de localização que se baseiam na informação de RSSI de sinais provenientes de PAs Wi-Fi. Dentre outras coisas, estima-se que o erro das estimativas de um sistema de localização Wi-Fi que considera 10 observações a cada iteração deve ser no máximo de 5m, com intervalo de confiança de 99\%. Além disso, 
ele mostra um estudo interessante que indica que as distribuições de RSSIs podem ser aproximadas por gaussianas. Há a implementação de um método determinista similar a um k-NNSS e de uma rede neural. Apesar de apresentar resultados pouco confiáveis, este trabalho é um importante inspirador de idéias que se seguiram.

Em relação a métodos deterministas diferentes de k-NNSS, dois trabalhos merecem citação: o de Gwon, Jain e Kawahara (2004), que propõe uma alternativa para incluir no modelo o fato de que estimativas consecutivas não devem se encontrar muito distantes umas das outras; e o de Krumm e Platt (2003), que emprega um método de interpolação que permite que o sistema funcione bem mesmo que tenham sido feitas medidas para gerar o mapa de RSSI em um número reduzido de posições do ambiente.

Castro et al. (2001) desenvolveram o primeiro trabalho a sugerir uma proposta probabilística. Nele propõe-se uma rede bayesiana cuja implementação corresponde a um filtro bayesiano simples. Sugere-se ainda a criação de um novo nó na rede que representaria a localização do dispositivo em um instante anterior, o que modelaria a dependência entre estimativas consecutivas de localização. Em Roos et al. (2002), as estimativas de localização do sistema proposto chegam a apresentar um resultado muito bom, mas para isso o sistema usa como entrada seqüências com 20 observações. Neste trabalho utiliza-se um filtro bayesiano simples e seu principal foco está em definir formas mais eficazes de representar a distribuição de RSSI do sinal de um PA. Elnahrawy, Li e Martin (2004) propõem dois métodos: um determinista e um probabilístico baseado em filtro bayesiano simples. A novidade deste trabalho é uma proposta de fornecer os resultados em termos de áreas e não em termos de um ponto específico do ambiente.

Youssef e Agrawala (2005) apresentam os melhores resultados dentre os trabalhos encontrados na literatura sobre o tema. Seu maior mérito está em capturar melhor as nuâncias do comportamento do sinal, incluindo a modelagem das variações de RSSI causadas por movimentos em espaços pequenos e uma análise da correlação entre observações de RSSI em seqüência. Seu trabalho baseia-se em filtros bayesianos simples, mas algumas questões podem ser levantadas quanto ao desempenho desta proposta ao tentar localizar um dispositivo em movimento.

O primeiro trabalho encontrado na literatura a utilizar localização markoviana é o de Haeberlen et al. (2004). Nele, utiliza-se um mapa topológico do ambiente (DUDEK; JENKIN, 2000) que fornece informações sobre suas restrições físicas (como, por exemplo, a impossibilidade de caminhar através de paredes). Krumm e Horvitz (2004), que também utilizam localização markoviana, propõem um algoritmo de interpolação que possibilita a 
construção do mapa de RSSI com a realização de medidas em apenas alguns dos pontos do ambiente (a origem deste trabalho vem de Krumm e Platt (2003)). Os resultados apresentados com o algoritmo de interpolação são próximos aos dos melhores trabalhos, tendo-se economizado $80 \%$ do tempo da fase de treinamento. Xiang et al. (2004) apresentam um trabalho que utiliza dois métodos para realizar as estimativas - a localização markoviana e um filtro bayesino simples - e uma máquina de estados para controlar qual dos métodos deve ser utilizado em cada momento, sem apresentar, no entanto, resultados especialmente significativos. Por fim, o trabalho de Ladd et al. (2005) apresenta um método com duas etapas. Na primeira, um filtro bayesiano simples determina a célula mais provável segundo um conjunto de sinais observados e, na segunda, essa informação é fornecida como entrada para um algoritmo de localização markoviana que considera então a estimativa de localização feita no instante anterior.

Tem-se conhecimento de apenas dois trabalhos que utilizam filtro de partículas em localização Wi-Fi (Berna et al. (2003) e Liao et al. (2003)). No entanto, verifica-se que um ponto interessante desse método é que ele tem propriedades que ajudam na implementação de aprendizado não-supervisionado do comportamento do usuário. Ambos os trabalhos utilizam esse aprendizado como forma de melhorar seu desempenho.

Duas propostas de sistemas que utilizam redes neurais, depois de Smailagic, Small e Siewiorek (2000), foram encontradas: a de Battiti, Nhat e Villani (2002), que propõe uma rede neural com dois neurônios na camada de saída (cujos sinais correspondem a coordenadas de posição); e a de Saha et al. (2003), que propõe uma rede com 19 neurônios na camada de saída, onde cada um desses neurônios corresponde a uma das células do ambiente.

Yamasaki et al. (2005) foi o único trabalho encontrado que utiliza TDOA para localização Wi-Fi. A proposta deste trabalho implica em modificações nos aparelhos dos PAs e seus resultados são apenas moderados quando comparados a outros.

Alguns trabalhos não tratam especificamente de localização Wi-Fi para dispositivos móveis, mas têm uma relação direta com a área e merecem ser mencionados. Hightower e Borriello (2004) propõem um modelo de filtro de partículas mais robusto para localização em geral e sugerem que esse é um modelo passível de ser usado em localização Wi-Fi. O trabalho de Howard, Siddiqi e Sukhatme (2003) utiliza os sinais de PAs Wi-Fi para ajudar na localização de robôs. Ele utiliza um filtro de partículas, método que, neste caso, se encaixa razoavelmente bem considerando que a informação do odômetro permite melhorar bastante a precisão do modelo de movimento. LaMarca et al. (2005) propõem 
um sistema que faz uso de sinais de PAs Wi-Fi para localização de dispositivos móveis em áreas do tamanho de cidades e também utiliza filtro de partículas.

Por fim, o trabalho de Wallbaum (2002) propõe uma arquitetura para a implementação de um serviço de localização de dispositivos móveis em redes Wi-Fi.

Um resumo das características dos principais trabalhos citados é apresentado na tabela 2.3 .

Tabela 2.3: Características dos principais trabalhos de localização Wi-Fi.

\begin{tabular}{|c||c|c|c||c|c||c|c||c|c||c|}
\hline \multicolumn{1}{|c||}{} & \multicolumn{3}{|c||}{ A } & \multicolumn{3}{c||}{ B } & \multicolumn{2}{|c||}{ C } & \multicolumn{2}{|c||}{ D } \\
\hline Trabalhos & $\mathbf{1}$ & $\mathbf{2}$ & $\mathbf{3}$ & $\mathbf{1}$ & $\mathbf{2}$ & $\mathbf{1}$ & $\mathbf{2}$ & $\mathbf{1}$ & $\mathbf{2}$ & \\
\hline \hline Bahl e Padmanbham (2000) & $\mathrm{X}$ & - & - & - & $\mathrm{X}$ & $\mathrm{X}$ & $\mathrm{X}$ & $\mathrm{X}$ & $\mathrm{X}$ & $\mathrm{X}$ \\
\hline Smailagic, Small e Siewiorek (2000) & $\mathrm{X}$ & - & $\mathrm{X}$ & - & $\mathrm{X}$ & $\mathrm{X}$ & - & $\mathrm{X}$ & - & - \\
\hline Gwon, Jain e Kawahara (2004) & $\mathrm{X}$ & - & - & - & $\mathrm{X}$ & - & $\mathrm{X}$ & $\mathrm{X}$ & - & $\mathrm{X}$ \\
\hline Krumm e Platt (2003) & $\mathrm{X}$ & - & - & - & $\mathrm{X}$ & $\mathrm{X}$ & - & $\mathrm{X}$ & - & - \\
\hline Castro et al. (2001) & - & $\mathrm{X}$ & - & $\mathrm{X}$ & - & $\mathrm{X}$ & - & $\mathrm{X}$ & - & - \\
\hline Roos et al. (2002) & - & $\mathrm{X}$ & - & - & $\mathrm{X}$ & $\mathrm{X}$ & - & $\mathrm{X}$ & - & - \\
\hline Elnahrawy, Li e Martin (2004) & $\mathrm{X}$ & $\mathrm{X}$ & - & $\mathrm{X}$ & - & $\mathrm{X}$ & - & $\mathrm{X}$ & - & - \\
\hline Youssef e Agrawala (2005) & - & $\mathrm{X}$ & - & - & $\mathrm{X}$ & $\mathrm{X}$ & - & $\mathrm{X}$ & - & - \\
\hline Haeberlen et al. (2004) & - & $\mathrm{X}$ & - & $\mathrm{X}$ & - & $\mathrm{X}$ & $\mathrm{X}$ & $\mathrm{X}$ & - & $\mathrm{X}$ \\
\hline Krumm e Horvitz (2004) & - & $\mathrm{X}$ & - & - & $\mathrm{X}$ & $\mathrm{X}$ & $\mathrm{X}$ & $\mathrm{X}$ & - & $\mathrm{X}$ \\
\hline Xiang et al. (2004) & - & $\mathrm{X}$ & - & - & $\mathrm{X}$ & $\mathrm{X}$ & $\mathrm{X}$ & $\mathrm{X}$ & - & $\mathrm{X}$ \\
\hline Ladd et al. (2005) & - & $\mathrm{X}$ & - & - & $\mathrm{X}$ & $\mathrm{X}$ & $\mathrm{X}$ & $\mathrm{X}$ & - & $\mathrm{X}$ \\
\hline Berna et al. (2003) & - & $\mathrm{X}$ & - & - & $\mathrm{X}$ & - & $\mathrm{X}$ & $\mathrm{X}$ & - & $\mathrm{X}$ \\
\hline Liao et al. (2003) & - & $\mathrm{X}$ & - & - & $\mathrm{X}$ & - & $\mathrm{X}$ & $\mathrm{X}$ & - & $\mathrm{X}$ \\
\hline Battiti, Nhat e Villani (2002) & - & - & $\mathrm{X}$ & - & $\mathrm{X}$ & $\mathrm{X}$ & - & $\mathrm{X}$ & - & - \\
\hline Saha et al. (2003) & - & - & $\mathrm{X}$ & $\mathrm{X}$ & - & $\mathrm{X}$ & - & $\mathrm{X}$ & - & - \\
\hline
\end{tabular}

As colunas da tabela representam as seguintes características:

A.1. Emprego de método determinista

A.2. Emprego de método probabilístico

A.3. Emprego de rede neural

B.1. Resultados dos experimentos em função da célula de localização

B.2. Resultados dos experimentos em função das coordenadas de localização 
C.1. Experimentos realizados com dispositivo parado

C.2. Experimentos realizados com dispositivo em movimento

D.1. Utilização de mapa de RSSI experimental

D.2. Utilização de modelo matemático das RSSIs do ambiente

E. Consideração de estimativa em intante anterior

\subsubsection{Questões relacionadas à metodologia da parte experimental}

Para que os resultados dos trabalhos apresentados possam ser comparados, deve-se avaliar como os experimentos foram realizados, qual a metodologia usada. Não existe um benchmark que sirva para uma comparação consistente de diferentes sistemas e os resultados dos trabalhos costumam ser apresentados em função de ambientes diferentes. Kaemarungsi e Krishnamurthy (2004) apresentam um estudo baseado numa análise teórica do desempenho do método de localização k-NNSS ao se variar alguns parâmetros do ambiente, tais como o número de pontos de acesso, a taxa de perda de potência do sinal em relação à distância do emissor e o desvio padrão da distribuição da RSSI de um PA. O estudo mostra que a exatidão da resposta de um sistema de localização é muito sensível a variações que são comuns de ambiente para ambiente, conclusão essa que se chega mesmo sem levar em consideração que há ainda outros fatores de influência no desempenho, como a configuração da disposição dos PAs no ambiente e a própria configuração física do ambiente em si. Isso indica que testes executados em ambientes diferentes servem simplesmente como uma indicação de desempenho mas não servem para uma comparação direta. Apenas comparações entre sistemas executando no mesmo ambiente têm um significado mais profundo, mas ainda assim, somente em relação ao ambiente onde o experimento tenha sido executado.

Outro problema para uma comparação entre propostas está em discordâncias que se verificam sobre a forma como o resultado é apresentado. O desempenho de um sistema pode ser apresentado de duas formas: em função de medidas do erro métrico observado das estimativas realizadas - tais como o erro médio das estimativas realizadas, o erro quadrático médio, o qüinquagésimo percentil da distribuição acumulada do erro, o nonagésimo percentil etc... -, ou em função da freqüência em que o sistema estima a célula correta de posição. Muitos trabalhos apresentam seus resultados apenas de uma ou outra forma. Além disso, resultados apresentados na última forma são muito dependentes do tamanho das células que tenha sido empregado no ambiente. 
Uma política comum de muitos trabalhos encontrados (SMAILAGIC; SMALL; SIEWIOREK, 2000; ROOS et al., 2002; YOUSSEF; AGRAWALA, 2005) é utilizar um agrupamento de um número significativo de observações na entrada de cada iteração do algoritmo do sistema de localização com o objetivo de melhorar seu desempenho. Isso é fácil de entender levando em consideração o conceito básico de estatística que diz que, quanto maior o número de amostras utilizadas, maior a certeza que se tem sobre a média de distribuição de uma variável aleatória (NEHMZOW, 2003). Quando se trata de localizar dispositivos que estão parados, essa política sem dúvida é válida. No entanto, se o dispositivo estiver em movimento, observações consecutivas não correspondem a observações realizadas na mesma posição, e o desempenho de um sistema que utiliza tal política passa a ser colocado em dúvida. Além disso, experimentos realizados em laboratório e a análise do código de drivers (para maior detalhes, veja o item A.3 do apêndice) mostram que os sensores Wi-Fi estão programados para dar como resposta não a RSSI do último sinal recebido, mas uma média ponderada que leva em consideração todo o histórico de medidas. Da mesma forma, isso ajuda quando o dispositivo está parado, mas é desastroso quando ele se movimenta. Dos trabalhos encontrados, apenas um comenta alterações realizadas no driver (HAEBERLEN et al., 2004).

Fica claro que o desempenho de um sistema ao tentar localizar um dispositivo que está parado pode ser bem diferente de seu desempenho se o dispositivo estiver em movimento. Poucos trabalhos mostram resultados para este último caso (dos trabalhos que agrupam observações, nenhum o faz). Ainda assim, quando mostram, algumas vezes a metodologia dos experimentos é questionável, trabalhando em áreas restritas, realizando movimentos intermitentes - parando em pontos de controle de forma a facilitar o estabelecimento da posição real do dispositivo, informação essencial para que o erro do sistema possa ser aferido -, ou trabalhando com simuladores que simplificam demais o comportamento do ambiente. De fato, é difícil realizar experimentos em movimento contínuo pois é difícil determinar a posição real do dispositivo no momento de cada estimativa.

Isso tudo leva a observar que a área de estudos em localização Wi-Fi é carente de duas ferramentas importantes: uma metodologia para experimentos de localização de um dispositivo que se encontre em movimento; e um benchmark para comparação de resultados de diferentes propostas. Como essas ferramentas ainda não existem, os resultados dos trabalhos apresentados têm que ser analisados profundamente antes de se efetuar qualquer conclusão definitiva. 


\subsubsection{Análise do desempenho das técnicas com base nos trabalhos apresentados}

Diferentes técnicas podem ser empregadas na criação de um sistema de localização Wi-Fi. Como o objetivo deste trabalho é desenvolver um sistema que traga alguma melhoria em relação às propostas existentes, é importante estabelecer como ponto de partida a técnica que apresenta os melhores resultados. Por isso, nesta seção, os resultados dos trabalhos que empregam cada uma delas serão avaliados e discutidos.

A primeira técnica a ser analisada é a TDOA. Um único trabalho foi encontrado (YAMASAKI et al., 2005), o que indica que o meio acadêmico não vem mostrando muito interesse por essa linha de desenvolvimento. Duas são as principais razões para isso: modificações teriam que ser feitas no hardware dos PAs para captar com precisão os tempos de chegada dos sinais; e, mesmo com as modificações realizadas, as estimativas de localização utilizando TDOA não prometem maior precisão. O sistema proposto por Yamasaki et al. (2005) mostra isso. Em testes realizados em um ambiente com um número grande de PAs, apresentou erro de 2,4m para o 670 . percentil - que deve corresponder a um erro médio de cerca de $2 \mathrm{~m}$ - o que é um resultado apenas moderado.

Em relação a métodos deterministas, o que mais se encontra na literatura são estudos com k-NNSS. Além dos trabalhos que têm como foco o próprio método (BAHL; PADMANBHAM, 2000; BRUNATO; KALLó, 2002; SMAILAGIC et al., 2002), uma série de outros trabalhos utiliza o método como parâmetro de comparação (ROOS et al., 2002; GWON; JAIN; KAWAHARA, 2004; KRUMM; HORVITZ, 2004). No trabalho de Bahl, onde a proposta do método foi encontrada pela primeira vez, o erro médio da implementação do método k-NNSS bruto é de cerca de $3 \mathrm{~m}$, mas quando se acrescenta a ele um modelo que relaciona uma série de estimativas consecutivas, o erro médio cai para cerca de 2,4m. Em trabalhos onde se apresenta comparação com métodos probabilísticos, o desempenho do k-NNSS é sempre pior. Outros métodos deterministas foram propostos, mas seus resultados costumam apresentar erros da mesma grandeza.

Três são os métodos probabilísticos que são encontrados em trabalhos sobre localizaçao Wi-Fi: filtros de partículas; filtros bayesianos simples; e localização markoviana. Eles serão comentados a seguir.

Dos dois trabalhos que utilizam filtros de partículas encontrados, apenas o de Berna et al. (2003) pode ser comparado com outras propostas de localização Wi-Fi. Nele, o melhor resultado que o sistema consegue é um erro médio de $2,1 \mathrm{~m}$, sendo que ele inicia com esse erro em torno de $2,8 \mathrm{~m}$ e o método de aprendizagem usado melhora seu desempenho. A 
outra proposta encontrada que utiliza filtro de partículas (LIAO et al., 2003) depende de restrições de mobilidade que não são consideradas em outros trabalhos, o que torna difícil a comparação de resultados.

Dos trabalhos com filtros bayesianos simples, os melhores resultados são encontrados em Roos et al. (2002), onde se aprensenta um erro médio de 1,6m, e em Youssef e Agrawala (2005), onde o erro médio do sistema é menor do que 1m. Ambos os sistemas utilizam um agrupamento de um número grande de observações a cada iteração do localizador e apresentam experimentos de localização apenas com o dispositivo parado.

Os trabalhos que utilizam localização markoviana são os que apresentam os conjuntos de experimentos mais completos (juntamente com alguns trabalhos com métodos deterministas como Bahl e Padmanbham (2000) e Gwon, Jain e Kawahara (2004), e o trabalho de Berna et al. (2003)), considerando situações em que o dispositivo está de fato em movimento. Ladd et al. (2005) apresenta um erro de 1,5m com uma confiança de $83 \%$ - o erro médio ficando em torno de $1 \mathrm{~m}$ - com o dispositivo parado, mas seus resultados não são particularmente bons quando o dispositivo está em movimento. Krumm e Horvitz (2004) apresenta um erro médio de cerca de 1,5m com o dispositivo em movimento - o que é um resultado muito bom. Por fim, Haeberlen et al. (2004) faz experimentos com um simulador de um dispositivo em movimento baseado na informação das RSSIs coletadas no ambiente. Seus resultados são dados em termos da porcentagem de estimativas corretas da célula de localização do dispositivo. Experimentos são feitos variando uma série de parâmetros do sistema. Na melhor configuração encontrada para o sistema, obteve-se uma porcentagem de estimativas corretas de 95\%, para células de $20 \mathrm{~m}^{2}$ em média.

Dos três trabalhos que utilizam redes neurais encontrados, dois apresentam resultados a partir dos quais não se pode tirar conclusões importantes: a proposta de Smailagic, Small e Siewiorek (2000) apresenta um desempenho fraco, mas a estrutura da rede utilizada e o processo de aprendizado não são bem descritos, o que levanta questões sobre a implementação; e a proposta de Saha et al. (2003), cujos resultados são muito bons, mas onde o número de células do ambiente é irrealisticamente baixo e os experimentos utilizam observações que fazem parte do grupo de exemplos usados no aprendizado da rede, o que não é uma metodologia correta pois não dá uma idéia do poder de generalização da rede resultante (RUSSEL; NORVIG, 2003). O terceiro trabalho encontrado (BATTITI; NHAT; VILLANI, 2002) é um trabalho bem detalhado e que apresenta resultados interessantes. Com poucos exemplos colhidos no ambiente (o que é uma vantagem em relação às técnicas que utilizam o mapa de RSSI) e apenas três PAs, o sistema obteve um erro médio de 1,5m. Mas como só são apresentados experimentos com o dispositivo parado e nada se comenta 
sobre alterações no driver, questões podem ser levantadas quanto ao seu desempenho ao tentar localizar um dispositivo em movimento. É, entretanto, uma técnica que precisa ser mais explorada para que se possa entender suas limitações.

Como foi comentado no item 2.3.2, é muito difícil fazer uma comparação mais definitiva de desempenho sem que os sistemas sejam executados no mesmo ambiente. Por isso, foram feitas implementações de algumas propostas que utilizam filtros bayesianos e localização markoviana e uma série de testes preliminares foram executados com o dispositivo em movimento em um ambiente de testes com diversos PAs (para maiores detalhes sobre os testes, veja o capítulo 5). Os sistemas que utilizavam localização markoviana apresentaram um desempenho significativamente melhor que os que utilizavam filtros bayesianos simples. Particularmente, um sistema baseado na proposta de Haeberlen et al. (2004) com alguns ajustes de parâmetros foi o que mostrou o melhor desempenho. Esse sistema será a base do desenvolvimento da proposta apresentada neste trabalho, e sua descrição em detalhes será apresentada no próximo capítulo.

\subsubsection{Adaptabilidade a variações no ambiente}

A maioria dos trabalhos encontrados na literatura sobre sistemas de localização Wi-Fi costuma incluir dentre as vantagens deste tipo de sistema o fato de que não necessita de investimentos em infra-estrutura pois pode aproveitar as instalações existentes no ambiente. De fato, isso tanto é possível que, nos experimentos realizados neste trabalho (apresentados no capítulo 5), não houve a necessidade de qualquer instalação - além daquela já existente no ambiente - para que os sistemas funcionassem bem.

Como foi discutido no início deste capítulo, utilizar uma infra-estrutura existente deve implicar operar com sinais de PAs sobre os quais não se tem qualquer controle e dos quais, muitas vezes, tem-se pouca ou nenhuma informação. Como se espera que um sistema funcione bem nessas condições, é muito importante que ele seja robusto o suficiente para se adaptar a variações que podem ocorrer nessa infra-estrutura.

Essa preocupação, no entanto, não tem sido levantada. Uma boa parte dos trabalhos apresentados não considera explicitamente a possibilidade de que o sinal de um PA pode não estar presente em uma observação, o que deve ser levado em consideração mesmo que se tenha completo controle da infra-estrutura, pois isso pode acontecer por motivos comuns como o fato de o ambiente a ser coberto pelo sistema de localização ter uma área maior que a área de alcance de um PA, ou o fato de que falhas sempre podem acontecer na transmissão dos sinais (para maiores detalhes sobre falhas na transmissão de sinais, 
veja o item A.2.2 do apêndice). Os trabalhos que consideram que o sinal de um PA pode não estar presente incluem essa informação nas distribuições da RSSI para cada ponto de medida do ambiente que ficam gravadas no mapa de RSSI. O sistema básico que será usado como ponto de partida e referência neste trabalho faz isso.

No entanto, questões ainda precisam ser respondidas quanto ao desempenho de sistemas quando um ou mais PAs usados como referência são desligados, quando a quantidade de PAs numa mesma área é tal que os canais causem interferências entre si ou quando há alterações físicas no ambiente, situações que podem ocorrer se o administrador do sistema de localização não tiver controle sobre a infra-estrutura que o apóia. 


\section{Um sistema básico de localização $\mathrm{Wi}-\mathrm{Fi}$}

A análise dos trabalhos encontrados na literatura e testes preliminares realizados em laboratório mostraram que o modelo de sistema que se encaixa melhor ao problema de localizar dispositivos móveis em redes Wi-Fi utiliza uma variação de localização markoviana com considerações topológicas sobre o ambiente, modelo retirado do trabalho de Haeberlen et al. (2004). Neste capítulo, será descrito um sistema que emprega esse modelo. Ele servirá como ponto de partida para a elaboração de uma nova proposta e como referência na definição do seu desempenho.

Como foi explicado no capítulo anterior, a localização markoviana é um método que faz parte do conjunto de técnicas que utilizam um modelo discreto do ambiente. A construção deste modelo discreto - o mapa de RSSI - constitui o que se chama de fase de treinamento do sistema e será apresentada na primeira seção deste capítulo. Em seguida, o método de localização markoviana, que constitui a fase de execução do sistema, será descrito com as adaptações necessárias ao contexto de localização Wi-Fi. Por fim, algumas definições específicas do sistema básico de localização Wi-Fi serão discutidas.

\subsection{A fase de treinamento: construção do mapa de RSSI}

O procedimento básico para se construir um mapa de RSSI de um determinado ambiente é marcar em um mapa métrico uma série de Pontos de Medida (PM) de forma que toda a área esteja coberta. Pode-se distribuir os pontos no mapa uniformemente, mantendo uma distância equivalente entre cada par de pontos adjacentes, ou atribuir um ponto a cada sala, quarto, pedaço de corredor, ou seja, a áreas que tenham um significado em termos de localização.

São realizadas então algumas séries de observações, com um dispositivo móvel posicio- 
nado nas áreas correspondentes a cada um dos PMs marcados no mapa. Seja $A=\left\{p_{a} \mid a=\right.$ $1,2, \ldots, \mathcal{A}\}$, o conjunto de PAs onde $\mathcal{A}$ representa o número total de PAs existentes no ambiente. Cada observação feita em cada PM pode então ser descrita como um vetor de $\mathcal{A}$ posições $O_{t}=\left[o_{a, t} \mid a=1,2, \ldots, \mathcal{A}\right]$, onde $t$ representa o instante da medida e $o_{a, t}$ representa a RSSI de $p_{a} \in A$ no instante $t$ observada pelo dispositivo em questão. Quando o sinal de um determinado PA não está presente na observação, seu respectivo valor $o_{a, t}$ é considerado igual a um valor menor que a RSSI do sinal mais fraco que o dispositivo consegue captar. Para a descrição que será apresentada, esse valor será considerado como sendo $\mathcal{R}$ min -1 , onde $\mathcal{R}$ min é o mínimo valor possível de ser observado.

\subsubsection{Realização das medidas de observação}

As medidas de observação nos PMs podem ser feitas de várias formas, mas três delas são as mais freqüentes.

A primeira forma é realizá-las com o dispositivo parado numa posição fixa durante um determinado tempo. Neste caso, em cada um dos PMs marcados no mapa métrico são feitas quatro séries de medições - com o dispositivo orientado para Norte, Sul, Leste e Oeste, ou para outras quatro direções ortogonais, quaisquer que sejam - e é dessa forma que se leva em consideração o efeito da orientação. Trabalhos que usam essa técnica (BAHL; PADMANBHAM, 2000; LADD et al., 2002), mesmo nos seus melhores casos, não apresentam resultados significativamente melhores, e aumentam em quatro vezes o número de estados do mapa (um para cada orientação considerada), o que significa maior complexidade computacional.

A segunda forma de se realizar as medidas de observação é, para cada um dos PMs, sem sair do lugar, girar lentamente com o dispositivo móvel em mãos, obtendo assim observações relativas a várias orientações (KRUMM; HORVITZ, 2004). Esse procedimento é particularmente interessante para métodos que precisam realizar interpolações com os dados do mapa, pois caracteriza a distribuição de RSSI em uma região que tende a um ponto (PM) em um espaço contínuo.

A terceira forma é provavelmente a que melhor representa as características das células como um todo. Para cada uma das células do ambiente (que devem corresponder aos PMs), durante um certo tempo, anda-se lentamente, variando altura e orientação do dispositivo, percorrendo toda sua área, enquanto se transporta o dispositivo móvel que está realizando as medidas de observação (HAEBERLEN et al., 2004). Esse procedimento, se for feito de forma meticulosa, pode demorar um pouco mais, mas tende a obter bons 
resultados.

O tempo que o dispositivo móvel deve permanecer realizando as medições em um mesmo PM (que, como se viu, pode corresponder a uma célula, um ponto fixo, ou um ponto associado com uma direção) pode ser um tempo fixo pré-determinado (HAEBERLEN et al., 2004; KRUMM; HORVITZ, 2004) ou pode ser determinado por uma função de convergência da distribuição de RSSI observada (LADD et al., 2002).

\subsubsection{O armazenamento da informação obtida}

O mapa de distribuição de RSSI armazena os dados obtidos nas medições em registros. Um registro do mapa de distribuição de RSSI corresponde sempre a um PM e pode ser identificado pelas coordenadas desse PM definidas no mapa métrico, e em certos casos, por uma direção que represente a orientação do dispositivo móvel. O mapa deve armazenar em cada registro uma informação referente a cada um dos PAs que são visíveis no ambiente. Mais formalmente, o mapa deve ser composto por $\mathcal{I}$ registros, $M=\left\{R_{i} \mid i=1,2, \ldots, \mathcal{I}\right\}$, sendo $\mathcal{I}$ o número de PMs no ambiente. O conteúdo de cada registro deve ser dado por uma tupla, $R_{i}=\left(e_{i}, C_{i}\right)$, onde $e_{i}$ representa a identificação do PM $i$ ao qual o registro corresponde, e $C_{i}$ representa o vetor de atributos armazenado. Este vetor pode ser descrito como $C_{i}=\left[R s s i_{i, a} \mid a=1,2, \ldots, \mathcal{A}\right]$, onde $R s s i_{i, a}$ é a informação relativa ao PA a no PM $i$.

A primeira forma de se armazenar a informação obtida nas medições feitas com o dispositivo móvel é construir um histograma para cada PA a em cada registro $i$ do mapa. Para isso divide-se o universo de RSSIs em regiões de mesma largura, cada uma dessas regiões com uma barra correspondente no histograma. A altura de cada barra do histograma é dada pelo número de observações cujo valor de RSSI (considerando inclusive valores $\mathcal{R}$ min -1 ) recai na região correspondente. A informação armazenada neste caso é um vetor que representa o histograma:

$$
\operatorname{Rssi}_{i, a}=\left[b_{i, a, n} \mid n=1,2, \ldots, \mathcal{N}\right]
$$

onde $b_{i, a, n}$ representa a altura da barra $n$ do histograma do PA a no registro $i$ do mapa, e $\mathcal{N}$ é o número de barras. O histograma tem a propriedade de descrever com uma boa aproximação a forma da distribuição que caracteriza o sinal de um PA registrado em um determinado PM do mapa. Ele tem, no entanto, duas desvantagens: necessita muito espaço de memória; e, como as medições em um PM não duram mais que poucos minutos ou segundos, a forma que se obtém é muito menos suave que a real distribuição do sinal 
- conclusão que se chega ao realizar as medidas de observação durante um tempo longo (XIANG et al., 2004).

A segunda forma consiste em armazenar parâmetros que descrevem uma função de distribuição de probabilidade que se aproxima da distribuição de RSSI que foi observada. O que se faz com mais freqüência é modelar a distribuição de probabilidade como sendo uma função gaussiana (HAEBERLEN et al., 2004; YOUSSEF; AGRAWALA, 2005), e assim a informação armazenada pode ser descrita dessa forma:

$$
\operatorname{Rssi}_{i, a}=\left(\mu_{i, a}, \sigma_{i, a}, f_{i, a}\right),
$$

onde $\mu_{a, i}$ representa a média das RSSIs observadas para o PA $a$ no PM correspondente ao registro $i$ do mapa, e $\sigma_{a, i}$ representa a variância desse mesmo conjunto de observações - ambos parâmetros calculados considerando apenas as amostras onde o sinal do PA a esteve presente. O terceiro parâmetro $f_{i, a}$, que não faz parte de uma descrição usual de uma função gaussiana, serve para armazenar a freqüência em que o sinal do PA $a$ esteve presente nas amostras do conjunto de observações, isto é, que apresentou valor igual a $\mathcal{R}$ min -1 .

A desvantagem da utilização desta forma é que nem sempre as distribuições de RSSI se aproximam da função gaussiana. No entanto, Hashemi (1993) mostra um estudo que diz que a função que melhor representa a distribuição de RSSI em uma determinada área é de fato a função gaussiana (isso considerando que a medida de RSSI seja feita em dBm, que é uma medida logarítmica).

\subsection{A fase de execução: localização markoviana em re- des Wi-Fi}

Para se entender a localização markoviana é preciso primeiro entender o que é um modelo de estados ocultos de Markov - ou HMM - que constitui a estrutura sobre a qual o algoritmo de localização deve ser executado. Nesta seção, o que será apresentado não é uma descrição genérica de um HMM, mas sim uma descrição um pouco mais específica, já discorrendo sobre as particularidades de sua implementação para o contexto de localização Wi-Fi. Em seguida, será feita a apresentação do algoritmo de localização, que é a parte do modelo que corresponde de fato à execução do sistema de localização. 


\subsubsection{O modelo de estados ocultos de Markov - HMM}

Um HMM deriva das cadeias de Markov (CM). Uma cadeia de Markov é uma forma de representar probabilidades de se observar cada um dos possíveis valores de uma variável aleatória em um determinado instante do tempo (RABINER, 1989). Cada um desses valores numa cadeia de Markov é chamado de estado. A princípio, a probabilidade de um estado num determinado instante é função das distribuições de probabilidade em todos os instantes anteriores. No entanto, segundo a suposição de Markov, pode-se sintetizar toda a história pregressa em um único instante relevante para a determinação da probabilidade de um estado em um determinado momento, que é o instante imediatamente anterior. As cadeias de Markov partem desse princípio e em seu modelo representam os estados (que correspondem a um evento observável) e probabilidades de transição entre estados. A figura 3.1 mostra um exemplo em um grafo com três estados $-e_{1}, e_{2}$ e $e_{3}$ representados pelos vértices - onde as arestas representam as probabilidades de transição entre os estados. A probabilidade de um estado $e_{j}$ em um determinado momento $t$ é dada por:

$$
P\left(\mathbf{q}_{t}=e_{j}\right)=\sum_{i=1}^{\mathcal{I}} P\left(\mathbf{q}_{t-1}=e_{i}\right) P\left(\mathbf{q}_{t}=e_{j} \mid \mathbf{q}_{t-1}=e_{i}\right),
$$

onde $\mathbf{q}_{t}$ é a variável aleatória de estado no tempo $t$ e $\mathcal{I}$ indica o número de estados no modelo.

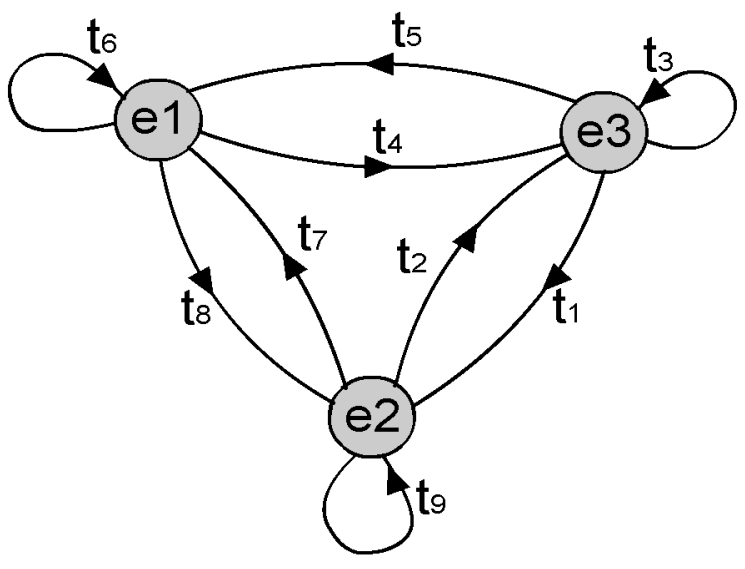

Figura 3.1: Representação de uma cadeia de Markov.

Quando as observações não correspondem diretamente aos estados, pode-se dizer que os estados não são observáveis, ou melhor, que estão ocultos, e tem-se então um modelo de estados ocultos de Markov ou um HMM. Neste modelo, a observação de um determinado valor implica uma certa probabilidade de se estar em um determinado estado, para cada 
um dos estados do modelo. Um HMM é composto por cinco elementos: um conjunto de estados, um conjunto de possíveis observações, probabilidades de essas observações serem feitas nos estados, probabilidades de transição entre estados e uma distribuição inicial de probabilidade de estado. Em localização Wi-Fi, esses elementos têm características próprias e elas serão descritas a seguir.

Os estados de um HMM em localização Wi-Fi representam células ou regiões do ambiente que, por sua vez, correspondem aos PMs registrados no mapa de distribuição de RSSI. Considerando que o mapa métrico do ambiente onde tenham sido definidos os PMs seja um mapa de duas dimensões, determina-se que o conjunto de estados $E$, formado por $\mathcal{I}$ estados, é dado por $E=\left\{e_{i}=\left(x_{i}, y_{i}\right) \mid i=1,2 \ldots, \mathcal{I}\right\}$, onde cada estado $e_{i}$ é composto pelas coordenadas do ponto central da respectiva célula, $x_{i}$ e $y_{i}$.

Uma observação num determinado instante $t$ pode ser descrita como um vetor $O_{t}=$ $\left[o_{a, t} \mid a=1,2, \ldots, \mathcal{A}\right]$. Considerando que as RSSIs observadas são valores inteiros do intervalo $[\mathcal{R} \min -1, \mathcal{R} \max ]$ - com $\mathcal{R} \min$ e $\mathcal{R} \max$ dependente do hardware utilizado, e $\mathcal{R}$ min - 1 correspondendo à ausência de sinal - o conjunto de observações é constituído por todos os vetores de $\mathcal{A}$ posições formados pelas $(\mathcal{R} \max -\mathcal{R} \min +2)^{\mathcal{A}}$ possíveis combinações de valores pertencentes a esse intervalo.

Sendo assim, o conjunto de observações é extremamente grande, e não há como armazenar nem calcular todas as probabilidades de observações para cada estado, o que implica que elas devem ser calculadas a partir do mapa de RSSI durante a execução do algoritmo de localização.

Em cada registro $i$ - associado a uma célula do ambiente - o mapa armazena um vetor de atributos $C_{i}=\left[R s s i_{i, a} \mid a=1,2 \ldots, \mathcal{A}\right]$. Como se viu, existem duas formas de armazenamento que podem ser usadas. Para a primeira, onde $R s s i_{i, a}=\left[b_{i, a, n} \mid n=\right.$ $1,2, \ldots, \mathcal{N}]$, a probabilidade de o valor observado do PA a ser igual a rssi, dado que o dispositivo está na célula $i$, pode ser calculada assim:

$$
P\left(\mathbf{o}_{a}=r s s i \mid \mathbf{q}=e_{i}\right)=\frac{b_{i, a, g}}{\sum_{n=1}^{\mathcal{N}} b_{i, a, n}}
$$

onde q é a variável aleatória que representa o estado, $\mathbf{o}_{a}$ é a variável aleatória que representa o sinal observado do PA $a$, e $g$ é o índice da região que inclui rssi. A consideração sobre a probabilidade do sinal de um PA estar ausente é feita automaticamente a partir do momento em que os valores Rmin - 1 estiverem incluídos dentre os valores considerados no histograma, como foi explicado na seção anterior. 
Para a segunda forma, onde $R s s i_{i, a}$ armazena os parâmetros de uma função que representa uma distribuição de probabilidade, o que se faz é discretizar tal função em intervalos pequenos para que o cálculo possa ser feito. Para cada um dos possíveis valores de RSSI pode-se calcular $P\left(\mathbf{o}_{a}=r s s i \mid \mathbf{q}=e_{i}\right)$ da seguinte forma:

$$
P\left(\mathbf{o}_{a}=r s s i \mid \mathbf{q}=e_{i}\right)=\eta_{a, i}\left[G_{a, i}(r s s i)+\lambda\right]
$$

onde

$$
G_{a, i}(r s s i)=\int_{r s s i-0.5}^{r s s i+0.5} \frac{\exp \left[-\left(x-\mu_{a, i}\right)^{2} / 2 \sigma_{a, i}^{2}\right]}{\sigma_{a, i} \sqrt{2 \pi}} d x \text {. }
$$

$G_{a, i}$ representa a discretização da distribuição gaussiana com média $\mu_{a, i}$ e variância $\sigma_{a, i}, \eta_{a, i}$ é um fator de normalização e $\lambda$ é um valor que previne que qualquer observação tenha probabilidade muito próxima a zero. Uma probabilidade do sinal do PA a estar ausente $-P\left(\mathbf{o}_{a}=\mathcal{R} m i n-1 \mid \mathbf{q}=e_{i}\right)$ - deve ser calculada com base no parâmetro $f_{a, i}$. Então $\eta_{a, i}$ é obtido de forma que:

$$
\sum_{r s s i=\mathcal{R} \min -1}^{\mathcal{R} \max } P\left(\mathbf{o}_{a}=r s s i \mid \mathbf{q}=e_{i}\right)=1
$$

Para ambas as formas de armazenamento, a probabilidade de uma determinada observação $O_{t}$ condicional a um estado $e_{i}$ é dada então por

$$
P\left(O_{t} \mid \mathbf{q}_{t}=e_{i}\right)=\prod_{a=1}^{\mathcal{A}} P\left(\mathbf{o}_{a}=o_{a, t} \mid \mathbf{q}=e_{i}\right),
$$

sendo $\mathbf{q}_{t}$ a variável aleatória do estado de localização do dispositivo no tempo $t$.

A probabilidade de transição entre dois estados $e_{j}$ e $e_{i}-$ aqui representada por $P_{\text {trans }}\left(e_{j}, e_{i}\right)$ com $P_{\text {trans }}\left(e_{j}, e_{i}\right)=P\left(\mathbf{q}_{t+1}=e_{i} \mid \mathbf{q}_{t}=e_{j}\right)$ e $\sum_{i=1}^{\mathcal{I}} P_{\text {trans }}\left(e_{j}, e_{i}\right)=1$ - é a probabilidade de um dispositivo, estando no estado $j$ em um instante $t$, passar a estar, no próximo instante $t+1$, no estado $i$. Uma forma de determinar as probabilidades de transição de um modelo é considerar as probabilidades de transição entre um estado $j$ e todos os outros estados $i-\operatorname{com} i$ de 1 a $\mathcal{I}$, exceto $j$ - como sendo função da distância euclidiana entre $e_{j}$ e $e_{i}$, considerando um peso fixo para a transição reflexiva (a transição de um estado para ele mesmo, ou seja, a transição que acontece quando o dispositivo permanece na mesma posição). Uma outra alternativa seria considerar um mapa topológico do ambiente onde os vértices representem os estados, e usar então os caminhos mais curtos no mapa entre cada par de vértices como sendo as distâncias usadas para o cálculo das probabilidades de transição. 
Um mapa topológico é uma representação abstrata do ambiente na forma de um grafo onde os vértices representam lugares discretos - que devem corresponder, no caso do HMM para localização Wi-Fi, aos estados do modelo - e as arestas, a conectividade entre eles (DUDEK; JENKIN, 2000), de forma que, entre dois vértices do grafo somente exista uma aresta se for possível caminhar de um vértice a outro sem passar antes por qualquer outro vértice do mapa. Por exemplo, se existirem dois pontos espacialmente próximos mas que têm uma parede entre eles (como pontos em salas adjacentes), no mapa topológico tais pontos não possuem uma aresta que os ligue. A vantagem de se usar um mapa topológico é que ele traz para o modelo as informações sobre as restrições físicas do ambiente, fazendo com que as probabilidades de transição reflitam melhor o que acontece de fato.

Uma observação importante a ser feita aqui é que, neste trabalho, os vértices do que está sendo chamado de mapa topológico, quando colocado no contexto de um HMM, sempre devem corresponder aos estados do modelo, mesmo que não correspondam a lugares que tenham de fato um significado topológico - como salas, quartos etc. - mas a células pequenas distribuídas em uma área sem separação física. De qualquer forma, a definição do parágrafo anterior que condiciona a existência de arestas no mapa topológico à existência de conexão direta entre as células que os vértices representam continua válida.

A distribuição de probabilidade do estado inicial pode ser considerada uniforme em todo o conjunto de estados - o que significa que, a princípio, nada se sabe sobre a localização do dispositivo móvel -, pode ser probabilidade 1 para um estado específico e 0 para todos os outros - o que significa que se conhece a localização inicial do dispositivo - ou pode ainda representar uma situação intermediária entre os dois extremos.

\subsubsection{O algoritmo de localização}

Definidos os elementos que compõem o HMM para localização, pode-se então explicar o algoritmo de localização usado para realizar as estimativas, que, no caso da localização markoviana, se baseia em um algoritmo de percurso no HMM chamado algoritmo direto (ver forward procedure em Rabiner (1989)). A figura 3.2 ilustra o algoritmo completo de localização. Enquanto em execução, o algoritmo mantém a distribuição de probabilidade do estado calculada no instante anterior $\mathbf{P}\left(\mathbf{q}_{t-1} \mid O_{t-1}\right)$ (no primeiro instante, essa informação é representada pela distribuição de probabilidades do estado inicial). Então, para cada estado do modelo no instante $t$, dois módulos são executados: o módulo de transição, responsável pelo cálculo do fator de transição $\sum_{j=1}^{\mathcal{I}} P\left(\mathbf{q}_{t-1}=e_{j} \mid O_{t-1}\right) P_{\text {trans }}\left(e_{j}, e_{i}\right)$, que representa o somatório das probabilidades de o dispositivo ter transitado de cada 
um dos estados do modelo para o estado em questão entre o instante anterior e o atual, probabilidades estas que são dadas em função da distribuição de probabilidade do estado no instante anterior, $\mathbf{P}\left(\mathbf{q}_{t-1} \mid O_{t-1}\right)$, e das probabilidades de transição entre estados do modelo; e o módulo de observação, que calcula $P\left(O_{t} \mid \mathbf{q}_{t}=e_{i}\right)$ com base na informação do mapa de RSSI e na observação $O_{t}$ feita no instante $t$, conforme foi explicado no item anterior. Os resultados dos dois módulos são multiplicados e, por fim, passados por um módulo de normalização para se obter a probabilidade do estado $i$ dada a observação $O_{t}$ :

$$
P\left(\mathbf{q}_{t}=e_{i} \mid O_{t}\right)=\eta P\left(O_{t} \mid \mathbf{q}_{t}=e_{i}\right) \sum_{j=1}^{\mathcal{I}} P\left(\mathbf{q}_{t-1}=e_{j} \mid O_{t-1}\right) P_{\text {trans }}\left(e_{j}, e_{i}\right) .
$$

Realizado o cálculo para cada um dos estados do modelo, obtém-se então uma distribuição de probabilidade da variável de estado no instante $t-\mathbf{P}\left(\mathbf{q}_{t} \mid O_{t}\right)$ - que corresponde à resposta do algoritmo direto. No entanto, o sistema precisa fornecer uma informação sobre a localização do dispositivo em uma forma mais adequada ao entendimento do usuário, por isso, um módulo estimador, que recebe como entrada a distribuição calculada, é executado e retorna enfim a informação de localização. Este módulo pode simplesmente selecionar o estado de maior probabilidade, mas o mais comum é que ele realize uma média dos estados ponderada pelas probabilidades calculadas para cada um deles, o que representa a esperança matemática da distribuição (BOZIC, 1979).

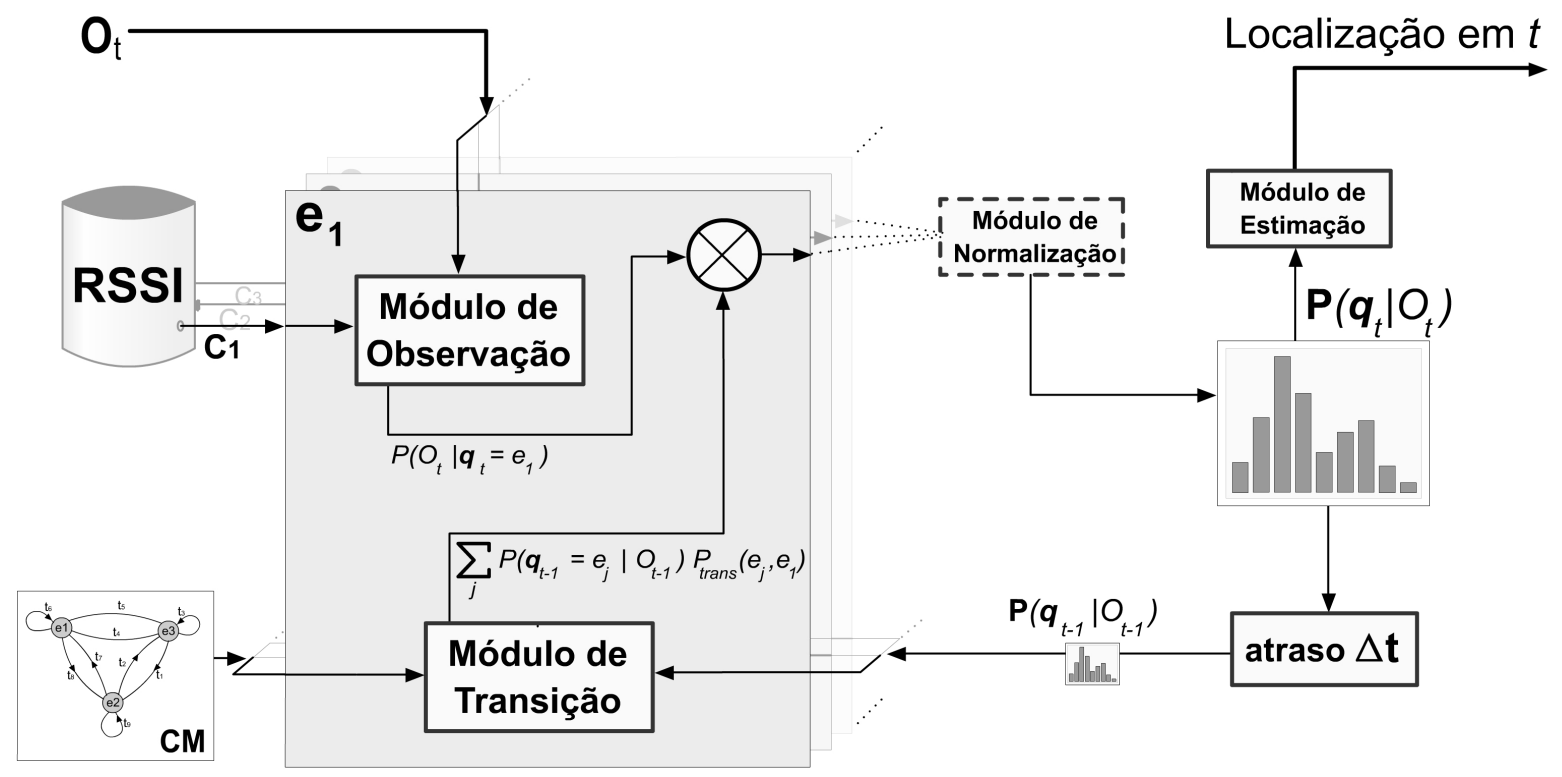

Figura 3.2: Esquema do algoritmo de localização completo.

Uma observação importante deve ser feita sobre o processo de normalização. O fator 
normalizador (representado na equação 3.7 por $\eta$ ) é calculado no módulo de normalização de forma que o somatório das probabilidades condicionais calculadas para todos os estados do modelo seja igual a 1. Isso é importante para se determinar a distribuição de probabilidade da variável de estado, mas não para o resultado final do algoritmo, já que esse resultado é um função de uma comparação entre estados e não depende de valores absolutos de probabilidade. Se estes valores não tiverem sido normalizados - o que significa simplesmente que todos os valores correspondem a $P\left(\mathbf{q}_{t}=e_{i} \mid O_{t}\right) / \eta$ - nem o cálculo da esperança, nem a seleção do estado de maior probabilidade são afetados. Por isso, a implementação do algoritmo de localização pode ser feita sem o módulo de normalização.

\subsection{Especificações do sistema básico de localização Wi- $\mathrm{Fi}$}

Até aqui, descreveu-se em linhas gerais um modelo para localização de dispositivos móveis em redes Wi-Fi que utiliza um modelo discreto do ambiente empregando o método de localização markoviana. Para que se implemente um sistema baseado nesse modelo, algumas definições - que o modelo como foi descrito deixa em aberto - têm que ser feitas. Basicamente, o que precisa ser definido é:

- a forma de realização das medidas para a construção do mapa de RSSI;

- a forma de representação das distribuições de RSSIs;

- a forma do cálculo das probabilidades de transição; e

- a distribuição de probabilidade do estado inicial.

Como foi descrito no capítulo anterior, é muito difícil comparar resultados para localização Wi-Fi. Apesar de cada uma das metodologias utilizadas para realizar as medições no ambiente aparecerem em diversos trabalhos, não se encontrou nenhum que comparasse o desempenho de um sistema em função de diferentes metodologias utilizadas em um mesmo

ambiente. Assim, escolheu-se para realização de tais medidas a terceira forma descrita no item 3.1.2 - aquela na qual se coleta as RSSIs dos PAs do ambiente em toda a área da célula, variando altura e orientação do dispositivo - pois ela parece se enquadrar melhor no modelo, como foi argumentado na sua descrição.

Quanto à forma de representação das distribuições de RSSI, duas comparações podem ser encontradas na literatura (HAEBERLEN et al., 2004; ROOS et al., 2002), com relatos 
controversos sobre qual das formas produz melhores resultados. Como o modelo utilizado aqui é baseado no trabalho de Haeberlen et al. (2004), escolheu-se a representação feita através de gaussianas, que é a forma proposta em seu trabalho. É importante observar, no entanto, que a escolha feita para o sistema básico foi empregada também no sistema proposto, de forma a não ter influência nos resultados comparativos. Não há razões para crer que, se fossem utilizados histogramas em ambos os sistemas, a comparação entre eles apresentaria conclusões diferentes daquelas que são descritas nos próximos capítulos.

Quanto ao cálculo das probabilidades de transição, definiu-se que ele seria feito em função de um mapa topológico e de algumas considerações sobre as células do ambiente e o comportamento dos usuários dos dispositivos. Considere, para efeito de ilustração, que as células de um ambiente sejam quadradas e tenham 1,5m de lado, e que o tempo considerado entre cada observação é de cerca de $0.2 \mathrm{~s}^{1}$. No melhor caso, uma pessoa teria que andar a $6 \mathrm{~m} / \mathrm{s}$ para passar por duas células contíguas entre uma observação e outra. É bastante razoável assumir que isso não acontece com uma pessoa que carrega um dispositivo móvel, já que $6 \mathrm{~m} / \mathrm{s}$ é a velocidade de um corredor de maratonas. Assim, para o cálculo das probabilidades de transição, estabelece-se uma probabilidade pré-determinada para a transição reflexiva, define-se probabilidade zero para a transição entre um vértice e todos os outros aos quais ele não está diretamente ligado no mapa topológico, e define-se uma probabilidade inicialmente equivalente para todas as transições representadas pelas arestas que possuem um mesmo vértice como antecessor.

É preciso então definir o valor das probabilidades de transição reflexiva. Para isso, foram utilizadas as caminhadas realizadas no ambiente de testes, e através delas verificouse que, enquanto caminhava, a pessoa que carregava o dispositivo permanecia na mesma célula, em média, cerca de 15 iterações do programa antes de passar para uma nova célula, o que indica que cerca $95 \%$ das vezes a transição de estados foi reflexiva. Esse foi o valor usado nos testes finais para ambos os sistemas.

O cálculo das probabilidades de transição feito dessa forma atende bem a um sistema de localização onde pessoas carregam seus dispositivos a pé, mas não serve caso se leve em consideração a possibilidade da utilização de veículos de transporte. Se esse for o caso, um sistema que defina probabilidades de transição em função das distâncias entre vértices no grafo que representa o mapa topológico deve ser a melhor alternativa. Não obstante, a forma aqui descrita atende bem à situação em que os testes deste trabalho

\footnotetext{
${ }^{1} \mathrm{O}$ valor obtido em testes no laboratório que analisaram a resposta do hardware utilizado foi na verdade menor que esse (como pode ser visto no item A.3 do apêndice) e, nos experimentos realizados, a largura da menor célula do ambiente era de $2 \mathrm{~m}$.
} 
foram realizados e, da mesma maneira que a forma da representação das distribuições de RSSI, a forma do cálculo das probabilidades de transição não deve influenciar nos resultados dos testes comparativos, já que será empregada em ambos os sistemas.

Por fim, definiu-se que a distribuição de probabilidade do estado inicial deve ser uniforme em todo o conjunto de estados, o que permite que o sistema seja iniciado a qualquer momento estando o dispositivo em qualquer posição do ambiente.

Em resumo, as principais considerações e especificações apresentadas para o sistema básico são que ele:

- considera um modelo discreto do ambiente com células cuja menor dimensão deve ser no máximo de 1,5m;

- utiliza uma abordagem probabilística para estimar a localização do dispositivo;

- constrói um mapa de RSSI em fase de treinamento, com movimentação pelas células (diversas alturas, orientações etc) e armazenamento da informação em representação por gaussianas e freqüência de presença do sinal;

- possui um mapa topológico do ambiente;

- considera um dispositivo móvel conduzido por uma pessoa caminhando;

- utiliza restrições topológicas e fisiológicas (de pessoa caminhando) para definir as probabilidades de transição entre estados;

- define, para o ambiente onde o sistema será executado (em função de experimentos que dependem dos tamanhos das células do ambiente), a probabilidade de transição reflexiva com sendo 0,95 ;

- considera distribuição de probabilidade do estado inicial uniforme no conjunto de estados.

Todas essas considerações valem também para o sistema proposto neste trabalho que será apresentado no próximo capítulo.

Uma última observação deve ser feita quanto ao módulo de estimativas de localização. Todos os sistemas desenvolvidos neste trabalho realizam as duas operações mencionadas na descrição do módulo de estimador (veja seção anterior), de forma que suas respostas são dadas em termos de coordenadas e em termos da célula de localização, permitindo assim que eles sejam analisados para ambos os casos. 


\section{WBLS: o sistema de localização proposto}

Um sistema de localização Wi-Fi faz uso de um tipo de informação muito ruidoso. Como foi explicado nos capítulos anteriores, a melhor forma que se tem encontrado para lidar com essa informação é a utilização de métodos probabilísticos, mais particularmente o método conhecido como localização markoviana. Para se conseguir um sistema que apresente alguma melhoria de desempenho, o primeiro passo é compreender quais são os alicerces deste método. Dessa forma é possível estabelecer quais pontos podem ser melhorados e quais deles, se alterados, teriam impacto relevante em termos de melhoria no desempenho do sistema.

Neste trabalho está sendo proposto um sistema de localização chamado WBLS ( $W i$ reless Based Location System) que é uma variação do sistema básico descrito. A novidade que ele traz é uma alteração na forma do cálculo das probabilidades de observação. A definição do foco de desenvolvimento da proposta, uma análise dos objetivos que ela busca e sua descrição detalhada é o que é apresentado neste capítulo.

\subsection{Definição do foco de desenvolvimento da proposta}

Na primeira parte desta seção será apresentada uma análise dos principais componentes do sistema básico com o objetivo de definir o que pode ser melhorado nele considerando o contexto de localização Wi-Fi. Em seguida, será apresentada uma análise do ruído característico da informação recebida pelo sistema, que deve servir para indicar como o sistema básico pode ser alterado para que se obtenha uma melhoria de desempenho.

\subsubsection{Análise crítica do sistema básico}

A execução do algoritmo do sistema básico pode ser resumida a três componentes: o módulo de estimação, o módulo de transição e o módulo de observação. 
Em relação à implementação do módulo de estimação, apenas duas formas foram encontradas na literatura, as duas descritas no item 3.2.2. De fato, estas são as formas que têm uma correspondência natural aos dois tipos de resposta que o sistema de localização pode fornecer: no caso da estimativa em termos da célula de localização, é natural retornar o estado mais provável; e no caso da estimativa em termos de coordenadas de posição, é natural utilizar a esperança matemática da distribuição. Quanto ao último caso, há ainda um estudo feito por Youssef e Agrawala (2005) que mostra que, se o sistema retornar a média das coordenadas dos estados ponderadas pelas suas probabilidades, o desempenho obtido é melhor do que se o sistema simplesmente retornar as coordenadas do estado de maior probabilidade.

Não obstante, no caso de a distribuição de probabilidade do estado de localização possuir picos esparsamente espalhados pelo ambiente, é possível que se obtenha melhores resultados através da média das coordenadas de apenas um certo número de estados mais próximos ao estado de maior probabilidade. No entanto, uma análise de distribuições calculadas pelo algoritmo de localização em diferentes situações mostrou que este não parece ser o caso mais comum. A figura 4.1 mostra três distribuições resultantes de três iterações do algoritmo em diferentes situações, que ilustram o argumento. Por causa dessas observações, essa alteração não foi explorada no presente trabalho.
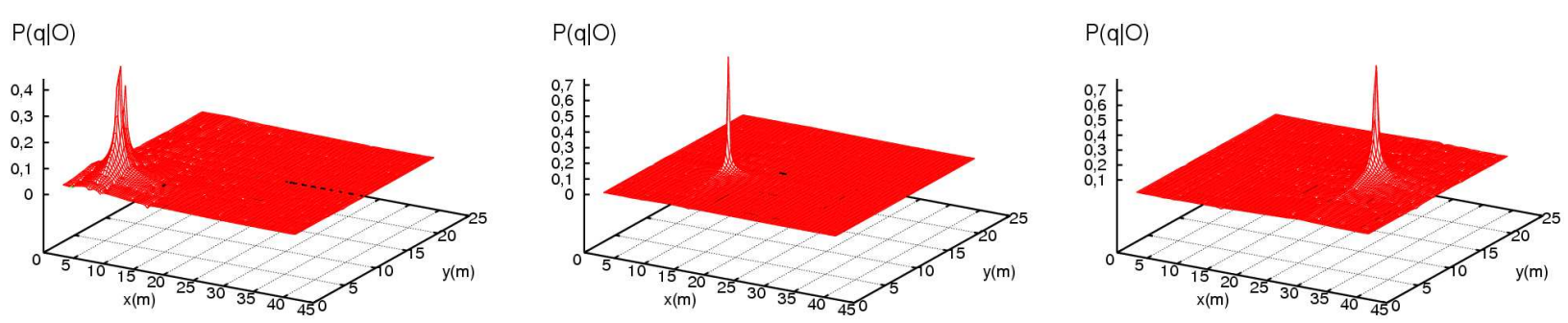

Figura 4.1: Distribuições de probabilidade do estado calculadas pelo algoritmo de localização. O eixo vertical representa $P(\mathbf{q} \mid O)$ e os eixos horizontais indicam coordenadas das células do ambiente.

O segundo módulo a ser analisado é o módulo de transição. Melhorar o desempenho desse módulo significa alterá-lo de forma que se consiga estabelecer probabilidades de caminhos que correspondam melhor à realidade. A forma de se conseguir isso é manter um modelo com probabilidades de transição mais coerentes com o comportamento dos usuários do sistema. Em um experimento realizado em laboratório com os dados coletados para os experimentos finais e variando a combinação de PAs presentes, obteve-se em um determinado caminho uma diminuição de até $15 \%$ no erro médio do sistema utili- 
zando probabilidades de transições calculadas a partir do próprio percurso do caminho. É claro que numa situação real isso não é possível. Mas talvez seja possível aproximar tais probabilidades caso se leve em consideração que certos comportamentos se repetem com freqüência. É isso que fazem os trabalhos sobre predição de movimento que se encontram na literatura (BRUCE; GORDON, 2004; ASHBROOK; STARNER, 2002), que buscam modelar os caminhos mais freqüentes percorridos pelo usuário.

No entanto, aprender probabilidades de transição baseando-se no comportamento do usuário tem inconvenientes. Há duas formas de se fazer isso. A primeira delas é através de aprendizado supervisionado. Em um aprendizado supervisionado, exemplos dos comportamentos que devem ser aprendidos pelo sistema precisam ser fornecidos por um supervisor. No contexto de localização Wi-Fi, tais exemplos podem ser obtidos da mesma forma que foram feitas as capturas dos caminhos para os experimentos finais deste trabalho (veja detalhes no capítulo 5), mas isso significaria um aumento do custo da fase de treinamento, que já é uma das principais desvantagens do sistema.

A segunda forma é utilizar algum tipo de aprendizado não supervisionado que possa ser realizado durante a própria fase de execução do sistema (ou utilizando os dados obtidos nessa fase). O trabalho de Moura e Costa (2006) apresenta um sistema que utiliza um algoritmo Viterbi, executado durante os intervalos de tempo em que o usuário se movimenta carregando o dispositivo, para estabelecer o caminho mais provável percorrido por um usuário do sistema dentro destes intervalos. Com base nos caminhos retornados pelo algoritmo, o sistema atualiza então as probabilidades de transição. Os resultados apresentados foram satisfatórios a princípio, mas os experimentos foram apenas realizados com caminhadas geradas por um simulador. Quando experimentos com caminhadas reais são executados, verifica-se que a informação é mais ruidosa do que se previa nas simulações. Como resultado, a informação obtida através do Viterbi nestes experimentos apresenta uma correlação baixa com os caminhos de fato percorridos, invalidando portanto essa informação para o aprendizado das probabilidades de transição.

O terceiro e último módulo a ser analisado é o módulo de observação. A probabilidade de uma observação dado um determinado estado é função de um produtório das probabilidades relativas aos sinais percebidos de cada um dos PAs do ambiente, como mostra a equação:

$$
P\left(O_{t} \mid \mathbf{q}_{t}=e_{i}\right)=\prod_{a=1}^{\mathcal{A}} P\left(\mathbf{o}_{a}=o_{a, t} \mid \mathbf{q}=e_{i}\right)
$$

Assim, quando o número de PAs no ambiente é relativamente grande, a disparidade 
entre probabilidades calculadas para diferentes estados apresenta uma tendência de ser também muito grande, o que confere ao módulo de observação um peso maior na estimativa de localização. É interessante notar que, mesmo em regiões onde o número de PAs visíveis é pequeno, o produtório apresentado considera a informação de todos os PAs. Isso pode resultar em situações como a que mostra a figura 4.2. Nela encontram-se dois gráficos que representam as probabilidades de observação calculadas para todos os estados do ambiente em dois instantes consecutivos. Verifica-se que a região mais provável no primeiro instante (figura 4.2-a) tem, no instante seguinte, uma probabilidade muito baixa e nem sequer está próxima da região mais provável (figura 4.2-b) - a distância entre uma região e outra é de cerca de $10 \mathrm{~m}$. Se essa informação puder ser menos ruidosa certamente o sistema melhorará seu desempenho.

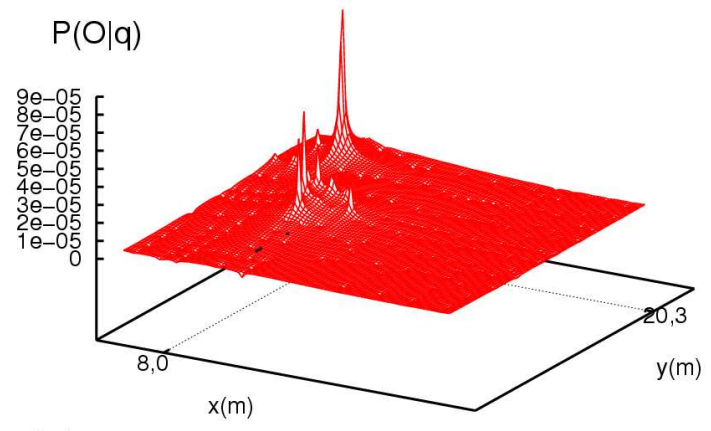

(a)

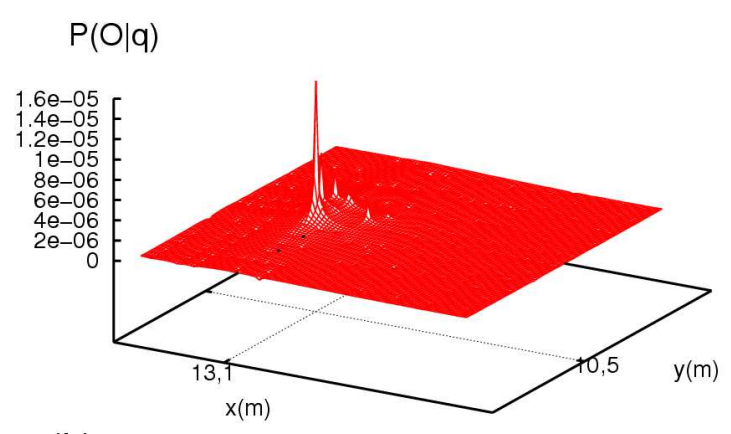

(b)

Figura 4.2: Distribuição das probabilidades de observação em dois instantes consecutivos. O eixo vertical representa $P(O \mid \mathbf{q})$ e os eixos horizontais indicam coordenadas das células do ambiente.

\subsubsection{Análise do ruído característico da informação}

Para encontrar alguma forma de diminuir o ruído proveniente da informação que o sistema recebe, primeiramente procurou-se definir uma fonte de ruído importante que pudesse ser tratada, e para isso consideraram-se duas possibilidades: o aparecimento de sinais não esperados e a verificação de sinais esperados que freqüentemente não são captados nas observações.

Para verificar a ocorrência do aparecimento de sinais não esperados, duas análises foram realizadas utilizando as medidas feitas para a construção do mapa de RSSI do ambiente de testes (descrito no próximo capítulo em detalhes). Na primeira, foram contadas todas as amostras de sinais obtidos cujas RSSIs distanciavam das médias calculadas para 
as respectivas distribuições mais que três vezes os desvios calculados, isso apenas para os casos onde as distribuições tinham médias acima de um limiar que será chamado neste trabalho de Limiar de Sensibilidade Absoluta (LSA). Considerar apenas sinais cuja média da respectiva distribuição de RSSI esteja acima do LSA implica considerar apenas sinais cuja RSSI do sinal, por maior que seja sua oscilação, tenha um valor dentro do limite de sensibilidade do aparelho (uma explicação detalhada da determinação do LSA é explicada no item A.3.4 do apêndice). O número de amostras contadas representa 0,4\% do conjunto total de amostras envolvidas nessa análise, indicando uma correspondência com a expectativa de que as distribuições se comportam como gaussianas (no caso de distribuições gaussianas, a porcentagem de amostras que distanciam da média três vezes o desvio é de $0,3 \%$ ). Este resultado mostra uma tendência clara de que o sinal vindo de um determinado PA deve oscilar em torno de uma RSSI média, oscilação essa que não deve ser muito grande (a média dos desvios observados foi de $2,4 \mathrm{dBm}$ ).

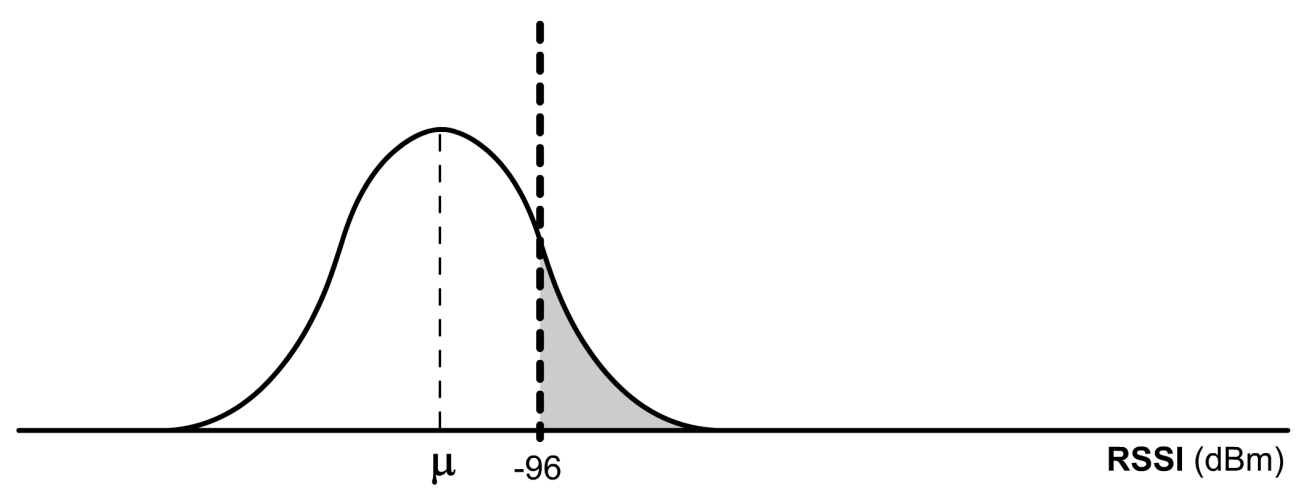

Figura 4.3: Distribuição da RSSI de um sinal que se aproxima da sensibilidade do aparelho. A área hachurada dividida pela área total da função corresponde à freqüência de presença do sinal.

A segunda análise feita considerou amostras de sinais cujas médias observadas eram próximas ao limite de sensibilidade do aparelho (no caso, a faixa considerada foi de $-96 \mathrm{dBm}$ a $-90 \mathrm{dBm}$, sendo que a sensibilidade do aparelho utilizado era de $-96 \mathrm{dBm}$ ). Neste conjunto, a freqüência de presença observada foi de 14,8\%. A figura 4.3 ilustra o porquê disso. Quando a RSSI de um sinal tem média menor que a sensibilidade do aparelho, apenas parte dos sinais transmitidos apresenta RSSI maior que a sensibilidade (área hachurada na figura 4.3). É esperado que sinais, nestas condições, tenham uma freqüência de presença reduzida e que suas RSSIs se concentrem próximas ao valor de sensibilidade do aparelho. Por isso, ao analisar os sinais observados de baixa potência, esperava-se que estes correspondessem ao caso descrito, e que portanto tivessem uma freqüência baixa, como de fato se viu. Tudo isso leva a concluir que as RSSIs dos sinais observados cos- 
tumam corresponder bem ao que se espera e que, portanto, devem ser raros os casos do aparecimento de sinais não esperados.

Restava analisar se sinais esperados deixam de aparecer com freqüência. Para isso, primeiramente examinou-se a freqüência de presença de sinais que possuem médias acima do LSA. Para tais sinais esperava-se uma presença próxima a 100\% (para detalhes, veja o item A.3.4 do apêndice), mas 35\% dos casos mostraram uma freqüência menor que $78 \%$, e $17 \%$ dos casos, uma freqüência menor que $50 \%$.

Isso sugeriu a necessidade de uma investigação mais profunda. Analisaram-se então sinais de determinados PAs em PMs próximos uns dos outros e verificou-se que, em determinadas situações, tais sinais apresentavam freqüências muito diferentes entre si. A tabela 4.1 mostra a freqüência de presença de um determinado PA em seis pontos localizados dentro de uma mesma sala, que serve para ilustrar essa afirmação. Tais pontos foram medidos em um intervalo de tempo menor do que dez minutos e armazenados no mapa de RSSI. Verificam-se diferenças muito grandes entre os valores de freqüência (na tabela 4.1, de $55 \%$ a 90\%), variação que acontece em nível muito menor com as RSSIs obtidas (na tabela 4.1, de $63 \mathrm{dBm}$ a $70 \mathrm{dBm}$ ). Essa observação mostra que a informação obtida sobre a freqüência de presença de um sinal é muito ruidosa, e representa uma forte indicação de que ela pode, de fato, não ser confiável, o que implica a possibilidade de que sua utilização tenha um efeito prejudicial nas estimativas do sistema de localização .

Tabela 4.1: Freqüência de presença e RSSI de sinais em uma mesma sala.

\begin{tabular}{|c|c|c|c|}
\hline \multicolumn{2}{|c|}{ Coordenadas dos PMs } & \multicolumn{2}{c|}{ Informação do mapa } \\
\hline $\mathbf{X ~} \mathbf{( m )}$ & Y (m) & Freq. (\%) & RSSI (dBm) \\
\hline \hline $\mathbf{1 2 , 3}$ & $\mathbf{1 5 , 3}$ & 71 & 67 \\
\hline $\mathbf{1 0 , 0}$ & $\mathbf{1 5 , 3}$ & 55 & 65 \\
\hline $\mathbf{1 2 , 3}$ & $\mathbf{1 8 , 3}$ & 90 & 67 \\
\hline $\mathbf{1 0 , 0}$ & $\mathbf{1 8 , 3}$ & 82 & 63 \\
\hline $\mathbf{1 2 , 3}$ & $\mathbf{2 2 , 8}$ & 67 & 70 \\
\hline $\mathbf{1 0 , 0}$ & $\mathbf{2 2 , 8}$ & 89 & 70 \\
\hline
\end{tabular}

\subsection{Descrição do WBLS}

O WBLS é o sistema proposto neste trabalho. Seu diferencial é que ele procura lidar com o fato de que a informação obtida nas medições realizadas para a construção do mapa de 
RSSI sobre as freqüências de presença dos sinais pode não ser confiável. A modificação que ele propõe é uma nova forma para calcular as probabilidades de observação dado um estado. Essa modificação é apresentada aqui e, em seguida, é fornecida uma análise do seu significado matemático.

\subsubsection{A alteração proposta no sistema básico}

A proposta do WBLS é de fato bastante simples: no cálculo das probabilidades de observação para cada um dos estados, em vez de se realizar um produtório das probabilidades relativas a cada um dos PAs do ambiente (como mostrado na equação 4.3), passam a ser consideradas apenas as probabilidades relativas aos sinais presentes. Sendo assim, a probabilidade que se deve calcular agora, para cada PA $a$, é uma probabilidade condicional também à presença do sinal, o que implica uma alteração na forma do cálculo. Essa alteração será explicada apenas para o modelo que utiliza gaussianas para a representação das distribuições de RSSI, mas nada impede que o mesmo princípio seja aplicado em um modelo que usa histogramas ou qualquer outro tipo de representação.

Similar ao que foi descrito no capítulo anterior, calcula-se $P\left(\mathbf{o}_{a}=r s s i \mid \mathbf{q}=e_{i}, \mathbf{S}_{a}\right)$ da seguinte forma:

$$
P\left(\mathbf{o}_{a}=r s s i \mid \mathbf{q}=e_{i}, \mathbf{S}_{a}\right)=\eta_{a, i}\left[G_{a, i}(r s s i)+\lambda\right]
$$

sendo rssi um valor de RSSI que tenha sido observado, $G_{a, i}$, a discretização da distribuição gaussiana do PA a no estado $i$ segundo o mapa de RSSI, $\eta_{a, i}$, um fator de normalização e $\lambda$, um valor que previne que qualquer observação tenha probabilidade muito próxima a zero. Nota-se que esta equação é praticamente idêntica à equação 3.3 apresentada na descrição da localização markoviana no capítulo anterior, diferenciando-se dela pela presença da condição $\mathbf{S}_{a}$, que significa que o sinal do PA a deve estar presente - ou seja, que $\mathbf{o}_{a} \geq \mathcal{R} \min$. A grande diferença que acontece no cálculo se dá na determinação do fator de normalização $\eta_{a, i}$, que é calculado respeitando o princípio representado pela equação:

$$
\sum_{r s s i=\mathcal{R} \min }^{\mathcal{R} \max } P\left(\mathbf{o}_{a}=r s s i \mid \mathbf{q}=e_{i}, \mathbf{S}_{a}\right)=1
$$

Aqui, o intervalo de RSSI considerado é de $[\mathcal{R} \min , \mathcal{R} \max ]$, diferente do cálculo realizado no sistema básico (equação 3.5) que considera também $\mathcal{R}$ min -1 (valor que representa a ausência de sinal). Dessa forma, deixa-se de considerar a informação sobre a freqüência de presença de um sinal e baseia-se o cálculo apenas nas RSSIs de fato observadas pelo dispositivo que está sendo localizado. 


\subsubsection{Análise matemática da proposta}

Na proposta apresentada, o produtório realizado para se determinar a probabilidade de uma observação $O_{t}$ dado o estado $i$ deve considerar apenas os sinais presentes. Mas quais são as implicação matemáticas disso?

Considerando a princípio que:

$$
P\left(O_{t} \mid \mathbf{q}_{t}=e_{i}\right)=\prod_{a=1}^{\mathcal{A}} P\left(\mathbf{o}_{a}=o_{a, t} \mid \mathbf{q}=e_{i}\right),
$$

pode-se representar as probabilidades que compõem o produtório da seguinte maneira (KRUMM; HORVITZ, 2004):

$$
P\left(\mathbf{o}_{a}=o_{a, t} \mid \mathbf{q}=e_{i}\right)=\left\{\begin{array}{ll}
P\left(\mathbf{o}_{a}=o_{a, t} \mid \mathbf{q}=e_{i}, \mathbf{S}_{a}\right) P\left(\mathbf{S}_{a} \mid \mathbf{q}=e_{i}\right) & \text { se } o_{a, t} \geq \mathcal{R} \min \\
P\left(\overline{\mathbf{S}_{a}} \mid \mathbf{q}=e_{i}\right) & \text { se } o_{a, t}<\mathcal{R} \min
\end{array}\right\}
$$

sendo $P\left(\mathbf{S}_{a} \mid \mathbf{q}=e_{i}\right)$ a probabilidade do sinal do PA a estar presente no estado $i$ e $P\left(\overline{\mathbf{S}_{a}} \mid \mathbf{q}=e_{i}\right)$, a probabilidade do sinal do PA a não estar presente no estado $i$. Esta última corresponde a $P\left(\mathbf{o}_{a}=\mathcal{R} m i n-1 \mid \mathbf{q}=e_{i}\right)$, probabilidade que deve ser calculada com base na freqüência de presença do sinal do PA a no estado $i\left(f_{a, i}\right)$, conforme explicado no item 3.2 (isso implica que $P\left(\mathbf{S}_{a} \mid \mathbf{q}=e_{i}\right.$ ), por ser igual a $1-P\left(\overline{\mathbf{S}_{a}} \mid \mathbf{q}=e_{i}\right)$, também seja função de $\left.f_{a, i}\right)$.

A probabilidade de um determinado estado $i$, dada uma observação $O_{t}$, é dada pela equação 3.7 , que pode ser escrita assim:

$$
P\left(\mathbf{q}_{t}=e_{i} \mid O_{t}\right)=\eta P\left(O_{t} \mid \mathbf{q}_{t}=e_{i}\right) T\left(e_{i}\right),
$$

onde

$$
T\left(e_{i}\right)=\sum_{j=1}^{\mathcal{I}} P\left(\mathbf{q}_{t-1}=e_{j} \mid O_{t-1}\right) P_{t r a n s}\left(e_{j}, e_{i}\right) .
$$

Segundo as equações 4.3 e 4.4, pode-se substituir o fator $P\left(O_{t} \mid \mathbf{q}_{t}=e_{i}\right)$ na equação 4.5 de forma que se tem:

$$
P\left(\mathbf{q}_{t}=e_{i} \mid O_{t}\right)=\eta \prod_{a=1}^{\mathcal{A}}\left\{\begin{array}{ll}
P\left(\mathbf{o}_{a}=o_{a, t} \mid \mathbf{q}=e_{i}, \mathbf{S}_{a}\right) P\left(\mathbf{S}_{a} \mid \mathbf{q}=e_{i}\right) & \text { se } o_{a, t} \geq \mathcal{R} \min \\
P\left(\overline{\mathbf{S}_{a}} \mid \mathbf{q}=e_{i}\right) & \text { se } o_{a, t}<\mathcal{R} \min
\end{array}\right\} T\left(e_{i}\right) .
$$


A proposta apresentada determina que $P\left(\mathbf{q}_{t}=e_{i} \mid O_{t}\right)$ seja calculada da seguinte forma:

$$
P\left(\mathbf{q}_{t}=e_{i} \mid O_{t}\right)=\eta^{\prime} \prod_{a=1}^{\mathcal{A}}\left\{\begin{array}{ll}
P\left(\mathbf{o}_{a}=o_{a, t} \mid \mathbf{q}=e_{i}, \mathbf{S}_{a}\right) & \text { se } o_{a, t} \geq \mathcal{R} \min \\
1 & \text { se } o_{a, t}<\mathcal{R} \min
\end{array}\right\} T\left(e_{i}\right)
$$

A partir das equações 4.7 e 4.8, conclui-se que:

$$
\eta F\left(e_{i}, O_{t}\right)=\eta^{\prime}
$$

onde

$$
F\left(e_{i}, O\right)=\prod_{a=1}^{\mathcal{A}}\left\{\begin{array}{ll}
P\left(\mathbf{S}_{a} \mid \mathbf{q}=e_{i}\right) & \text { se } o_{a} \geq \mathcal{R} \min \\
P\left(\overline{\mathbf{S}_{a}} \mid \mathbf{q}=e_{i}\right) & \text { se } o_{a}<\mathcal{R} \min
\end{array}\right\} \text {. }
$$

Como esse mesmo raciocínio pode ser feito para qualquer estado do modelo, tem-se que:

$$
F\left(e_{i}, O_{t}\right)=F\left(e_{j}, O_{t}\right) \forall i, j
$$

A definição da equação 4.11 deve ser válida qualquer que seja a observação considerada. Considere então duas possíveis observações $O^{\prime}$ e $O^{\prime \prime}$, de forma que todos os sinais de PAs presentes na primeira estão presentes na segunda e todos os sinais de PAs ausentes na primeira estão ausentes na segunda, com exceção do sinal do PA de índice 1, que na primeira observação está presente e na segunda, ausente. Determina-se a função $F^{\prime}\left(e_{i}\right)$ como sendo:

$$
F^{\prime}\left(e_{i}, O\right)=\prod_{a=2}^{\mathcal{A}}\left\{\begin{array}{ll}
P\left(\mathbf{S}_{a} \mid \mathbf{q}=e_{i}\right) & \text { se } o_{a} \geq \mathcal{R} \min \\
P\left(\overline{\mathbf{S}_{a}} \mid \mathbf{q}=e_{i}\right) & \text { se } o_{a}<\mathcal{R} \min
\end{array}\right\},
$$

de forma que $F^{\prime}\left(e_{i}, O^{\prime}\right)=F^{\prime}\left(e_{i}, O^{\prime \prime}\right) \forall i$. Então pode-se escrever a equação 4.11 para cada uma das possibilidades levantadas da seguinte maneira:

$$
\begin{gathered}
P\left(\mathbf{S}_{1} \mid \mathbf{q}=e_{i}\right) F^{\prime}\left(e_{i}, O^{\prime}\right)=P\left(\mathbf{S}_{1} \mid \mathbf{q}=e_{j}\right) F^{\prime}\left(e_{j}, O^{\prime}\right), \\
P\left(\overline{\mathbf{S}_{1}} \mid \mathbf{q}=e_{i}\right) F^{\prime}\left(e_{i}, O^{\prime \prime}\right)=P\left(\overline{\mathbf{S}_{1}} \mid \mathbf{q}=e_{j}\right) F^{\prime}\left(e_{j}, O^{\prime \prime}\right) .
\end{gathered}
$$

Substituindo $P\left(\overline{\mathbf{S}_{1}} \mid \mathbf{q}=e_{i}\right)$ por $1-P\left(\mathbf{S}_{1} \mid \mathbf{q}=e_{i}\right)$ na equação 4.14 , tem-se:

$$
\left[1-P\left(\mathbf{S}_{1} \mid \mathbf{q}=e_{i}\right)\right] F^{\prime}\left(e_{i}, O^{\prime \prime}\right)=\left[1-P\left(\mathbf{S}_{1} \mid \mathbf{q}=e_{j}\right)\right] F^{\prime}\left(e_{j}, O^{\prime \prime}\right)
$$

Dividindo-se os termos da equação 4.15 pelos termos da equação 4.13, tem-se:

$$
\frac{\left[1-P\left(\mathbf{S}_{1} \mid \mathbf{q}=e_{i}\right)\right]}{P\left(\mathbf{S}_{1} \mid \mathbf{q}=e_{i}\right)}=\frac{\left[1-P\left(\mathbf{S}_{1} \mid \mathbf{q}=e_{j}\right)\right]}{P\left(\mathbf{S}_{1} \mid \mathbf{q}=e_{j}\right)},
$$

o que implica que

$$
P\left(\mathbf{S}_{1} \mid \mathbf{q}=e_{i}\right)=P\left(\mathbf{S}_{1} \mid \mathbf{q}=e_{j}\right)
$$


Essa demonstração pode ser feita para qualquer um dos PAs do ambiente. O que ela significa? Ela significa que, segundo a proposta apresentada, a probabilidade de presença do sinal de um PA considerada em todos os estados de um ambiente - ou seja, em toda a sua área - é a mesma. A vantagem disso é que esse modelo representa condições em que o sinal é afetado em todas as direções, como quando uma interferência no sinal ocorre próxima ao PA, e se adapta a uma probabilidade de presença do sinal que pode variar no tempo. A desvantagem desse modelo é que ele não considera explicitamente a área de cobertura de um PA, como faz o sistema básico.

\subsection{Discussão sobre implicações da proposta}

A proposta do WBLS surgiu da intenção de se eliminar uma fonte de ruído na informação que é fornecida ao sistema de localização com o objetivo de se obter estimativas de localização de melhor qualidade. No entanto, o que se propõe para eliminar parte do ruído implica a eliminação de uma certa quantidade de informação (no caso, a informação de freqüência de presença de sinal $f$ ). Por isso, uma questão que precisa ser analisada é se o quanto se ganha com a eliminação do ruído compensa o que se perde com o descarte de parte da informação. Na verdade, esta questão está vinculada a outra mais abrangente que consiste em saber quão grande dever ser o ruído na informação da freqüência de presença de um sinal para que seja melhor desconsiderá-la completamente, conforme sugerido no modelo proposto. Tudo isso precisa ser analisado para uma compreensão da aplicabilidade da proposta e essa análise será realizada na parte experimental deste trabalho, que será apresentada no capítulo seguinte.

Não obstante a motivação inicial ter sido sempre buscar uma melhoria de desempenho, ao propor esse novo modelo, o WBLS ganha uma capacidade de lidar com um problema muito interessante e que tem recebido pouca atenção. Quando se fala em localização Wi-Fi, é muito comum citar como uma de suas vantagens o fato de se poder utilizar uma infra-estrutura de PAs já instalada no ambiente como sendo parte ou mesmo toda a referência do sistema de localização. Como foi discutido em capítulos anteriores, isso implica lidar com emissores de sinais sobre os quais se tem pouco ou nenhum controle. Situações em que um desses emissores é desligado, seja para manutenção, seja por falha da rede elétrica, ou por outro motivo qualquer, devem ter um efeito prejudicial em um sistema de localização como os que têm sido propostos na literatura - inclusive o sistema básico descrito no capítulo anterior. O WBLS, no entanto, por considerar apenas os sinais presentes nas observações, deve sofrer muito pouco com esse tipo de situação. Este será 
o segundo ponto a ser analisado na parte experimental deste trabalho. 


\section{Parte experimental}

Este capítulo apresenta os experimentos realizados neste trabalho. Ele inicia com uma descrição do ambiente de testes que fornece informações sobre o espaço físico onde foram capturados os dados para os experimentos, entre eles o mapa de RSSI e as seqüências de observações obtidas em caminhadas pelo ambiente. Em seguida são descritos alguns detalhes da metodologia utilizada na realização dos experimentos. Por fim os experimentos são apresentados seguidos de uma discussão de seus resultados.

\subsection{O ambiente de testes}

Os testes foram realizados em uma área de $45 \mathrm{~m}$ por $25 \mathrm{~m}$ do segundo andar do bloco $\mathrm{C}$ do prédio da Engenharia Elétrica da Escola Politécnica da Universidade de São Paulo. A planta do local é mostrada na figura 5.1. Nela se vêm marcados os 181 PMs utilizados na construção do mapa de RSSI do local. A área é composta por salas, um banheiro, um acesso à escada e um corredor de cerca de $4 \mathrm{~m}$ de largura. A distância média entre PMs adjacentes é de pouco mais que $2 \mathrm{~m}$. O pé direito do andar é de cerca de $4 \mathrm{~m}$. Os sinais de 18 PAs podem ser observados na área, sendo que 4 deles se encontram nela e estão representados na planta por losangos. Em cada PM pode-se observar sinais de 10,9 PAs em média.

Os PMs marcados na planta do ambiente correspondem a células que por sua vez estão associadas a vértices do mapa topológico do ambiente. As arestas que compõem esse mapa foram determinadas com base nas restrições físicas do ambiente. Um total de 260 arestas compõe o mapa, com uma média de 2,87 arestas incidindo em cada vértice.

Para a realização das medidas foi utilizado um computador portátil Satelite 6500 executando um sistema operacional Linux 2.4.25 com uma placa de rede Wi-Fi com chipset Atheros RX5004G. Foram necessárias algumas alterações no driver para conseguir estabilidade e melhorar o intervalo de tempo entre os rastreamentos (mais detalhes sobre o hardware empregado podem ser encontrados no item A.3 do apêndice). 


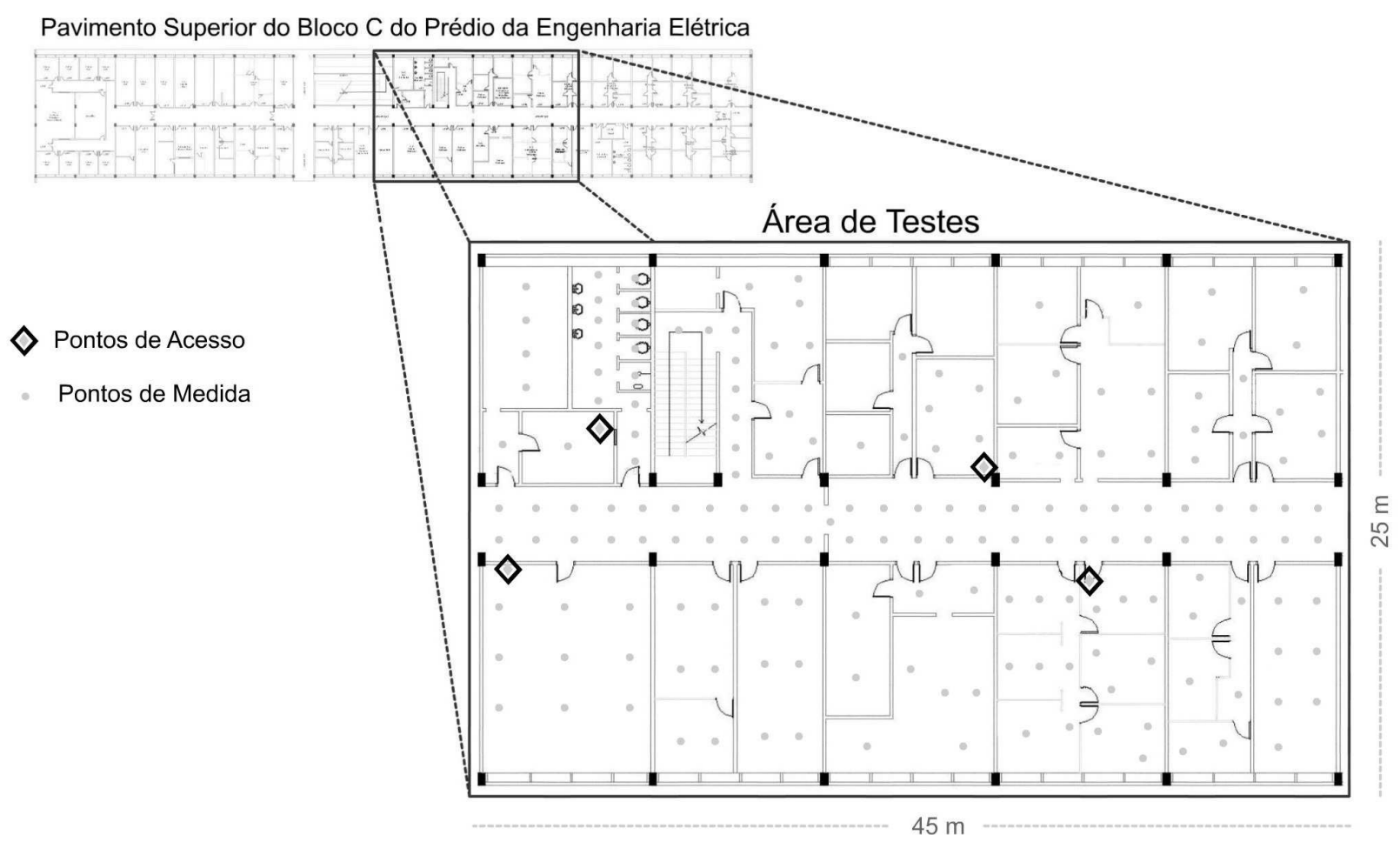

Figura 5.1: Planta da área onde foram realizados os experimentos.

O mapa de RSSI do local foi construído conforme a definição do item 3.3. Em cada PM foram realizadas 150 observações, o que corresponde a uma permanência de cerca de 30s em cada PM. Os registros dos 181 PMs foram gravados em 2 dias, cerca de 4 horas por dia, porque o procedimento tinha que ser parado de tempos em tempos para o recarregamento da bateria do dispositivo.

\subsection{Metodologias para realização dos experimentos}

A análise de desempenho de um sistema de localização, quando se trata de localizar dispositivos em movimento, não é um procedimento trivial. Uma forma de aferir o desempenho de um sistema é compará-lo com o desempenho de um sistema ideal, que no caso de localização é um sistema que estima a posição verdadeira em que o dispositivo se encontra a cada instante. Determinar tais posições para a realização dessa comparação enquanto o dispositivo não está fixo em um lugar é a principal dificuldade desse tipo de análise. A primeira parte dessa seção descreve como isso foi feito neste trabalho.

Para uma compreensão mais clara de como variações nas características do comporta- 
mento do ambiente têm efeito no sistema de localização, foi construído um simulador que gera os sinais que devem ser observados pelo dispositivo ao se deslocar por determinados caminhos. Na configuração do simulador desenvolvido para este trabalho, é possível variar o grau de correlação entre as freqüências de presença dos sinais esperadas - obtidas na geração do mapa de RSSI - e as freqüências observadas durante as caminhadas. A utilização de um simulador que permite variar uma ou mais características do ambiente é uma forma de ampliar a compreensão sobre o contexto estudado e é uma das contribuições deste trabalho. A segunda parte desta seção descreve como o simulador foi modelado.

Por fim, para a realização de experimentos que forneçam resultados de uma significância representativa mesmo trabalhando com dados de um único ambiente, definiu-se um procedimento cuja função é simular diferentes ambientes para a execução do sistema de localização. A configuração geral dos experimentos realizados neste trabalho, que inclui a descrição desse procedimento, é descrita na terceira parte desta seção.

\subsubsection{Captura das seqüências de observações dos caminhos}

O procedimento definido para a captura das seqüências de observações que o dispositivo faz ao se deslocar por um determinado caminho foi baseado em uma metodologia utilizada em Ladd et al. (2005) e em Krumm e Horvitz (2004). Os caminhos, que devem ser definidos previamente, são compostos por segmentos de linha reta. Para cada segmento, marca-se na planta do ambiente os pontos de suas extremidades. Para gravar as seqüências de observações, uma pessoa carregando o dispositivo com o programa de captura de RSSIs (no caso, o dispositivo utilizado é o descrito na seção anterior) se posiciona no início do caminho e pressiona uma determinada tecla no instante em que inicia a caminhada, dando início assim à execução do programa. Cada segmento é atravessado com uma velocidade constante e a cada ponto do caminho marcado na planta - pontos estes que correspondem aos finais de segmentos - uma determinada tecla é pressionada indicando o início de uma caminhada por um novo segmento. O programa é configurado para gravar tantos segmentos quantos tiverem sido determinados para cada caminho. Ao fim da caminhada pelo último segmento marcado, o programa finaliza sua execução e retorna a seqüência de observações obtidas juntamente com as posições do dispositivo correspondentes a cada observação, calculadas com base nos tempos registrados para a travessia de cada segmento do percurso considerando movimento retilíneo uniforme em cada uma dessas travessias.

Foram definidos 10 percursos no ambiente - na verdade 5 caminhos percorridos em 2 sentidos, de ida e de volta - que consistiam em percursos que partiam de um ponto 
inicial indo até um determinado lugar-objetivo. Os dados obtidos nestes percursos foram utilizados para a realização dos experimentos. Cada caminho foi percorrido 7 vezes em cada sentido, resultando em um total de 70 caminhadas gravadas. A escolha dos caminhos foi feita com base no comportamento cotidiano das pessoas que freqüentam uma determinada sala do ambiente. Assim, os pontos de partida e chegada determinados foram: uma posição dentro da sala, uma posição dentro do banheiro, o acesso à escada e a saída do andar pelo corredor. Na figura 5.2, estão representados os 5 caminhos definidos para os experimentos deste trabalho.
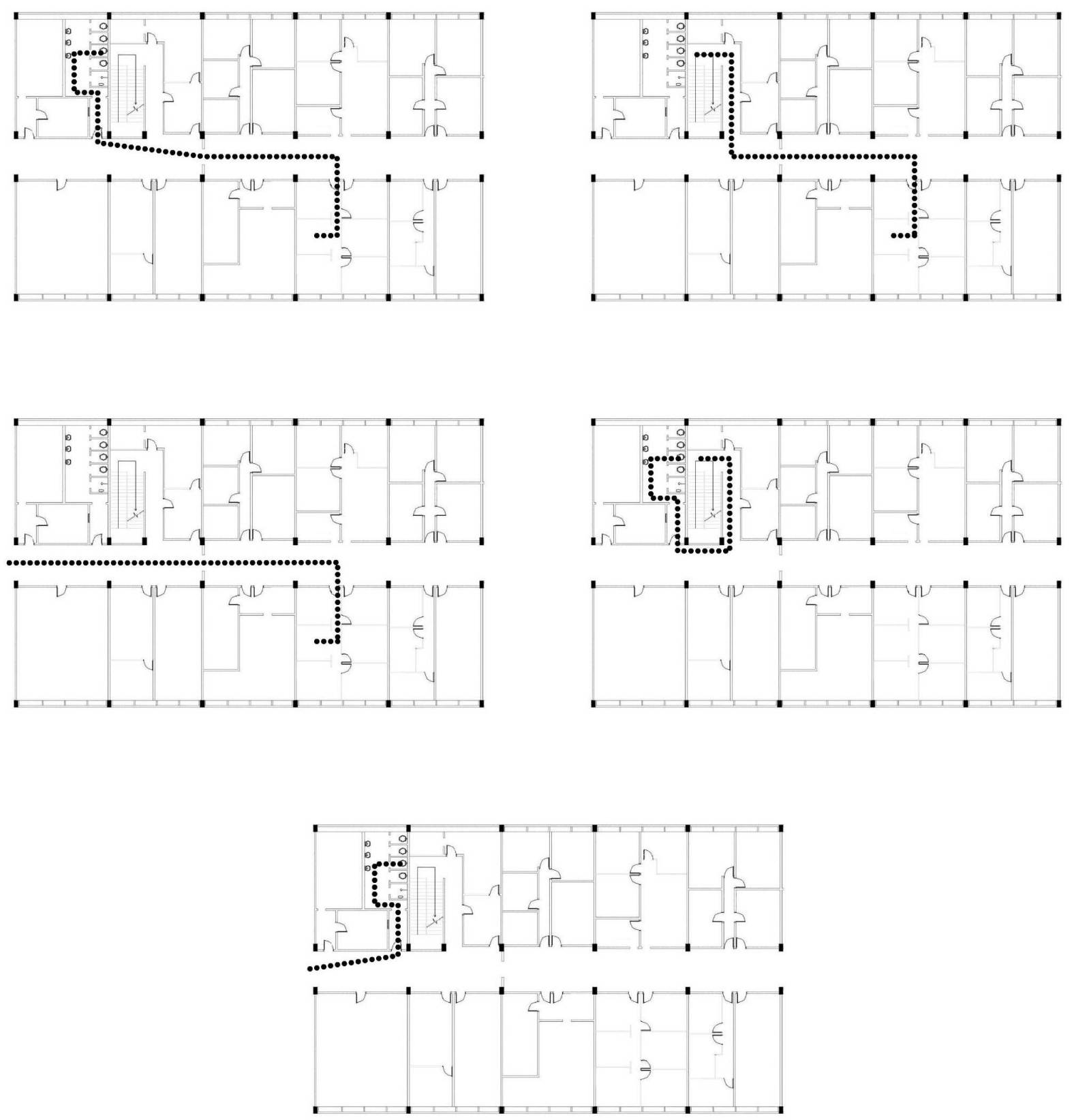

Figura 5.2: Caminhos percorridos nos experimentos de localização com o dispositivo em movimento. 


\subsubsection{O simulador de um dispositivo em movimento}

Como foi explicado no capítulo anterior, um dos objetivos dos experimentos realizados neste trabalho é definir as condições às quais o sistema proposto se adapta melhor. Mais especificamente, deseja-se estabelecer o quanto a informação sobre a freqüência de presença do sinal deve ser ruidosa para que a utilização do sistema proposto seja mais indicada do que a do sistema básico. Para isso foi desenvolvido um simulador cuja função é gerar seqüências de observações correspondentes àquelas que seriam recebidas por um dispositivo percorrendo determinados caminhos no ambiente. A vantagem da utilização de um simulador é que com ele é possível variar parâmetros do ambiente e assim determinar o desempenho de sistemas em diferentes condições. Como se deseja estabelecer o comportamento dos sistemas em função do ruído na informação de freqüência de presença de sinal, definiu-se que deve ser possível variar o grau de correlação entre as freqüências esperadas de presença dos sinais - obtidas na geração do mapa de RSSI - e as freqüências observadas durante as caminhadas. Segue a descrição de como isso foi feito.

O simulador desenvolvido recebe como entrada uma seqüência de pontos que definem os segmentos lineares de um determinado percurso. Com base nessa informação, o simulador calcula uma seqüência de posições que correspondem àquelas em que o dispositivo se encontra a cada 0.15 segundos - intervalo entre as observações feitas por um dispositivo (para detalhes sobre o intervalo entre observações considerado, veja o item A.3 do apêndice). As posições obtidas servem como entrada para um gerador de sinais. Para cada posição, o gerador de sinais calcula uma distribuição de probabilidade da RSSI (incluindo a probabilidade de ausência de sinal) para cada um dos PAs do ambiente. O cálculo de cada uma dessas distribuições é feito através de uma interpolação que utiliza os dados gravados no mapa de RSSI, de tal forma que, para uma determinada posição $l_{t}$ no instante $t$, a distribuição calculada para o PA $a$ deve ser uma mistura das distribuições completas (incluindo a probabilidade de ausência do sinal) das RSSIs do sinal deste PA em todos os PMs do mapa, cada uma delas ponderadas por uma função de núcleo que considera a distância do respectivo PM à posição do dispositivo $l_{t}$. A função de núcleo escolhida da foi:

$$
K\left(e_{i}\right)=\exp \left[\frac{-\left(\left|l_{t}-e_{i}\right|\right)^{2}}{\sigma^{2}}\right]
$$

com $\sigma=1$, sendo que $\left|l_{t}-e_{i}\right|$ representa a distância euclidiana entre $l_{t}$ e $e_{i}$, e $e_{i}$ corresponde à posição do $\mathrm{PM}$. Cada distribuição $\mathbf{P}\left(\mathbf{o}_{a} \mid \mathbf{q}=e_{i}\right)$ é construída determinando-se $P\left(\mathbf{o}_{a}=\right.$ rssi $\mid \mathbf{q}=e_{i}$ ) para todo rssi do intervalo $[\mathcal{R} \min -1, \mathcal{R} \max ]$ conforme a descrição do capítulo 3 (equações 3.3 e 3.5 ). 
A particularidade do cálculo feito no simulador está na freqüência de presença do sinal considerada para o cálculo de $P\left(\mathbf{o}_{a}=\mathcal{R} \min -1 \mid \mathbf{q}=e_{i}\right)$, que é a probabilidade do sinal do PA $a$ estar ausente no estado $i$ (lembrando que essa probabilidade é função direta da freqüência de presença considerada). Quando o simulador é executado para gerar as observações de um caminho, ele recebe o parâmetro $\alpha$, que representa o grau de correlação entre as freqüências de presença gravadas no mapa de RSSI e as freqüências de presença dos sinais durante as caminhadas. Assim, em lugar de considerar o parâmetro $f_{a, i}$ como a freqüência usada para determinar $P\left(\mathbf{o}_{a}=\mathcal{R}\right.$ min $\left.-1 \mid \mathbf{q}=e_{i}\right)$, o sistema calcula um parâmetro $f_{a, i}^{\prime}$ da seguinte forma:

$$
f_{a, i}^{\prime}=\alpha f_{a, i}+(1-\alpha) v
$$

onde $v$ representa um número aleatório entre 0 e 1 . Esse parâmetro $f_{a, i}^{\prime}$ é usado no lugar de $f_{a, i}$, e é dessa forma que é simulado o ruído presente na informação de freqüência de presença dos sinais.

Tendo calculado para a posição $l_{t}$ as distribuições de probabilidade da RSSI de cada um dos PAs do ambiente, a partir de cada uma dessas distribuições o simulador extrai uma amostra e forma assim a observação $O_{t}$. Repetindo esse procedimento para cada um dos elementos da seqüência de posições, tem-se a seqüência completa de observações obtida pela simulação de um caminho percorrido no mapa.

Os percursos cujas seqüências de observação foram simuladas para os experimentos deste trabalho são os mesmos percursos mostrados na figura 5.2.

\subsubsection{Realização dos experimentos}

Tendo sido armazenadas em um banco de dados as informações do mapa de RSSI, das seqüência de observações obtidas em caminhadas pelo ambiente e das seqüências de observações geradas pelo simulador, uma série de experimentos foi então realizada. A metodologia empregada em todos eles foi basicamente a mesma.

Os sistemas de localização foram programados para estimar seqüências de localizações para uma ou mais caminhadas gravadas no banco de dados. A cada iteração, o programa busca uma observação de uma determinada caminhada e realiza a estimativa de localização do instante correspondente, estimativa esta que é gravada em um arquivo de saída. Quando a seqüência de observações de uma determinada caminhada chega ao fim, o arquivo de saída possui a seqüência completa de posições estimadas para aquela caminhada, e pode-se então calcular uma série de medidas sobre o desempenho do sistema, 
comparando as estimativas com as posições verdadeiras.

Em todos os experimentos apresentados neste capítulo, os sistemas foram programados para realizar suas estimativas em termos de coordenadas e em termos da célula de localização de forma que fosse possível analisar seus comportamentos em ambos os casos. As medidas de desempenho calculadas para estimativas em termos de coordenadas foram: o erro de estimativa médio e a raiz do erro quadrático médio. As medidas de desempenho calculadas para estimativas em termos da célula de localização foram: a porcentagem de estimativas incorretas de célula de localização e o coeficiente de incerteza das estimativas (NEHMZOW, 2003).

Cada teste realizado executou um sistema de localização em uma série determinada de caminhos, considerando que o ambiente era composto apenas por um determinado subconjunto do conjunto de PAs existentes. Essa consideração de apenas um subconjunto dos PAs é feita por dois motivos: ela torna possível a utilização de uma combinação diferente de PAs em cada teste, o que é uma forma de simular ambientes diferentes; ela permite que se faça uma análise dos desempenhos dos sistemas em função do número de PAs presentes. Os resultados de um determinado conjunto de testes são dados em termos das médias e dos desvios padrão que se verificam para cada um das medidas analisadas.

Para os experimentos com o simulador, cada teste utilizou todos os caminhos gerados pelo simulador, e para os experimentos em ambiente real, todos os caminhos capturados em caminhadas reais no ambiente.

\section{$5.3 \quad$ Experimentos}

Os primeiros experimentos apresentados aqui consistem de testes preliminares que foram realizados para a determinação de um modelo que tivesse o melhor desempenho dentre as propostas encontradas na literatura. Estes testes ajudaram a definir o sistema básico descrito no capítulo 3, que serviu de base para o desenvolvimento da proposta do WBLS. O sistema proposto foi então analisado quanto ao seu desempenho em situações normais e em situações onde há falhas na transmissão de algum dos PAs do ambiente, como foi sugerido ao final do capítulo 4. Os experimentos que são descritos a seguir cobrem essas duas análises e fornecem os dados para uma discussão sobre o desempenho do sistema proposto apresentada no final desta seção.

Neste capítulo, todos os resultados são apresentados em termos do erro médio de cada um dos sistemas. As outras medidas de desempenho apresentam o mesmo com- 
portamento daquelo exibido pelo erro médio; assim, os gráficos relativos a essas outras medidas encontram-se somente no apêndice B.

\subsubsection{Testes preliminares}

A dificuldade em comparar resultados de propostas encontradas na literatura, explicada no capítulo 2, fez com que alguns testes preliminares que analisam o desempenho de implementações de algumas dessas propostas fossem realizados. Foram implementados quatro sistemas:

- uma variação da proposta de Roos et al. (2002),

- uma variação da proposta de Youssef e Agrawala (2005),

- o sistema proposto por Ladd et al. (2005) e

- o sistema proposto por Haeberlen et al. (2004) (que corresponde ao chamado sistema básico).

Cogitou-se a possibilidade da implementação de um quinto sistema, o proposto por Krumm e Horvitz (2004), mas seu funcionamento só difere fundamentalmente da proposta de Haeberlen enquanto o dispositivo está parado, situação que não é o foco deste trabalho. Os dois primeiros sistemas foram modificados para se adaptarem à situação de movimento (originalmente, eles foram projetados para o caso de o dispositivo estar parado em uma posição). A modificação foi simples: os sistemas passaram a considerar a cada iteração apenas 4 instantes de observação, como acontece na proposta de Ladd. Isso foi feito para que as estimativas não fossem prejudicadas pela latência que seria ocasionada ao ter que esperar um número muito grande de observações para realizar cada estimativa de localização.

Foram realizados testes com 15 combinações diferentes de PAs presentes no ambiente escolhidas de forma a apresentarem, cada uma delas, uma boa cobertura da área - usando as caminhadas reais no ambiente. Os erros médios de cada sistema, para cada um dos testes, são mostrados no gráfico da figura 5.3. Cada agrupamento de barras corresponde ao resultado de um único teste para as quatro implementações. O último agrupamento representa a média dos resultados. 


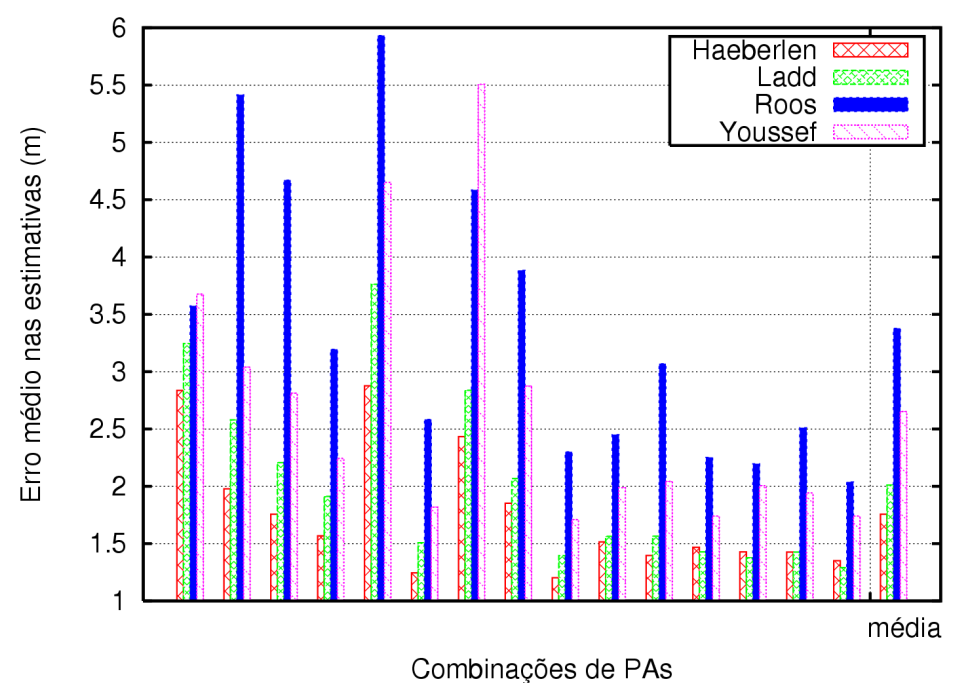

Figura 5.3: Desempenho de sistemas propostos na literatura em termos dos erros médios obtidos em função da combinação de PAs presentes.

Como era esperado, os dois sistemas que utilizam um filtro bayesiano simples tiveram os piores resultados. O sistema de Ladd obteve resultados próximos aos de Haeberlen, mas este último ainda foi o que apresentou o melhor desempenho na média, daí este ter sido escolhido como o sistema básico, descrito no capítulo 3.

\subsubsection{Análise de desempenho sem perda de sinal}

A primeira parte desta análise foi feita através de experimentos realizados com seqüências de observações simuladas. Dessa forma pode-se verificar quanto ruído seria necessário na informação de freqüência de presença dos sinais para que o desempenho do WBLS fosse superior ao do sistema básico. Esses experimentos foram importantes para mostrar que a premissa da proposta, que sugere que o sistema básico sofre muito mais com esse tipo de ruído do que o WBLS, é verdadeira.

A segunda parte desta análise foi feita com dados de caminhadas reais no ambiente e a comparação entre os desempenhos dos sistemas é apresentada em duas condições: considerando todos os PAs do ambiente e deixando de lado um deles que apresentou sinais de ter sido desativado durante parte da coleta de dados. 


\section{Experimentos com dados simulados}

Foram geradas 5 seqüências de observação simuladas - com valores de $\alpha$ variando de 0,6 a 1 (ver equação 5.1) - para cada um dos 10 percursos. Para cada $\alpha$ e cada combinação de $n$ PAs, executa-se o algoritmo de localização em cada um dos 10 percursos. Repete-se o procedimento para 100 combinações do mesmo número $n$ de PAs e extrai-se a média e o desvio padrão das medidas de desempenho obtidas em cada iteração. Este dado corresponde a um ponto das curvas construídas para o referente $\alpha$ nos gráficos apresentados a seguir. Nos experimentos realizados, o número $n$ de PAs presentes varia entre 7 e 16 .

Os primeiros resultados, apresentados na figura 5.4, mostram o desempenho do sistema básico em função do número de PAs para cada valor de $\alpha$. O mesmo resultado é apresentado para o WBLS na figura 5.5. Verifica-se que o desempenho do sistema básico cai consideravelmente com o decréscimo do coeficiente de correlação $\alpha$, o que não acontece com o WBLS, cujo desempenho não se altera de forma significativa.

Em seguida, os gráficos da figura 5.6 mostram o desempenho dos dois sistemas em condições onde o coeficiente $\alpha$ é 1, 0,8 e 0,6. Duas conclusões podem ser tiradas destes dados. Primeiro, a falta da informação sobre a freqüência de presença dos sinais tem mais influência quando há poucos PAs no ambiente, o que é mostrado pela inclinação mais acentuada das curvas do WBLS comparadas às curvas do sistema básico. Segundo, o desempenho do WBLS apresenta uma tendência de ultrapassar o desempenho do sistema básico conforme aumenta o ruído na informação de freqüência de presença dos sinais. 


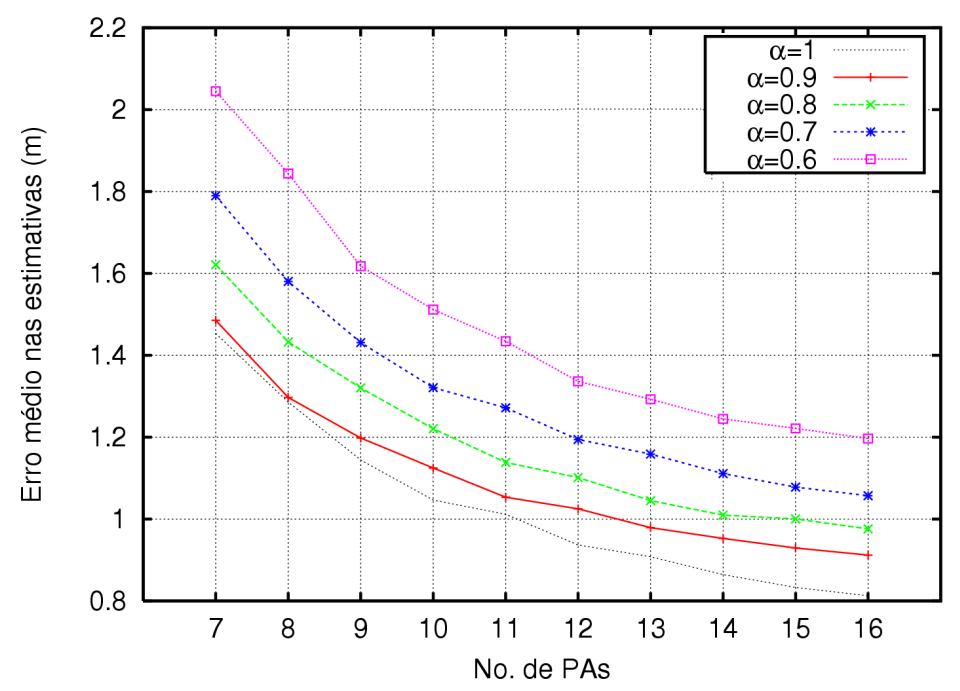

Figura 5.4: Desempenho do sistema básico com dados simulados variando o coeficiente de correlação $\alpha$. Cada ponto de curva indica a média de 100 execuções, com diferentes combinação de um número fixo de PAs.

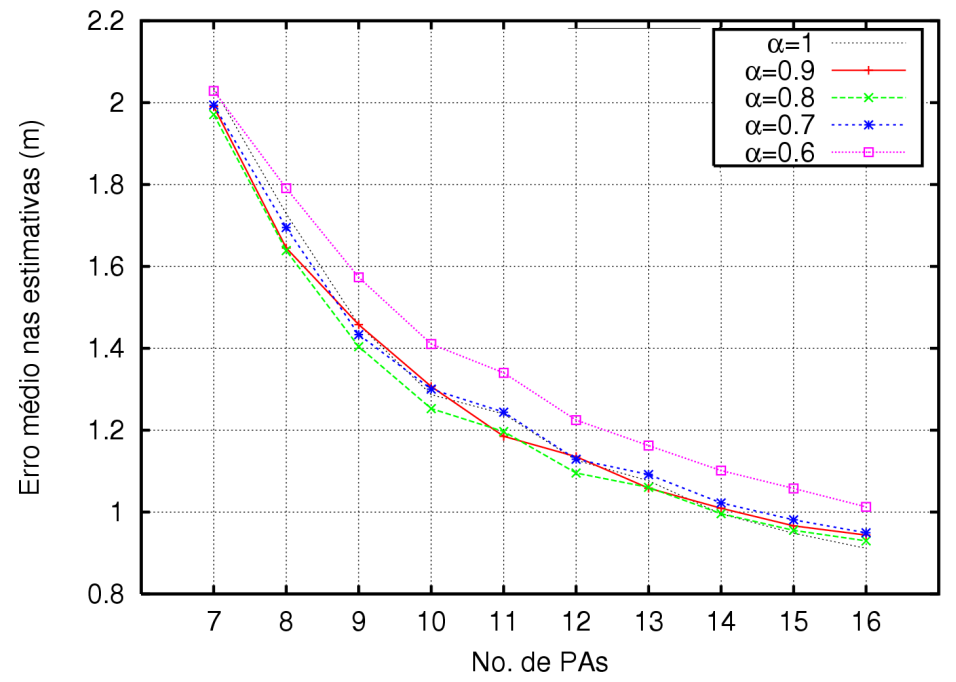

Figura 5.5: Desempenho do WBLS com dados simulados variando o coeficiente de correlação $\alpha$. Cada ponto de curva indica a média de 100 execuções, com diferentes combinação de um número fixo de PAs. 

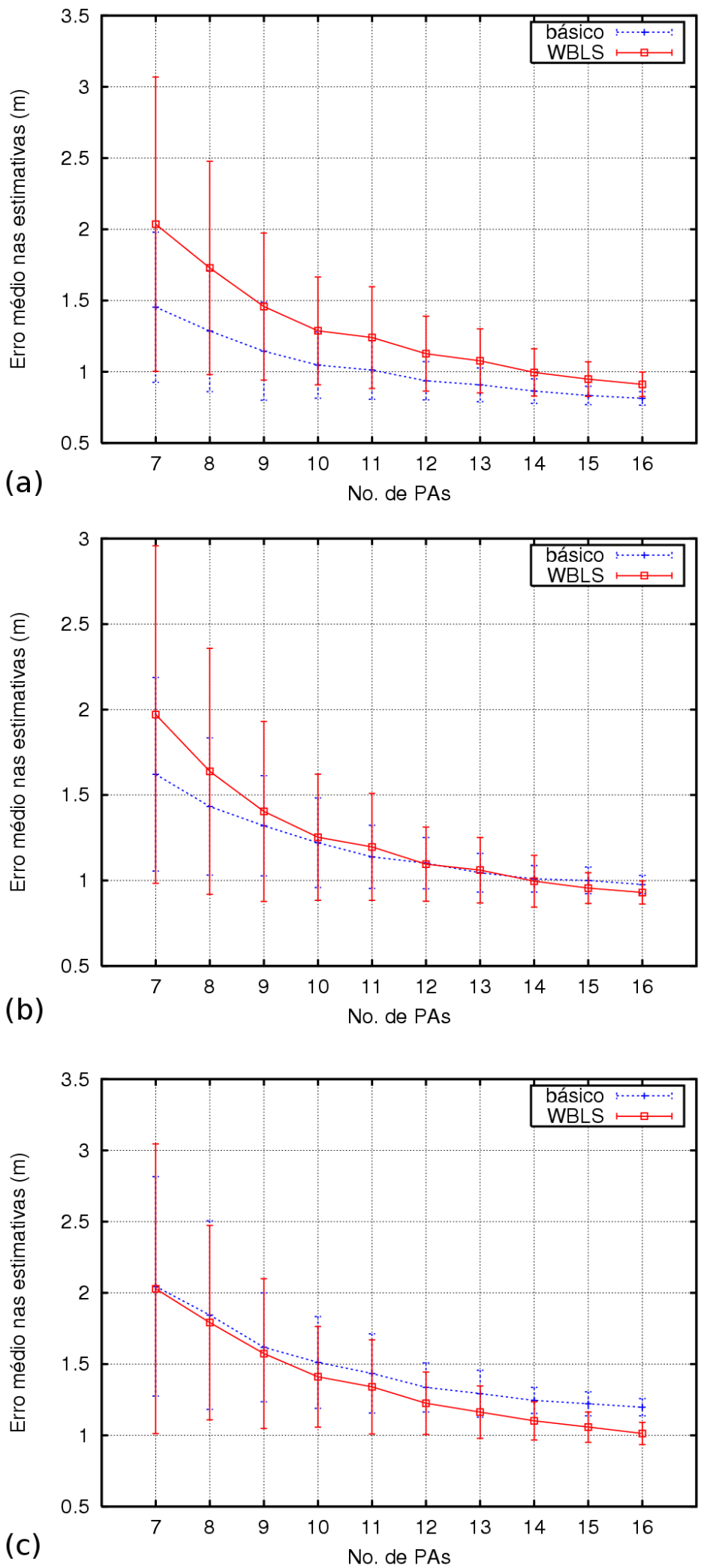

Figura 5.6: Comparação de desempenho entre o WBLS e o sistema básico em três grupos de dados simulados: (a) com coeficiente de correlação igual a 1; (b) com coeficiente de correlação igual a 0,8; e (c) com coeficiente de correlação igual a 0,6. 


\section{Experimentos em ambiente real}

Os experimentos com dados simulados confirmaram as previsões feitas pela proposta do WBLS. Era preciso então estabelecer se, em um ambiente real, o ruído é tal que o desempenho do WBLS supera o do sistema básico. Para isso, foi realizado primeiramente um experimento que utilizou as 70 caminhadas gravadas no banco de dados. Ambos os sistemas foram testados em 100 combinações diferentes de PAs para cada quantidade de PAs presentes entre 7 e 16. O resultado do experimento é mostrado no gráfico da figura 5.7. O desempenho do WBLS supera o do sistema básico a partir de 8 PAs presentes no ambiente, mostrando uma semelhança com o resultado obtido com dados simulados para $\alpha=0,6$.

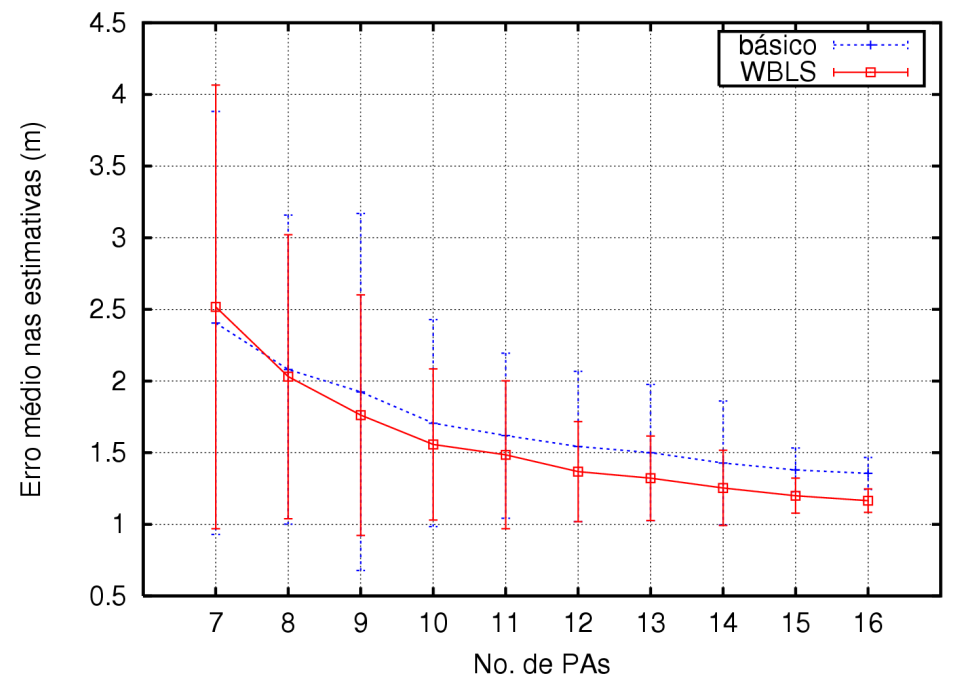

Figura 5.7: Comparação de desempenho entre o WBLS e o sistema básico com dados de percursos realizados em ambiente real. Cada curva representa a média e o desvio padrão de 70 caminhadas executadas com 100 combinações diferentes para cada quantidade de PAs considerados.

No entanto, uma análise mais cuidadosa dos dados obtidos nas caminhadas reais mostrou que o sinal de um dos PAs não estava presente em uma boa parte dos caminhos, o que sugere que ele tenha sido desligado em algum momento. Foi realizado um novo experimento similar ao anterior, mas agora sem considerar o PA citado. O resultado é mostrado na figura 5.8. Percebe-se que os desempenhos são muito próximos, mas o do sistema básico é ligeiramente superior. 


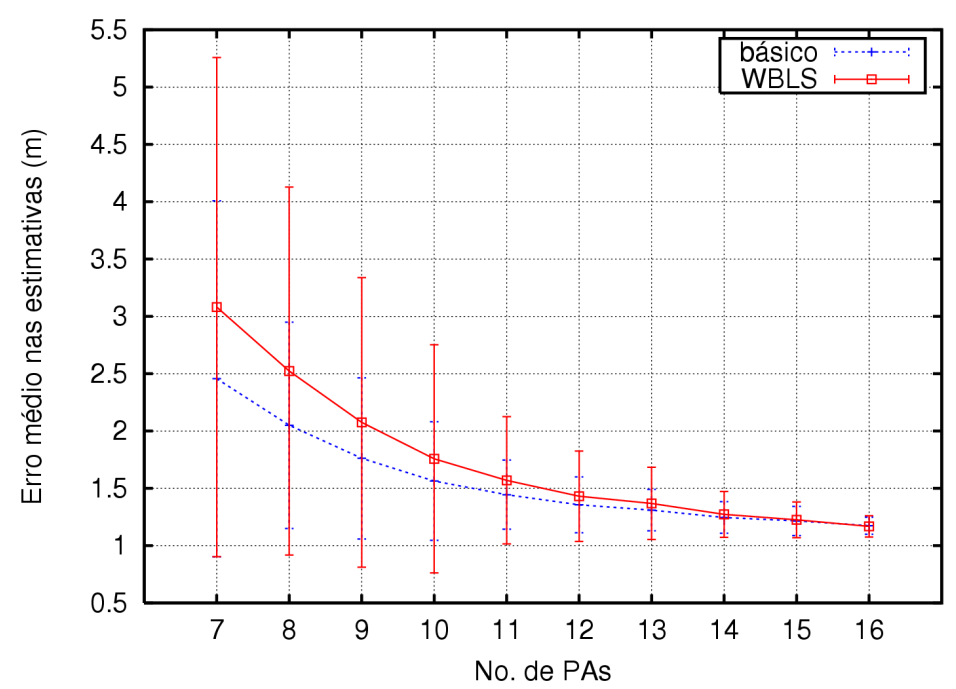

Figura 5.8: Comparação de desempenho entre o WBLS e o sistema básico desconsiderando PA com falha. Cada curva representa a média e o desvio padrão de 70 caminhadas executadas com 100 combinações diferentes para cada quantidade de PAs considerados.

Um teste $\mathrm{T}$ foi executado para as os resultados dos dois sistemas, para cada uma das quantidades de PAs presentes em ambos os experimentos. Os valores calculados nos testes $\mathrm{T}$ - que são apresentados nas tabelas 5.1 e 5.2 - devem ser maiores que 1,96 (no caso do número de amostras utilizadas nestes experimentos) para que a diferença entre médias possa ser considerada significativa $(\mathrm{P}<0,05)$ (NEHMZOW, 2003). No entanto, em ambos os experimentos, muitos dos resultados dos testes $T$ mostram que esse valor não foi atingido (em negrito nas tabelas), indicando que as diferenças entre as médias observadas não representam um argumento definitivo.

Tabela 5.1: Teste T para o primeiro experimento em ambiente real (figura 5.7).

\begin{tabular}{|c|c|c|c|c|c|c|c|c|c|c|}
\hline & \multicolumn{10}{c|}{ Quantidade de PAs presentes } \\
\hline & $\mathbf{7}$ & $\mathbf{8}$ & $\mathbf{9}$ & $\mathbf{1 0}$ & $\mathbf{1 1}$ & $\mathbf{1 2}$ & $\mathbf{1 3}$ & $\mathbf{1 4}$ & $\mathbf{1 5}$ & $\mathbf{1 6}$ \\
\hline \hline $\mathbf{T}=$ & $\mathbf{0 . 7 3 9}$ & $\mathbf{0 . 4 7 7}$ & $\mathbf{1 . 5 1 8}$ & 2.345 & 2.429 & 3.922 & 4.499 & 4.846 & 12.896 & 19.284 \\
\hline
\end{tabular}

Tabela 5.2: Teste T para o segundo experimento em ambiente real (figura 5.8).

\begin{tabular}{|c|c|c|c|c|c|c|c|c|c|c|}
\hline & \multicolumn{10}{|c|}{ Quantidade de PAs presentes } \\
\hline & $\mathbf{7}$ & $\mathbf{8}$ & $\mathbf{9}$ & $\mathbf{1 0}$ & $\mathbf{1 1}$ & $\mathbf{1 2}$ & $\mathbf{1 3}$ & $\mathbf{1 4}$ & $\mathbf{1 5}$ & $\mathbf{1 6}$ \\
\hline \hline $\mathbf{T}=$ & 3.62 & 3.047 & 2.428 & 2.781 & 2.268 & 2.247 & $\mathbf{1 . 5 3 6}$ & $\mathbf{0 . 7 2 2}$ & $\mathbf{0 . 6 8 2}$ & 19.284 \\
\hline
\end{tabular}


Existe ainda uma diferença notável do resultado do WBLS para o resultado do sistema básico. Esta diferença está nos desvios maiores apresentados pelos testes do WBLS. Isso se deve à ocorrência de algumas situações em que a combinação de PAs era tal que certas áreas ficavam com pouca cobertura. Como a ausência de sinal não é uma informação que o sistema proposto utiliza, ele acaba tendo um desempenho muito ruim nestas situações pior do que o do sistema básico - o que faz com que os desvios obtidos sejam tão grandes.

\subsubsection{Análise de desempenho com perda de sinal de um PA}

Foi sugerido, no capítulo 4, que o WBLS deve ser capaz de se adaptar melhor a uma situação onde o sinal de um ou mais PAs deixam de aparecer por um motivo qualquer. Para analisar esse tipo de situação foram realizados três experimentos que utilizaram as 70 caminhadas gravadas no banco de dados com uma pequena modificação. No primeiro experimento, os sinais de um PA pouco presente nas observações dos caminhos foram apagados - apenas dos registros dos caminhos, sem alterar o mapa de RSSI - simulando seu desligamento. No segundo experimento, os sinais de um PA muito presente foram apagados. No terceiro, os sinais de ambos foram apagados. Em cada experimento, os dois sistemas foram testados em 100 combinações diferentes de PAs para cada quantidade de PAs presentes entre 7 e 16. Os resultados dos três experimentos são mostrados nos gráficos da figura 5.9 .

Verifica-se nos três casos que o desempenho do WBLS é sempre superior. No entanto, no primeiro deles, o desempenho dos dois sistemas é bastante próximo, indicando que falhas em PAs pouco presentes nas observações tem um efeito menos importante, como de fato era de se esperar. Outra observação interessante é que os resultados dos dois sistemas mostram uma tendência de se aproximarem com o aumento do número de PAs no ambiente. A provável razão disso é que o fato de mais informação estar acessível deve diluir, para o sistema básico, o efeito danoso da informação da ausência do PA que está desligado. Por fim, pode-se notar que os desvios dos resultados do sitema básico são maiores que os do WBLS, indicando a ocorrência de alguns resultados extremamente ruins por parte do sistema básico. 

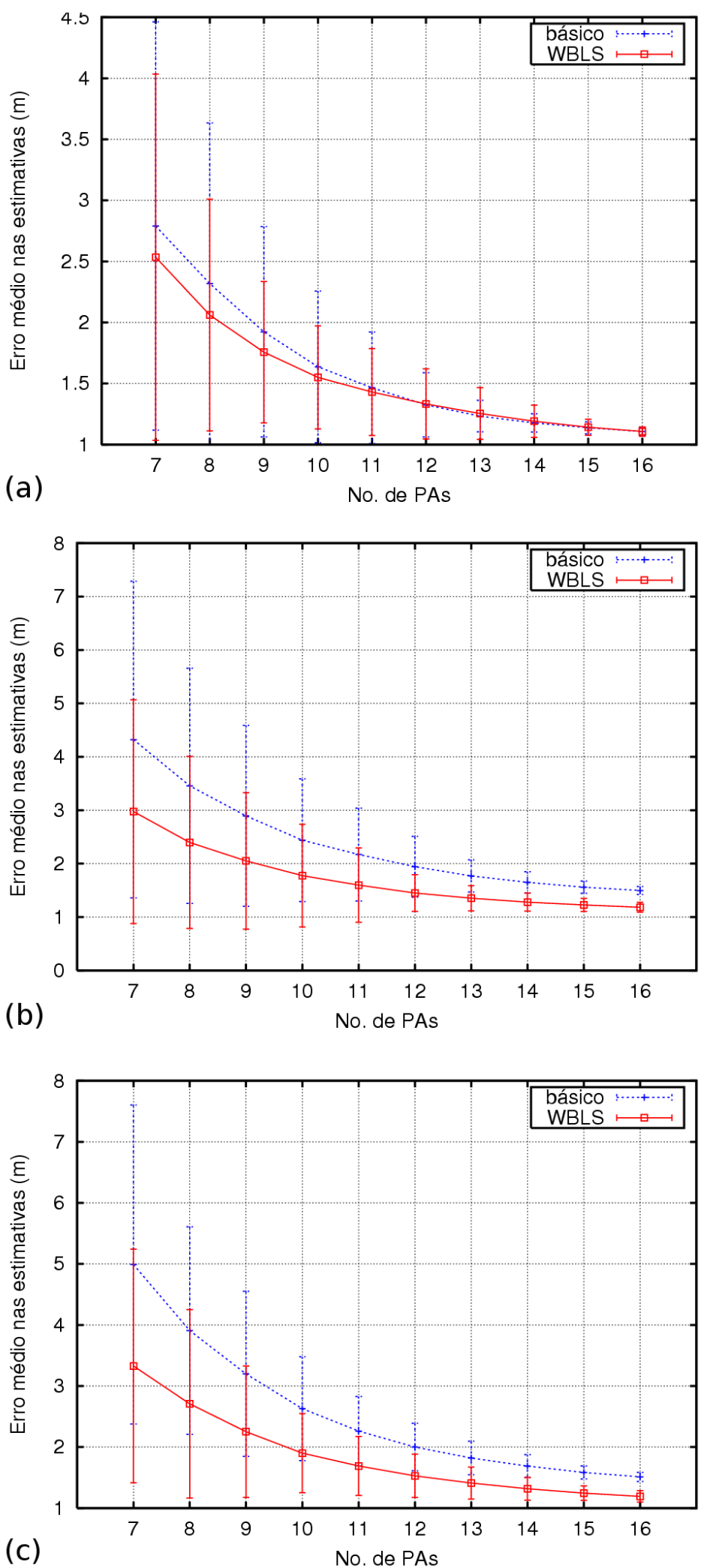

Figura 5.9: Comparação de desempenho entre o WBLS e o sistema básico com simulação de desligamento de certos PAs durante os percursos: (a) desligamento de um PA com baixa presença nas amostras realizadas na fase de treinamento; (b) desligamento de um PA com alta presença nas amostras; (c) desligamento de ambos PAs. 
Testes $\mathrm{T}$ foram realizados para os três experimentos e seus resultados estão nas tabelas 5.4, 5.3 e 5.5. Valores acima de 1,96 indicam que as médias diferem significativamente $(\mathrm{P}>0,05)$. Os valores calculados mostram que a diferença de desempenho entre os sistemas é sempre significante nos dois últimos experimentos.

Tabela 5.3: Teste $\mathrm{T}$ para o primeiro experimento com perda de sinal.

\begin{tabular}{|c|c|c|c|c|c|c|c|c|c|c|}
\hline & \multicolumn{10}{|c|}{ Quantidade de PAs presentes } \\
\hline & $\mathbf{7}$ & $\mathbf{8}$ & $\mathbf{9}$ & $\mathbf{1 0}$ & $\mathbf{1 1}$ & $\mathbf{1 2}$ & $\mathbf{1 3}$ & $\mathbf{1 4}$ & $\mathbf{1 5}$ & $\mathbf{1 6}$ \\
\hline \hline $\mathbf{T}=$ & $\mathbf{1 . 5 1 4}$ & 2.118 & 2.142 & $\mathbf{1 . 5 3 6}$ & $\mathbf{0 . 8 0 6}$ & $\mathbf{0 . 2 4 1}$ & $\mathbf{1 . 1 6 4}$ & $\mathbf{1 . 2 2}$ & $\mathbf{0 . 7 1}$ & $\mathbf{0 . 0 5 7}$ \\
\hline
\end{tabular}

Tabela 5.4: Teste $\mathrm{T}$ para o segundo experimento com perda de sinal.

\begin{tabular}{|c|c|c|c|c|c|c|c|c|c|c|}
\hline & \multicolumn{10}{|c|}{ Quantidade de PAs presentes } \\
\hline & $\mathbf{7}$ & $\mathbf{8}$ & $\mathbf{9}$ & $\mathbf{1 0}$ & $\mathbf{1 1}$ & $\mathbf{1 2}$ & $\mathbf{1 3}$ & $\mathbf{1 4}$ & $\mathbf{1 5}$ & $\mathbf{1 6}$ \\
\hline \hline $\mathbf{T}=$ & 4.955 & 5.18 & 5.291 & 5.913 & 6.852 & 9.87 & 14.506 & 18.94 & 26.69 & 35.312 \\
\hline
\end{tabular}

Tabela 5.5: Teste $\mathrm{T}$ para o terceiro experimento com perda de sinal.

\begin{tabular}{|c|c|c|c|c|c|c|c|c|c|c|}
\hline & \multicolumn{10}{|c|}{ Quantidade de PAs presentes } \\
\hline & $\mathbf{7}$ & $\mathbf{8}$ & $\mathbf{9}$ & $\mathbf{1 0}$ & $\mathbf{1 1}$ & $\mathbf{1 2}$ & $\mathbf{1 3}$ & $\mathbf{1 4}$ & $\mathbf{1 5}$ & $\mathbf{1 6}$ \\
\hline \hline $\mathbf{T}=$ & 6.841 & 6.976 & 7.305 & 9.068 & 10.232 & 11.936 & 14.417 & 18.654 & 28.249 & 35.516 \\
\hline
\end{tabular}

\subsubsection{Discussão dos resultados}

Os resultados dos experimentos mostram que o WBLS apresenta um comportamento coerente com a previsão. Com o aumento do ruído nas freqüências de presença dos sinais, o sistema proposto praticamente não tem qualquer alteração de desempenho enquanto que o sistema básico apresenta pioras consideráveis. No entanto, os experimentos realizados com dados de caminhadas em um ambiente real mostraram que, em uma situação onde todos os PAs considerados estão em funcionamento normal, apesar de próximo, o desempenho do WBLS é inferior ao do sistema básico, indicando que, nestas condições, a eliminação do ruído não compensa o que se perde com o descarte de parte da informação.

Já para o segundo caso, onde há falhas em pelo menos um dos PAs, o WBLS mostrou ser significativamente mais robusto que o sistema básico, principalmente quando o PA que falha costuma ter seu sinal detectado em boa parte da área considerada. 
Interessante notar que a condição em que o sistema básico apresenta um desempenho melhor muitas vezes pode não ser a condição mais comum. Com muitos PAs no ambiente, é razoável considerar que falhas acontecerão com uma certa freqüência. Os próprios dados coletados mostram isso, já que neles há claros indícios de que um dos PAs teve, por algum motivo, suas transmissões cortadas. Isso corrobora o argumento apresentado neste trabalho de que o problema de lidar com uma infra-estrutura sobre a qual não se tem controle é real e que o WBLS é uma boa alternativa para esse contexto. 


\section{Conclusão}

O trabalho apresentado traz o resultado de um estudo sobre localização Wi-Fi onde aparecem algumas contribuições para o campo de pesquisa. Neste capítulo, essas contribuições são discutidas e, em seguida, são listados os possíveis caminhos a serem explorados em trabalhos futuros. Por fim, são feitas as considerações finais que dão fechamento ao trabalho.

\subsection{Contribuições do trabalho}

O estudo sobre localização Wi-Fi apresentado aqui tem como primeira contribuição fornecer uma compreensão mais profunda sobre esse tipo de localização específica. Apenas um trabalho (NUNES, 2006) foi encontrado em língüa portuguesa com uma análise das características do problema, uma análise dos trabalhos apresentados e uma comparação de diferentes métodos, sendo que alguns dos pontos discutidos aqui foram tratados com mais profundidade, como a comparação entre os métodos probabilísticos e a análise dos resultados das propostas encontradas na literatura (o trabalho de Nunes (2006) tem um foco maior na infra-estrutura que envolve o sistema de localização e analisa mais questões relacionadas a ela).

A segunda contribuição é a proposta de um sistema de localização Wi-Fi - o WBLS desenvolvido para realizar estimativas de localização de dispositivos que estão de fato em movimento. O WBLS apresenta um modelo de observação que não considera a freqüência de presença dos sinais, o que lhe permite ser robusto para lidar com falhas nos PAs do ambiente - característica importante quando se trata de um ambiente tipicamente variável como acontece no contexto de localização Wi-Fi - e, em condições ideais, ainda apresentar resultados próximos aos dos melhores trabalhos reportados na literatura.

Por fim, este trabalho apresenta uma metodologia de experimentos que busca analisar o comportamento dos dispositivos em movimento e utiliza um simulador para analisar variações no ambiente. A utilização de um simulador em experimentos com localização 
Wi-Fi só foi encontrada em Haeberlen et al. (2004), mas o simulador não permitia alterações no comportamento do ambiente, servindo apenas como uma ferramenta para gerar seqüências de observações que representavam caminhadas pelo ambiente. No trabalho apresentado aqui, o simulador não apenas serviu para realização de experimentos com maior controle de parâmetros, mas também para aumentar a compreensão dos resultados obtidos com os dados reais.

\subsection{Trabalhos futuros}

Este trabalho apresentou uma proposta de um sistema de localização que explorou um dos caminhos possíveis de alteração no sistema básico apresentado. Duas outras possibilidades, no entanto, ainda podem ser exploradas: alterações no módulo de estimação do algoritmo de localização e a utilização de alguma forma de aprendizado das probabilidades de transição. Esta última, em particular, apresenta indícios de que pode trazer uma melhoria de desempenho interessante para os sistemas. Mas é questionável se tal melhoria iria compensar o aumento que o aprendizado deve causar na fase de treinamento. Ainda assim, essa possibilidade deve ser analisada mais profundamente para que se possa ter qualquer argumento definitivo.

Alguns argumentos lógicos apresentados aqui e resultados de trabalhos encontrados na literatura levaram este trabalho a enveredar por um estudo mais profundo de métodos probabilísticos. No entanto, a alternativa da utilização de redes neurais foi pouco explorada em trabalhos anteriores a este, e um deles em particular (BATTITI; NHAT; VILLANI, 2002) mostrou resultados interessantes. Aparentemente, a principal fraqueza das propostas apresentadas para utlização de redes neurais em localização Wi-Fi está no fato de que elas não levam em consideração a dependência entre estimativas consecutivas de localização. Tal fraqueza pode ser superada aumentado o número de entradas da rede ou empregando um esquema misto de localização markoviana e rede neural, como foi comentado no item 2.2.3, mas as conseqüências dessas alterações no contexto de localização Wi-Fi ainda não foram estudadas. A utilização de redes neurais pode trazer dois benefícios: uma melhor representação da realidade com a possível consideração das dependências condicionais entre probabilidades de sinais de diferentes PAs; e a necessidade de uma fase de treinamento menos exaustiva. Por esses motivos, este é um ramo da pesquisa que pode ainda ser explorado.

Por fim, o trabalho apresentado aqui descreve o funcionamento de um simulador que gera seqüências de observações correspondentes a caminhos percorridos num determinado 
ambiente. Um simulador que possa representar fielmente o comportamento de uma determinada classe de ambientes pode ser muito útil, pois pode tornar a pesquisa mais ágil e flexível. O simulador apresentado aqui tem a flexibilidade de variar a correlação entre as freqüências de presença dos sinais esperadas - obtidas na geração do mapa de RSSI - e as freqüências observadas durante as caminhadas. Seria interessante que a correlação entre as distribuições de sinais esperadas e as distribuições de sinais observadas durante caminhadas pudesse também ser variada, o que poderia aproximar melhor o comportamento de ambientes reais.

Um objetivo mais ousado seria construir um simulador que gerasse automaticamente um mapa de RSSI para um ambiente qualquer de características conhecidas, real ou fictício, com base na informação da sua topologia e da localização dos emissores de rádiofreqüência que devem servir de referência. Uma possível forma de se conseguir isso seria utilizando técnicas de ray tracing (FALSAFI; PAHLAVAN; YANG, 1996). O desenvolvimento de um simulador robusto e completo, que pudesse representar não apenas sinais Wi-Fi mas também outros sinais de rádio-freqüência, seria uma ferramenta de grande importância para diversas áreas de pesquisa.

\subsection{Considerações finais}

Este trabalho apresentou um estudo sobre localização Wi-Fi que resultou na proposta do sistema chamado WBLS. Uma série de experimentos foi apresentada e pode-se observar propriedades interessantes do sistema proposto, particularmente a capacidade de se adaptar a uma situação onde um ou mais PAs do ambiente podem falhar. No entanto, em condições ideais, onde se confia no comportamento dos PAs, um sistema básico que utiliza localização markoviana se mostra mais apropriado já que utiliza mais informação e assim oferece estimativas de melhor qualidade.

Assim, é possível dizer que, se o objetivo da implementação de um determinado serviço de localização Wi-Fi é obter a maior qualidade de estimativas possível, o ideal é trabalhar com um ambiente razoavelmente controlável e utilizar um sistema básico com localização markoviana. Mas se o objetivo for utilizar uma infra-estrutura de PAs existente, com um número suficiente de PAs presentes, o WBLS é o sistema indicado por ser mais robusto para lidar com essa infra-estrutura, sobre a qual tem-se pouco ou nenhum controle. 


\section{Referências}

ABOWD, G. D.; ATKESON, C. G.; HONG, J.; LONG, S.; KOOPER, R.; PINKERTON, M. Cyberguide: a mobile context-aware tour guide. Wireless networks, v. 3, n. 5, p. 421-433, oct 1997.

AMERICAN NATIONAL STANDARDS / INSTITUTE OF ELECTRICAL AND ELECTRONICS ENGINEERS. Std 802.11: Wireless LAN medium access control (MAC) and physical layer (PHY) specifications. Washington, 1999. 528 p.

ASHBROOK, D.; STARNER, T. Learning significant locations and predicting user movement with GPS. In: INTERNATIONAL SYMPOSIUM ON WEARABLE COMPUTERS, 6th, 2002. Proceedings... Piscataway, NJ, US: IEEE, 2002. p. 101-108.

ASTHANA, A.; CRAVATTS, M.; KRZYZANOWSKI, P. An indoor wireless system for personalized shopping assistance. In: WORKSHOP ON MOBILE COMPUTING SYSTEMS AND APPLICATIONS, 1st, 1994. Proceedings... Piscataway, NJ, US: IEEE, 1994. p. $69-74$.

BAHL, P.; PADMANABHAN, V. N. Enhancements to the RADAR user location and tracking system. San Diego: Microsoft Research, 2000. (Technical Report MSR-TR2000-12).

BAHL, P.; PADMANBHAM, V. N. Radar: an in-building RF-based user location and tracking system. In: INFOCOM - THE JOINT CONFERENCE OF THE IEEE COMPUTER AND COMMUNICATIONS SOCIETIES, 9th, 2000. Proceedings... Piscataway, NJ, US: IEEE, 2000. p. 775-784.

BALBACH, O. UMTS - competing navigation system and supplemental communication system to GNSS. In: ION GPS MEETING, 2000, Salt Lake City. Proceedings... Fairfax, VA: ION, 2000. p. 519-527.

BARDWELL, J. You believe you understand what you think I said. 2007. Disponível em $<$ http://madwifi.org/wiki/UserDocs/RSSI >. Acesso em fev. 2007.

BATTITI, R.; NHAT, T. L.; VILLANI, A. Location-aware computing: a neural network model for determining location in wireless LANs. Trento: Università degli Studi di Trento, 2002. (Technical Report DIT-02-0083).

BAYES, T. An essay towards solving a problem in the doctrine of chances. Philosophical transactions of the royal society of London, p. 370-418, 1763.

BERNA, M.; SELlNER, B.; LISIEN, B.; THRUN, S.; GORDON, G.; PFENNING, F. A learning algorithm for localizing people based on wireless signal strength that uses labeled and unlabeled data. In: INTERNATIONAL JOINT CONFERENCE ON 
ARTIFICIAL INTELligENCE - IJCAI, 16th, 2003. Proceedings... San Francisco: Morgan Kaufmann Publishers, 2003.

BISHOP, C. M. Neural networks for pattern recognition. Oxford: Oxford University Press, 1995.

BOZIC, S. M. Digital and Kalman filtering. London: Edward Arnold Ltd., 1979.

BRUCE, A.; GORDON, G. Better motion prediction for people-tracking. In: INTERNATIONAL CONFERENCE ON ROBOTICS AND AUTOMATION - ICRA, 2004, Barcelona. Proceedings... Piscataway, NJ, US: IEEE, 2004.

BRUMITT, B.; MEYERS, B.; KRUMM, J.; KERN, A.; SHAFER, S. Easyliving: technologies for intelligent environments. In: INTERNATIONAL SYMPOSIUM ON HANDHELD AND UBIQUITOUS COMPUTING, 2nd, 2000. Proceedings... Berlin/Heidelberger: Springer, 2000. p. 12-29.

BRUNATO, M.; KALLó, C. K. Transparent location fingerprinting for wireless services. In: MEDITERRANEAN AD HOC NETWORKING WORKSHOP - MED-HOC-NET, 1st, 2002, Sardegna. Proceedings... Laxenburg, AUT: IFIP, 2002.

CAFFERY, J. J.; STüBER, G. L. Overview of radiolocation in CDMA cellular systems. IEEE communications magazine, v. 36, p. 38-45, apr 1998.

CASTRO, P.; CHIU, P.; KREMENEK, T.; MUNTZ., R. R. A probabilistic room location service for wireless networked environments. In: INTERNATIONAL CONFERENCE ON UBIQUITOUS COMPUTING - UBICOMP, 3rd, 2001, Atlanta. Proceedings... Berlin/Heidelberger: Springer-Verlag, 2001. p. 18-34.

DEY, A. K.; ABOWD, G. D.; SALBER, D. A context-based infrastructure for smart environments. In: INTERNATIONAL WORKSHOP ON MANAGING INTERACTIONS IN SMART ENVIRONMENTS, 1st, 1999. Proceedings... Berlin/Heidelberger: SpringerVerlag, 1999. p. 114-128.

DUDEK, G.; JENKIN, M. Representing and reasoning about space. In: Computational principles of mobile robotics. Cambrigde: Cambridge University Press, 2000. cap. 5, p. $121-148$.

EKAHAU. Device support for Ekahau products. 2006. Disponível em $<$ http://www.ekahau.com/products/client/files/current/devices.html >. Acesso jun. 2006 .

ELNAHRAWY, E.; LI, X.; MARTIN, R. P. Using area-based presentations and metrics for localization systems in wireless LANs. In: INTERNATIONAL CONFERENCE ON LOCAL COMPUTER NETWORKS - LCN, 29th, 2004, Tampa. Proceedings... Piscataway, NJ, US: IEEE, 2004. p. 650-657.

FALSAFI, A.; PAHLAVAN, K.; YANG, G. Transmission techniques for radio LANs - a comparative performance evaluation using ray tracing. IEEE journal on selected areas in communications, v. 14, n. 3, p. 477-491, apr 1996. 
FEDERAL COMMUNICATIONS COMMISSION. FCC report and order 96-264:

Revision of the commissions rules to ensure compatibility with Enhanced 911 emergency calling systems. Washington, 1996.

FOX, D.; BURGARD, W.; DELlAERT, F.; THRUN, S. Monte carlo localization: efficient position estimation for mobile robots. In: NATIONAL CONFERENCE ON ARTIFICIAL INTELligENCE, 16th, 1999. Proceedings... Menlo, CA, US: American Association for Artificial Intelligence, 1999. p. 343-349.

FOX, D.; BURGARD, W.; THRUN., S. Markov localization for mobile robots in dynamic environments. Journal of artificial intelligence research, v. 11, p. 391-427, 1999.

FOX, D.; HIGHTOWER, J.; LIAO, L.; SCHUlZ, D.; BORRIELlO, G. Bayesian filtering for location estimation. Pervasive computing, v. 02, p. 24-33, jul 2003.

GELB, A.; CASPER, J. F.; NASH, R. A.; PRICE, C. F.; SUTHERLAND, A. A. Applied optimal estimation. Cambridge, MA, US: MIT Press.

GWON, Y.; JAIN, R.; KAWAHARA, T. Robust indoor location estimation of stationary and mobile users. In: JOINT CONFERENCE OF THE IEEE COMPUTER AND COMMUNICATIONS SOCIETIES - INFOCOM, 23rd, 2004, Hong Kong. Proceedings... Piscataway, NJ, US: IEEE, 2004. v. 2, p. 1032-1043.

HAEBERLEN, A.; FLANNERY, E.; LADD, A. M.; RUDYS, A.; WALLACH, D. S.; KAVRAKI, L. E. Practical robust localization over large-scale 802.11 wireless networks. In: INTERNATIONAL CONFERENCE ON MOBILE COMPUTING AND NETWORKING - MOBICOM, 10th, 2004, Philadelphia. Proceedings... New York: ACM press, 2004. p. 70-84.

HALLIDAY, D.; RESNICK, R.; WALKER, J. Fundamentals of physics. 6. ed. Hoboken, NJ, US: John Wiley and Sons, 2000.

HASHEMI, H. The indoor radio propagation channel. Proceedings of the IEEE, v. 81, p. 943-968, jul 1993.

HAZAS, M. A novel broadband ultrasonic location system. In: INTERNATIONAL CONFERENCE ON UBIQUITOUS COMPUTING - UBICOMP, 4th, 2002, Göteborg, SWE. Proceedings... Berlin/Heidelberg: Springer, 2002. p. 264-280.

HIGHTOWER, J.; BORRIELLO, G. A survey and taxonomy of location sensing systems for ubiquitous computing. Washington: Department of Computer Science and Engineering, University of Washington, 2001. (Technical Report UW-CSE 01-08-03).

Particle filters for location estimation in ubiquitous computing: a case study. In: INTERNATIONAL CONFERENCE ON UBIQUITOUS COMPUTING - UBICOMP, 6th, 2004, Tokyo. Proceedings... Berlin/Heidelberg: Springer-Verlag, 2004. p. 88-106.

HOWARD, A.; SIDDIQI, S.; SUKHATME, G. S. An experimental study of localization using wireless ethernet. In: INTERNATIONAL CONFERENCE ON FIELD AND SERVICE ROBOTICS - FSR, 4th, 2003, Yamanaka, JPN. Proceedings... AUS: Australian Robot Association, 2003. 
INSTITUTE OF ELECTRICAL AND ELECTRONICS ENGINEERS. Std 802.11a. Washington, 1999.

. Std 802.11b. Washington, 1999.

Std 802.11g. Washington, 2003.

KAEMARUNGSI, K.; KRISHNAMURTHY, P. Modeling of indoor positioning systems based on location fingerprinting. In: JOINT CONFERENCE OF THE IEEE COMPUTER AND COMMUNICATIONS SOCIETIES - INFOCOM, 23rd, 2004, Hong Kong. Proceedings... Piscataway, NJ, US: IEEE, 2004. v. 2, p. 1012-1022.

KAVEHRAD, M.; MCLANE, P. Spread spectrum for indoor digital radio. IEEE communications, v. 25, p. 33-40, jun 1987.

KRIZMAN, K.; BIEDMAN, T.; RAPPAPORT, T. Wireless position location: fundamentals, implementation strategies and sources of error. In: VEHICULAR TECHNOLOGY CONFERENCE, 47th, 1997. Proceedings... Piscataway, NJ, US: IEEE, 1997. p. 919-923.

KRUMM, J.; HORVITZ, E. LOCADIO: Inferring motion and location from Wi-Fi signal strengths. In: INTERNATIONAL CONFERENCE ON MOBILE AND UBIQUITOUS SYSTEMS - MOBIQUITOUS, 1st, 2004, Boston. Proceedings... Piscataway, NJ, US: IEEE, 2004. p. 4-13.

KRUMM, J.; PLATT, J. Minimizing calibration effort for an indoor 802.11 device location measurement system. Redmond, WA, US: Microsoft Research Lab., 2003. (Technical Report MSR-TR-2003-82).

KRUMM, J.; WILLIAMS, L.; SMITH, G. Smartmovex on a graph: an inexpensive active badge tracker. In: INTERNATIONAL CONFERENCE ON UBIQUITOUS COMPUTING - UBICOMP, 4th, 2002, Göteborg, SWE. Proceedings... Berlin/Heidelberg: Springer-Verlag, 2002. p. 299-307.

LADD, A. M.; BEKRIS, K. E.; MARCEAU, G.; RUDYS, A.; WALLACH, D. S.; KAVRAKI, L. E. Using wireless ethernet for localization. In: INTERNATIONAL CONFERENCE ON INTELLIGENT ROBOTS AND SYSTEMS - IROS, 2002, Lausanne, SWI. Proceedings... Piscataway, NJ, US: IEEE, 2002. p. 402-408.

LADD, A. M.; BERKIS, K. E.; RUDYS, A.; KAVRAKI, L. E.; WALLACH, D. S. Robotics-based location sensing using wireless ethernet. Wireless networks, v. 11, n. 1-2, p. 189-204, jan 2005.

LAMARCA, A.; CHAWATHE, Y.; CONSOLVO, S.; HIGHTOWER, J.; SMITH, I.; SCOTT, J.; SOHN, T.; HOWARD, J.; HUGHES, J.; POTTER, F.; TABERT, J.; POWLEDGE, P.; BORRIELLO, G.; SCHILIT, B. Place Lab: device positioning using radio beacons in the wild. In: INTERNATIONAL CONFERENCE ON PERVASIVE COMPUTING, 3rd, 2005, Munique. Proceedings... Berlin/Heidelberg: Springer-Verlag, 2005 .

LANGFELDT, N. A survey of Linux and Wi-Fi. 2007. Disponível em $<$ http://users.linpro.no/janl/hardware/wifi.html>. Acesso em fev. 2007. 
LIAO, L.; FOX, D.; HIGHTOWER, J.; KAUTZ, H.; SCHULZ, D. Voronoi tracking: location estimation using sparse and noisy sensor data. In: INTERNATIONAL CONFERENCE ON INTELLIGENT ROBOTS AND SYSTEMS - IROS, 2003, Las Vegas. Proceedings... Piscataway, NJ, US: IEEE, 2003. p. 723-728.

LONGSDON, T. Understanding the Navstar: GPS, GIPS and IVHS. 2. ed. New York: Springer, 1995.

MADWIFI. MadWifi - multiband Atheros driver for Wi-Fi. 2006. Disponível em $<$ http://madwifi.org/>. Acesso em jun. 2006.

MCCULLOCH, W. S.; PITTS, W. A logical calculus of the ideas immanent in nervous activity. Bulletin of mathematical biophysics, v. 5, n. 4, p. 115-137, dec 1943.

MOURA, A. I.; COSTA, A. H. R. Localização de dispositivos móveis em redes Wi-Fi com aprendizagem em tempo de execução. In: CONGRESSO BRASILEIRO DE AUTOMáTICA - CBA, 16o., 2006, Salvador. Anais... Natal: SBA, 2006.

NEHMZOW, U. Mobile robotics: a pratical introduction. 2. ed. Berlin/Heidelberg: Springer-Verlag, 2003.

NESKOVIC, A.; NESKOVIC, N.; PAUNOVIC, G. Modern approaches in modeling of mobile radio systems propagation environment. IEEE communications surveys and tutorials, v. 3, p. 2-12, 2000.

NUNES, B. A. A. Um sistema de localização para redes Wi-Fi baseado em níveis de sinal e modelo referenciado de propagação. Dissertação (Mestrado) - Universidade Federal do Rio de Janeiro, Rio de Janeiro, 2006.

PAHLAVAN, K.; LI, X.; MAKELA, J.-P. Indoor geolocation science and technology. IEEE communications magazine, v. 40, p. 112-118, feb 2002.

RABINER, L. R. A tutorial on hidden Markov models and selected applications in speech recognition. Proceedings of the IEEE, v. 77, p. 257-286, feb 1989.

ROOS, T.; MYLLYMAKI, P.; TIRRI, H.; MISIKANGAS, P.; SIEVANEN, J. A probabilistic approach to WLAN user location estimation. International journal of wireless information networks, v. 9, n. 3, p. 155-164, jul 2002.

RUSSEL, S. Detecting and locating rogue access points. Ames, IO, US: Department of Electrical and Computer Engineering, Iowa State University, 2003. (Technical Report CprE 537).

RUSSEL, S. J.; NORVIG, P. Artificial intelligence. 2. ed. Upper Saddle River, NJ, US: Prentice Hall, 2003.

SAHA, S.; CHAUDHURI, K.; SANGHI, D.; BHAGWAT, P. Location determination of a mobile device using IEEE $802.11 \mathrm{~b}$ access point signals. Wireless communications and networking, v. 3, p. 1987-1992, mar 2003.

SCHILlinG, D. L.; PICKHOLTZ, R. L.; MILSTEIN, L. B. Spread spectrum goes commercial. IEEE spectrum, v. 27, p. 40-44, aug 1990. 
SMAILAGIC, A.; SIEWIOREK, D. P.; ANHALT, J.; KOGAN, D.; WANG, Y. Location sensing and privacy in a context-aware computing environment. Wireless communications and networking, v. 9, p. 10-17, oct 2002.

SMAILAGIC, A.; SMALL, J.; SIEWIOREK, D. P. Determining user location for context aware computing through the use of a wireless LAN infrastructure. Pittsburgh, PA, US: Project Aura Report, Carnegie Mellon University, 2000. Disponível em: $<$ http://www-2.cs.cmu.edu/ aura/ $>$.

SPARACINO, F. Sto(ry)chastics: a bayesian network architecture for user modeling and computational storytelling for interactive spaces. In: INTERNATIONAL CONFERENCE ON UBIQUITOUS COMPUTING - UBICOMP, 5th, 2003, Tokyo. Proceedings... Berlin/Heidelberg: Springer-Verlag, 2003.

TAO, P.; RUDYS, A.; LADD, A. M.; WALLACH, D. S. Wireless LAN location-sensing for security applications. In: WORKSHOP ON WIRELESS SECURITY - WISE, 4th, 2003, Roma. Proceedings... New York: ACM Press, 2003. p. 11-20.

THRUN, S.; FOX, D.; BURGARD, W.; DELlAERT, F. Robust Monte Carlo localization for mobile robots. Artificial intelligence, v. 128, n. 1-2, p. 99-141, 2000.

WALLBAUM, M. WhereMoPS: an indoor geolocation system. In: SYMPOSIUM ON PERSONAL, INDOOR AND MOBILE RADIO COMMUNICATIONS - PIMRC, 14th, 2003. Proceedings... Piscataway, NJ, US: IEEE, 2002. p. 1967-1971.

WISOCKI, T. A.; ZEPERNICK, H.-J. Characterization of the indoor radio propagation channel at $2.4 \mathrm{GHz}$. Journal of telecommunications and information technology, p. 84-90, mar 2000 .

WüBBENA, G.; BAGGE, A.; SEEBER, G.; BöDER, V.; HANKEMEIER, P. Reducing distance dependent errors for real-time precise DGPS applications by establishing reference station networks. In: ION GPS MEETING, 9th, 1996, Kansas City. Proceedings... Fairfax, VA: ION, 1996. p. 1845-1852.

XIANG, Z.; SONG, S.; CHEN, J.; WANG, H.; HUANG, J.; GAO, X. A wireless LAN-based indoor positioning technology. IBM journal of research and development, v. 48, p. $617-626$, sep 2004.

YAMASAKI, R.; OGINO, A.; TAMAKI, T.; UTA, T.; MATSUZAWA, N.; KATO, T. TDOA location system for IEEE 802.11b WLAN. In: WIRELESS COMMUNICATIONS AND NETWORKING CONFERENCE - WCNC, 2005, New Orleans. Proceedings... Piscataway, NJ, US: IEEE, 2005. p. 2338-2343.

YOUSSEF, M.; AGRAWALA, A. The Horus WLAN location determination system. In: CONFERENCE ON MOBILE SYSTEMS, APPLICATIONS, AND SERVICES MOBISYS, 3rd, 2005, Seattle. Proceedings... New York: ACM press, 2005. p. 205-218. 


\section{Apêndice A - Questões técnicas sobre infra-estrutura para localização Wi-Fi}

Conhecer alguns detalhes da infra-estrutura utilizada por um serviço de localização Wi-Fi é importante para uma compreensão mais abrangente do problema de localizar dispositivos móveis em redes Wi-Fi. Algumas questões levantadas no texto serão discutidas aqui, como a necessidade de alterações nos drivers, as causas de falhas nos sinais dos PAs e o efeito de redes Wi-Fi transmitindo em canais vizinhos numa mesma área.

Este apêndice começa com algumas considerações sobre arquiteturas para implementação do serviço de localização Wi-Fi. Em seguida, descrevem-se algumas das partes mais relevantes da especificação IEEE 802.11 para redes Wi-Fi, responsável por especificar o funcionamento da infra-estrutura que dá suporte ao serviço de localização. Por fim, são feitas algumas considerações sobre a infra-estrutura de software e de hardware existente que implementa a especificação.

\section{A.1 Arquiteturas para um serviço de localização Wi-Fi}

Um serviço de localização é um programa ou conjunto de programas que executa em segundo plano fornecendo aos aplicativos a informação de localização do dispositivo e cujo principal componente é um sistema de localização como o que foi descrito neste trabalho. A sua implementação de baseia em uma arquitetura que permite a comunicação com os componentes de um nível mais baixo - como drivers e placas de rede Wi-Fi - que, por sua vez, fornecem a informação da RSSI através de um interface definida.

Há duas possibilidades para a arquitetura de um serviço de localização em redes WiFi. A primeira delas seria uma arquitetura centralizada em que o serviço fica instalado apenas no dispositivo móvel, que teria então que armazenar o mapa de RSSI e fazer todo o processamento do algoritmo de localização. As vantagens de se fazer isso seriam principalmente escalabilidade e manutenção da privacidade. Escalabilidade pois o serviço 
não estaria limitado a atender um certo número de usuários em função da capacidade de um servidor, e a manutenção da privacidade porque, como toda a execução do serviço seria feita localmente, a informação da localização do usuário (ou mesmo das RSSIs observadas, que proporcionaria a possibilidade de se inferir tal localização) não trafegaria na rede. Somente o usuário do dispositivo poderia saber onde ele está.

No entanto, há algumas desvantagens que tornam essa implementação menos atrativa. Primeiro, o algoritmo de localização apresentado consome uma quantidade considerável de memória que é função do número de registros do mapa (e conseqüentemente, de estados do modelo). Assim, o serviço fica limitado a lidar com ambientes de área não muito grande já que a quantidade de memória disponível em um PDA comum é relativamente pequena. Processamento também poderia ser um problema se o processador utilizado no dispositivo fosse muito lento. Trata-se de uma preocupação menor, no entanto. Em testes realizados em um PC com um processador PentiumII de $700 \mathrm{MHz}$, uma implementação do algoritmo proposto foi capaz de fazer cerca de 120 estimativas por segundo para um ambiente com 186 células.

Outra questão é a flexibilidade. Um localizador instalado em um dispositivo móvel seria capaz de determinar sua posição apenas no ambiente para o qual esse localizador tenha sido desenvolvido, já que dele faria parte o mapa do ambiente específico. Dessa forma, se um usuário de dispositivo móvel desejasse se localizar em diversos ambientes, teria que instalar um serviço de localização para cada um deles, o que é exaustivo e consome recursos.

Por fim, se de um lado a questão da privacidade é importante, de outro lado é interessante que se possa usar a informação da localização de dispositivos em um ambiente para efeitos de estatísticas que possam melhorar a alocação de recursos e o planejamento estratégico.

A segunda alternativa seria a de uma arquitetura distribuída, em que a grande parte do processamento seria realizada em um servidor (ou em um cluster de servidores). A figura A.1 ilustra como seria essa arquitetura. Nessa arquitetura distribuída, o processo do serviço de localização começa com um programa localizador, dentro do dispositivo móvel, pedindo um rastreamento da rede para o driver da rede sem-fio. O driver, por sua vez, retorna uma lista das redes encontradas com suas respectivas RSSIs, informação correspondente a uma observação conforme descrita nos dois capítulos anteriores. O programa localizador então passa essa informação para o servidor usando o serviço da camada de transporte da rede. Essa requisição chega ao servidor junto com uma identidade do dis- 


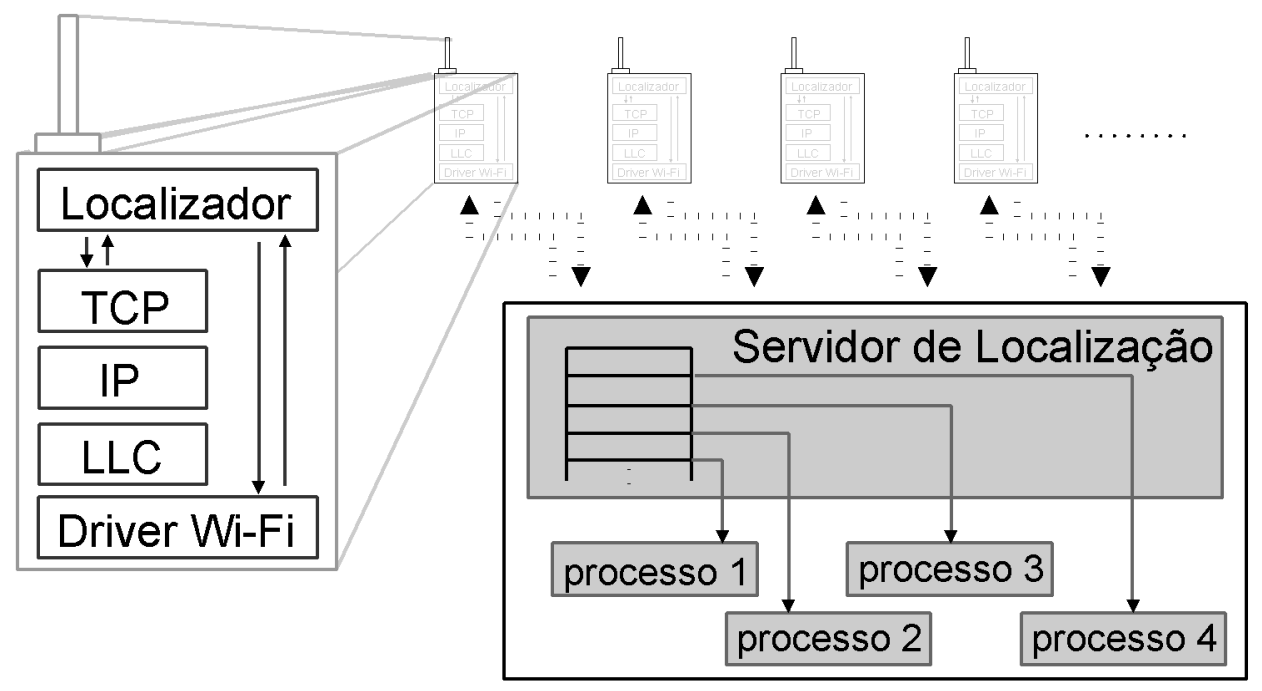

Figura A.1: Arquitetura distribuída para um serviço de localização Wi-Fi.

positivo - seu endereço de IP, por exemplo. O servidor acrescenta a identidade recebida em uma lista de dispositivos que estão sendo atendidos no momento, e inicia um processo paralelo para executar o algoritmo de localização especificamente para o novo dispositivo. O resultado de uma iteração do algoritmo é então retornado para o dispositivo móvel através da rede, que armazena essa informação em algum repositório ou a passa para algum aplicativo.

Numa segunda execução do ciclo, quando a requisição de localização chega ao servidor, este identifica a origem com uma das entradas da sua lista e a direciona para o processo responsável, que por sua vez executa uma nova iteração do algoritmo de localização. O ciclo é repetido até que o programa localizador seja desativado.

Essa arquitetura possibilita que um mesmo programa de localização instalado em um dispositivo móvel possa funcionar em ambientes diferentes que forneçam a infra-estrutura necessária. Seria preciso, no entanto, que, em cada ambiente onde o dispositivo entrasse, ele se associasse a uma rede sem fio disponível e fosse informado do endereço do servidor de localização. Uma forma de se facilitar esse processo seria ter na rede um dispositivo que, de tempos em tempos, fizesse um broadcast do endereço do servidor segundo algum padrão especificado previamente. Além da flexibilidade que essa arquitetura oferece, existe a vantagem de o programa localizador instalado no dispositivo móvel consumir muito pouca memória e processamento, recursos muitas vezes escassos nesse tipo de dispositivo. 


\section{A.2 Especificação 802.11 para redes $\mathrm{Wi}-\mathrm{Fi}$}

A especificação ANSI/IEEE 802.11 (ANSI/IEEE, 1999) é um documento que descreve o comportamento e as interfaces da camada física - PHY (Physical layer) - e da sub-camada de controle de acesso ao meio - MAC (Media Access Controle) - para conectividade sem fio em dispositivos fixos ou portáteis em uma área local, juntamente com uma entidade que é responsável pelo seu gerenciamento - LME (Layer Management Entity). A figura A.2 mostra uma pilha com as primeiras camadas do modelo de interconexão de um dispositivo que implementa a especificação 802.11. Ao lado da pilha há uma indicação da correspondência com o modelo OSI (Open System Interconnection) e em destaque está a parte que é descrita na especificação. O quadrado na lateral da pilha representa a entidade de gerenciamento - que faz parte também da especificação.

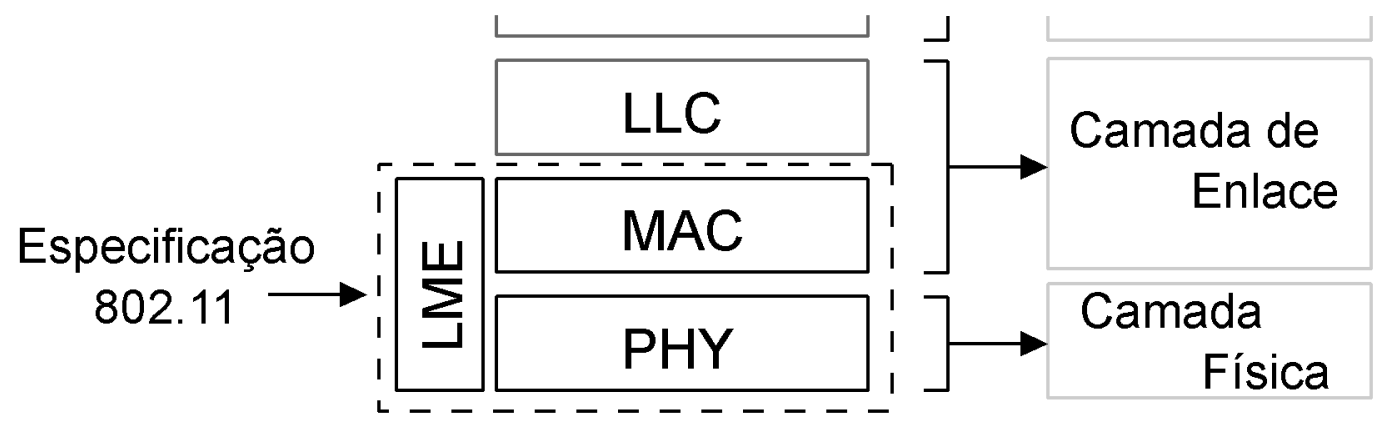

Figura A.2: Camadas inferiores de um modelo de interconexão de um dispositivo que implementa a especificação 802.11.

O entendimento de como funciona essa estrutura é bastante importante pois é ela que oferece a informação das RSSIs que são usadas no serviço de localização, além de ser parte integrante do processo de comunicação que deve ser usado em uma arquitetura distribuída. Nesta seção serão descritos os mecanismos e as funcionalidades mais relevantes da especificação 802.11 para um serviço de localização Wi-Fi.

\section{A.2.1 A sub-camada MAC}

A função da sub-camada MAC é basicamente receber quadros que vêm da rede através da camada PHY, repassando-os para a LLC se, de acordo com o endereço constante no quadro, este for destinado ao dispositivo; e controlar o momento de enviar quadros de dados para a rede - quadros que a LLC tenha lhe passado com esse propósito de acordo com uma política de acesso ao meio que procura evitar que dois dispositivos 
enviem dados ao mesmo tempo. A interface entre a LLC (Logical Link Layer) e a MAC é bastante simples, consistindo basicamente de primitivas de passagem de quadros em ambas as direções. No entanto, a MAC envia à rede mais do que quadros de dados. Há duas outras classes de quadros que a MAC utiliza: quadros de gerenciamento, e quadros de controle. Elas serão descritas nos itens a seguir.

\section{A.2.1.1 Configuração das camadas inferiores}

Para que se possa entender melhor os quadros de gerenciamento é importante saber como funciona o processo de configuração das camadas inferiores de um modelo de interconexão Wi-Fi. O usuário de um dispositivo Wi-Fi normalmente tem acesso à LME através de um programa de gerenciamento. De alguma forma (que pode ser simplesmente iniciar o programa, executar um comando ou clicar em um botão), o usuário pede a ela um rastreamento das redes disponíveis para associação ("conexão" é o termo mais usado entre usuários de redes Wi-Fi, mas escolheu-se "associação" por ser esse o termo usado na especificação). Esse pedido é repassado à MAC através de uma determinada interface (que é descrita em detalhes na especificação). Depois de um intervalo de tempo, a MAC retorna à LME identificações das redes disponíveis, cada qual com seu respectivo indicador de potência de sinal - entre outros dados -, e essa informação chega ao usuário. Ele escolhe então uma rede para se associar, fazendo esse pedido à LME (de novo, através do programa de gerenciamento) que, por sua vez, repassa o novo pedido à MAC. Só a partir do momento em que a MAC estabelece a associação é que os dados passados da LLC para a MAC são encaminhados para a rede (antes a MAC retornaria uma mensagem de erro para a LLC). O mesmo acontece com os quadros de dados que chegam da PHY para serem transferidos à LLC. Fazer rastreamento de redes disponíveis e se associar a alguma delas - entre outras coisas - são processos que a MAC executa através da troca de quadros de gerenciamento.

\section{A.2.1.2 Rastreamento de redes $\mathrm{Wi}-\mathrm{Fi}$}

O processo de rastreamento de redes tem particular importância para a localização Wi-Fi, pois ele é a forma mais simples e direta de se obter as RSSIs necessárias para o processo de localização. Segue assim uma breve descrição.

A MAC de um dispositivo que funciona como PA em uma rede Wi-Fi, de tempos em tempos, envia para a rede um quadro de gerenciamento chamado Beacon, que contém a identidade da rede assim como algumas de suas características. Todo Beacon que chega 
e é passado à MAC, vem com endereço de broadcast, por isso sempre é lido. Um processo de rastreamento passivo consiste ou em ficar esperando por um tempo a chegada de Beacons que forneçam informação sobre as redes presentes, ou simplesmente em retornar as informações armazenadas de Beacons recebidos recentemente. Esse tipo de rastreamento pode ser incerto demais, ou ser muito demorado, por isso existe a alternativa de se fazer um rastreamento ativo. Ele consiste de enviar para rede um quadro de broadcast chamado Probe Request. A MAC de um PA, ao receber um Probe Request, retorna imediatamente à rede um Probe Response - cujo conteúdo é basicamente o mesmo de um Beacon - para o endereço MAC do quadro original. Assim o processo fica mais ágil e preciso.

Dispositivos Wi-Fi transmitem e recebem sinais numa faixa de RF específica (que pode ser diferente para diferentes extensões da especificação como será descrito em A.2.2.2). Essa faixa é dividida em alguns canais de banda larga de forma que, para haver comunicação entre dois dispositivos Wi-Fi - um PA e um dispositivo móvel, por exemplo -, ambos devem estar recebendo e transmitindo no mesmo canal. Um processo de rastreamento completo, portanto, deve rastrear canal por canal, o que faz com que o rastreamento ativo seja o mais indicado.

\section{A.2.1.3 Controle de acesso ao meio}

A terceira classe de quadros que a MAC utiliza é a de quadros de controle. Eles são usados pela MAC no processo de controle de acesso ao meio que é feito de forma distribuída, ou seja, sem um controlador central (existe na especificação uma política de controle central, mas como detalhes não são relevantes ao escopo deste trabalho ela não será descrita). Simplificadamente, o que cada dispositivo faz é ficar "sentindo" o meio para saber se alguém está transmitindo. Se ele deseja iniciar uma transmissão, ele primeiro espera o meio ficar desocupado. A partir do instante em que detecta a desocupação do meio, ele espera por um intervalo de tempo pré-determinado acrescido de um intervalo de tempo aleatório. Só depois dessa espera, se o meio ainda estiver livre, ele inicia a transmissão, política esta que busca evitar a ocorrência de colisões - que é o que acontece quando dois dispositivos tentam transmitir ao mesmo tempo. O processo é mais complexo que isso, mas detalhes não são importantes para o entendimento do problema que este trabalho está tratando. O que importa saber é que há uma coordenação e essa coordenação se baseia em "sentir" o meio e evitar colisões (daí o nome da política: CSMA/CA - Carrier Sense Media Access / Collision Avoidance).

O principal exemplo de situações onde se usam os quadros de controle é o que segue. 
Ao iniciar uma transmissão, um dispositivo envia um quadro de controle RTS (Request To Send) para o destinatário dos dados que serão transmitidos. Esse quadro contém a informação da duração da transmissão. O dispositivo destinatário retorna então um CTS (Clear To Send). Todos os outros dispositivos sabem assim quanto tempo o meio deverá ficar ocupado. Ao final do envio dos dados, o destinatário deve enviar um quadro ACK (Acknowledge), dizendo que os dados chegaram bem. Se essa mensagem não for recebida pelo dispositivo que está enviando os dados, ele inicia um reenvio da mensagem antes de passar o intervalo de tempo padrão que todos os dispositivos esperam, garantindo assim o controle do meio até que sua operação seja bem sucedida.

\section{A.2.1.4 A interface MAC-PHY e a obtenção da RSSI}

Para realizar suas tarefas, a MAC tem que se comunicar com a PHY, seja para enviar ou receber dados que devem ser transmitidos entre dispositivos através da rede, seja para passar comandos de controle entre as camadas. Duas primitivas simples - para passar dados da MAC para a PHY (transmissão) e vice-versa (recepção) - servem para o primeiro propósito. Já para o segundo propósito são necessárias mais primitivas: da MAC para a PHY - pedido de início de transmissão e aviso de final -; e da PHY para a MAC indicação da ocupação do meio (enviada toda vez que o estado, ocupado ou desocupado, muda), indicação de início de recebimento de dados e aviso de final de recebimento.

Particularmente para um serviço de localização Wi-Fi, é interessante conhecer como funciona a recepção de um quadro MAC envolvendo as duas camadas. Isso porque é nesse processo que a PHY passa à MAC a informação da RSSI.

Quando percebe uma alteração na energia do meio, ultrapassando um determinado patamar, a PHY passa à MAC uma indicação de que o meio está agora "ocupado". Em seguida, a PHY examina o cabeçalho referente à sua camada no quadro que está chegando. Se essa análise concluir que o cabeçalho é válido e o quadro não está corrompido, a PHY envia à MAC a indicação de início de recebimento. Essa indicação é passada juntamente com um vetor de informações dentre as quais está a RSSI percebida pela PHY naquele quadro específico. O processo de recebimento então tem seqüência com a passagem dos dados que chegam da PHY para a MAC, até que, por fim, a primitiva de final de recebimento é enviada.

A RSSI é, portanto, observada na PHY a cada quadro que chega, e essa informação é sempre transmitida à MAC. No entanto, não há na especificação uma determinação de como a MAC deve usá-la. Poder-se-ia esperar que a informação sobre a RSSI associada a 
uma rede - informação que é passada à LME depois de uma requisição de rastreamento fosse a RSSI do último quadro Beacon ou Probe Response que tenha sido recebido dessa mesma rede. No entanto, isso não é o que se observa quando se trabalha com os drivers existentes, o que será explicado na próxima seção.

\section{A.2.2 A camada PHY}

A camada PHY é a responsável por receber os quadros da MAC e transformá-los a fim de que possam ser transmitidos na forma de sinais de rádio, ao mesmo tempo em que se ocupa em "escutar" o meio, detectar ausência e presença de sinais, e quando presentes, extrair dos sinais a informação para reconstruir os quadros que devem ser passados à MAC. A especificação 802.11 divide esta camada em duas subcamadas: a PLCP (Physical Layer Convergence Protocol); e a PMD (Physical Medium Dependent). A primeira é responsável por permitir que a MAC opere independente da forma em que se dará o tratamento físico dos quadros e a segunda é quem faz tal tratamento, providenciando os meios e os métodos de transmissão e recepção de dados através de sinais de RF que trafegam no ar.

Detalhes de cada uma das subcamadas não são relevantes ao escopo deste trabalho, mas algumas informações relacionadas à especificação da PHY são e por isso serão apresentadas a seguir. Primeiramente, serão tratadas questões relacionadas aos canais de transmissão de dados e interferências. As principais extensões da especificação serão então apresentadas e, por fim, algumas questões relacionadas ao tempo de transmissão dos quadros.

\section{A.2.2.1 Canais de transmissão de dados e interferências}

Como foi dito anteriormente, os sinais de RF emitidos por dispositivos Wi-Fi pertencem a uma faixa de freqüência determinada, a qual vai de $2.400 \mathrm{MHz}$ a $2.500 \mathrm{MHz}$. Esta faixa é dividida em 14 canais de banda larga (cerca de $30 \mathrm{MHz}$ ) onde o sinal transmitido é modulado utilizando uma técnica de espalhamento espectral (SCHILLING; PICKHOLTZ; MILSTEIN, 1990). Essa técnica é responsável por uma resistência muito grande do sinal em relação a interferências, sejam causadas por emissores externos de RF dentro do mesmo espectro (principalmente fornos micro-ondas (WISOCKI; ZEPERNICK, 2000)), sejam causadas pelos múltiplos caminhos de um mesmo sinal (KAVEHRAD; MCLANE, 1987). Segundo a regulamentação americana dos 14 canais especificados no documento, apenas os primeiros 11 podem ser utilizados (no padrão europeu são usados 13 canais e no japonês, apenas 1, o último). 
A especificação 802.11 ainda determina que, nessa faixa de freqüências, os canais estão distribuídos de forma que canais adjacentes se situam separados por apenas $5 \mathrm{MHz}$. Como a largura da banda é de $30 \mathrm{MHz}$, isso significa que os canais se sobrepõem uns aos outros. Assim, apesar de haver disponíveis de 11 a 13 canais, o máximo número de canais sem sobreposição é 3. A figura A.3 ilustra isso.

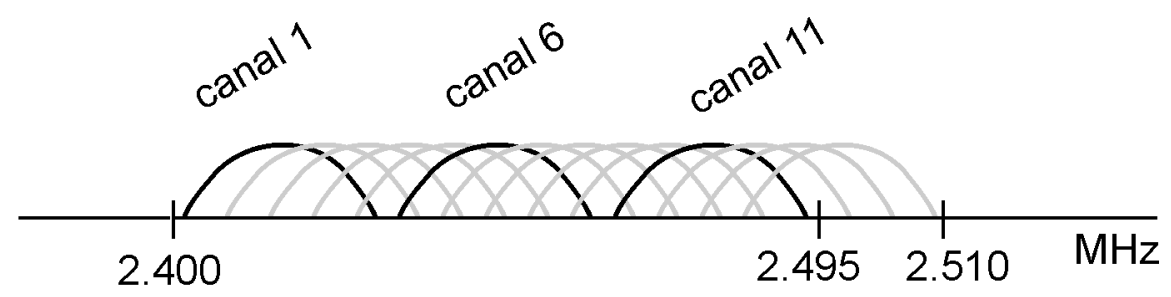

Figura A.3: Canais de transmissão para redes Wi-Fi.

Para o presente trabalho, a principal questão a ser analisada em relação à especificação dos canais Wi-Fi diz respeito à interferência entre as redes sem fio instaladas em um determinado ambiente. Isso porque dessa análise devem surgir os primeiros argumentos que explicam os motivos pelos quais as freqüências de presença do sinal dos PAs obtidas na construção de um mapa de RSSI de um ambiente representam uma informação tão ruidosa. Além fornecer os primeiros argumentos, a análise da questão da inteferência dá ainda suporte para os argumentos restantes que serão desenvolvidos ao longo dos próximos itens.

A configuração ideal para um ambiente completamente coberto por redes Wi-Fi é dada pela figura A.4. Nota-se que duas células adjacentes nunca utilizam o mesmo canal de transmissão e nem mesmo canais que se sobrepõem. A especificação diz que, neste caso, um sinal recebido vindo da célula à qual um certo dispositivo está associado deve ter uma taxa de erro de quadro de no máximo $8 \%$, mesmo que este sinal esteja na presença de um segundo sinal proveniente de uma célula adjacente e que tenha intensidade $35 \mathrm{~dB}$ maior que o primeiro na posição onde se encontra o dispositivo. Assim, células vizinhas convivem sem prejudicar o desempenho de uma ou de outra, o que garante um funcionamento bastante confiável da rede, dado que a configuração ideal seja respeitada.

No entanto, a prática mostra que essa configuração é rara. Primeiro porque a instalação de PAs que fornecem acesso a uma rede em uma determinada área é feita sem um controle central e organizador, cada PA pertencendo a um proprietário diferente que pouco sabe sobre outros PAs presentes. Segundo porque em certos ambientes como esco- 


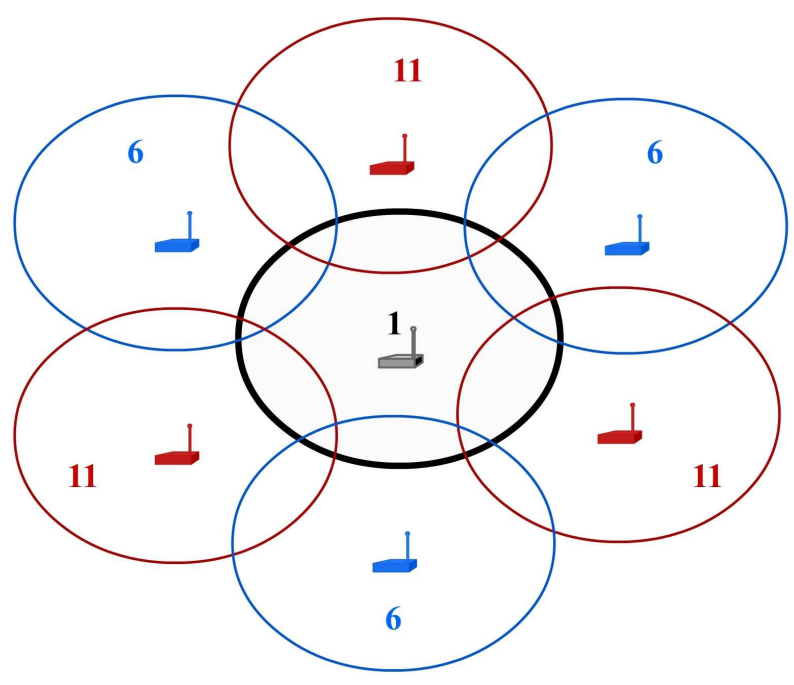

Figura A.4: Configuração ideal para implementação de redes vizinhas.

las, escritórios ou shopping centers a quantidade de PAs presentes pode ser muito grande e é comum que mais do que 3 células se sobreponham. De fato, encontra-se significativo número de trabalhos onde se obteve em experimentos uma média de 4 a 6 redes presentes em cada observação ou medição (HAEBERLEN et al., 2004; YOUSSEF; AGRAWALA, 2005). Mesmo no presente trabalho, ao construir-se um mapa de uma área de um prédio universitário, encontraram-se pontos onde se observava até 11 redes presentes.

Em um cenário assim, passam a ser consideradas algumas possíveis situações. A primeira delas é a de células que ocupam um mesmo espaço e utilizam canais com separação menor que a largura da banda, sendo $5 \mathrm{MHz}$ o pior caso. Mesmo que o próprio aparelho escolha automaticamente o canal a transmitir (o que se supõe implicar numa escolha ótima, dada a configuração das redes presentes), com 11 redes presentes é bastante possível que essa situação aconteça. Neste caso, o que se vê é que quadros transmitidos ao mesmo tempo em canais vizinhos até conseguem chegar a seus destinatários, já que a técnica de espalhamento espectral torna possível extrair o sinal mesmo assim, mas a taxa de erro de quadros deve aumentar muito, fazendo com que a taxa efetiva de transmissão de dados na rede caia consideravelmente.

O segundo cenário é o de células ocupando o mesmo espaço físico e transmitindo no mesmo canal. Isso pode acontecer de duas formas. A primeira delas é quando os PAs estão separados por uma distância que permite que um "sinta" a presença do outro. A figura A.5-a representa essa configuração. Se o aparelho escolhesse automaticamente provavelmente não escolheria um canal ocupado e essa configuração não aconteceria nunca (ou, ao menos, seria rara). Mas há muitos PAs em que a escolha de canal só pode ser feita 


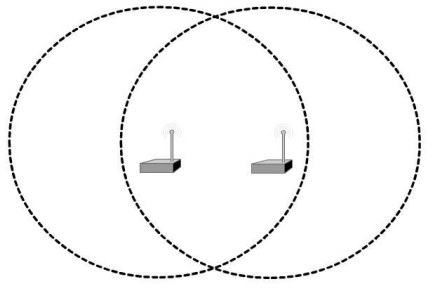

(a)

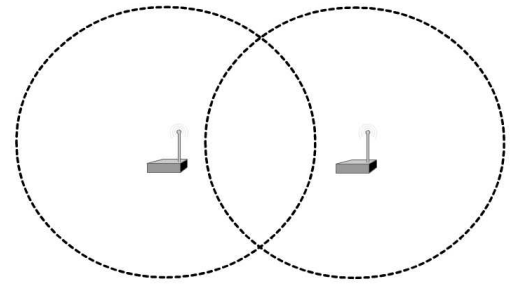

(b)

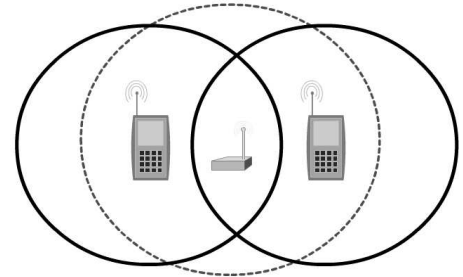

(c)

Figura A.5: Utilização de mesmo canal no mesmo espaço físico.

manualmente e, neste caso, essa configuração passa a ser bastante possível. Numa situação como essa, o sistema até funcionaria bem, já que a política de controle do meio, sendo descentralizada como foi descrita anteriormente, permite que as duas redes coexistam sem colisões freqüentes. No entanto, o problema que se cria é o de aumento de tráfego e conseqüente queda da taxa de transmissão aparente. A influência do congestionamento de uma rede no sucesso do rastreamento realizado nela por um dispositivo móvel será explorada nos itens a seguir.

A segunda forma de duas redes ocuparem o mesmo canal em um mesmo espaço físico acontece no caso exemplificado pela figura A.5-b. Nela há dois PAs que não "sentem" um ao outro por estarem a uma distância maior que o alcance da sua sensibilidade e, no entanto, geram uma área entre eles em que o sinal de ambos coexiste. Esta configuração pode acontecer mesmo que o ambiente não esteja sobrecarregado de redes, bastando para isso que os administradores de cada uma delas não tenha conhecimento da outra. Neste caso, quando houver uma transmissão simultânea, os sinais interferirão inevitavelmente um com o outro e os quadros chegarão corrompidos aos seus destinatários. Estes por sua vez não retornarão os correspondentes ACK e a transmissão passa a se repetir até que os emissores do sinal concluam que os dispositivos destinatários não estão mais presentes. Isso deve fazer com que o sinal deixe de ser enviado. Um caso semelhante pode acontecer também com dois dispositivos móveis em vez de dois PAs, como mostrado na figura A.5c. Se esse tipo de colisão acontecer no momento do rastreamento da rede, ao dispositivo móvel parecerá que a rede em questão não está presente. Como não se pode prever quando ocorrerá este tipo de colisão, também não se pode prever quando aparentará estar presente ou não uma determinada rede sujeita e tais configurações. 


\section{A.2.2.2 Extensões da especificação 802.11}

As extensões mais implementadas e, por isso, mais importantes para este trabalho são: 802.11a, 802.11b, 802.11g (IEEE, 1999a, 1999b, 2003). Todas as três especificam uma ou mais formas de aumentar a taxa de transmissão de dados utilizando banda larga com espalhamento espectral. A primeira difere das outras duas por utilizar uma faixa de freqüência diferente, acima de $5 \mathrm{GHz}$ (8 canais entre $5.150 \mathrm{MHz}$ e $5.350 \mathrm{MHz}$, e 4 canais entre $5.725 \mathrm{MHz}$ e $5.825 \mathrm{MHz}$ segundo o padrão americano), o que implica menor interferência (inclusive pelo fato de que, dentro desta faixa, os canais de transmissão foram especificados de forma a apresentar menos sobreposição), mas que tem a desvantagem de ser mais facilmente absorvida por obstruções no caminho, o que restringe seu uso a espaços mais abertos ou a células menores. Além de não apresentar essas desvantagens, 802.11b aos poucos tomou conta do mercado pelo fato de utilizar uma tecnologia parecida com a CDMA utilizada em celulares (SCHILlinG; PICKHOLTZ; MILSTEIN, 1990) o que garantia uma infra-estrutura para produção de chipsets que podia ser aproveitada. No entanto, a taxa de transmissão que se atingia com 802.11 b era cerca de 5 vezes menor que aquela que se atingia com 802.11a (que, por sua vez, tem uma taxa relativamente alta devido à modulação empregada - OFDM).

Uma evolução foi então a extensão 802.11g, que usava a mesma faixa de RF da 802.11b $(2.4 \mathrm{GHz})$ e ao mesmo tempo implementava a tecnologia de transmissão da 802.11a (com modulação OFDM). Para entrar no mercado, no entanto, dispositivos que implementam 802.11g garantem compatibilidade com 802.11b, o que tem uma conseqüência: se houver na rede algum dispositivo usando 802.11b, todos que usam 802.11g passam a funcionar com a modulação mais lenta.

O conjunto de taxas de transmissão suportadas por cada uma das extensões é diferente. A especificação 802.11 original previa duas taxas de transmissão possíveis: de $1 \mathrm{Mbits} / \mathrm{s}$ e $2 \mathrm{Mbits} / \mathrm{s}$. Com o esquema de modulação proposto, a extensão 802.11a especifica taxas de transmissão que vão do $6 \mathrm{Mbits} / \mathrm{s}$ a $54 \mathrm{Mbits} / \mathrm{s}$. Já a $802.11 \mathrm{~b}$, especifica uma modulação que permite taxas de $5.5 \mathrm{Mbits} / \mathrm{s}$ e $11 \mathrm{Mbits} / \mathrm{s}$. Por fim, a extensão $802.11 \mathrm{~g}$ possibilita as mesmas taxas de transmissão especificadas em 802.11a e 802.11b, além de algumas outras intermediárias.

Para que um dispositivo perceba o sinal de um determinado PA, mesmo que sua placa seja compatível com todas as extensões, o PA deve transmitir segundo a mesma extensão para a qual o dispositivo está configurado. É possível alterar dinamicamente a configuração do modo de transmissão e recepção da placa, possibilitando o rastreamento de redes 
em cada uma das extensões, mas isso torna o processo mais dispendioso e praticamente inviável para o emprego em um serviço de localização. Portanto, ao desenvolver um serviço de localização em redes Wi-Fi é importante garantir que todos os PAs do ambiente trabalhem com a mesma extensão.

\section{A.2.2.3 Considerações sobre tempo de transmissão de quadros e sobrecarga de uma rede}

Como foi mencionado no item anterior, é raro nos dias de hoje encontrar um aparelho Wi-Fi que não implemente alguma das extensões descritas. Como os aparelhos 802.11b normalmente trabalham a $11 \mathrm{Mbits} / \mathrm{s}$, é razoável dizer que a taxa de transmissão mínima em redes Wi-fi deve ser de $11 \mathrm{Mbits} / \mathrm{s}$, o que deve ser o caso mais comum já que aparelhos da extensão 802.11 g costumam se adaptar ao limite da 802.11 b, e cada vez menos se encontram aparelhos 802.11a.

Com essa informação, pode-se então estimar o tempo de duração de um processo de rastreamento ativo de um canal Wi-Fi. A camada PHY acrescenta a cada quadro MAC que envia, um preâmbulo de 144 bits (que serve para sincronização) e um cabeçalho de 48 bits onde se define a modulação e a taxa de transmissão utilizada para o quadro. Esses bits são enviados a uma taxa de $1 \mathrm{Mbit} / \mathrm{s}$ independentemente da taxa de transmissão do resto do quadro. Assim, a transmissão do preâmbulo e do cabeçalho deve levar cerca de $100 \mu$ s. O quadro de gerenciamento MAC Probe Request deve ter cerca de 70 bytes, enquanto que o quadro Probe Response deve ter cerca de 100 bytes. A uma taxa de $11 \mathrm{Mbits} / \mathrm{s}$, o envio de um quadro do primeiro tipo (somente o quadro MAC) deve levar cerca de $50 \mu \mathrm{s}$ e do segundo cerca de $75 \mu \mathrm{s}$. A especificação determina que o tempo da propagação no ar de um sinal pode ser considerado como de $1 \mu \mathrm{s}$. Ainda há outros tempos a serem levados em conta como a troca do estado da antena (de transmissão para recepção e vice-versa) entre outros que somados não levam mais que $30 \mu \mathrm{s}$. Assim, uma troca de quadros no processo de rastreamento de um canal onde há apenas um PA deve levar cerca de $390 \mu \mathrm{s}$, sem contar o processamento interno nos aparelhos, nem os atrasos ocasionados por tráfego na rede ou erro nos quadros. Para um caso extremo onde há, num determinado ponto do espaço, 3 PAs sintonizados no mesmo canal, o tempo para o envio do Probe Request e das 3 respostas não deve chegar a $800 \mu$ s.

Quando um dispositivo pede um rastreamento da rede, as camadas MAC e PHY fazem com que, para cada canal, o dispositivo emita um Probe Request e durante um tempo pré-determinado espere, "sentindo" o meio para receber a(s) resposta(s). Como será explicado com mais detalhes na próxima seção, o menor tempo de espera que se 
consegue em um aparelho comum é de $10 \mathrm{~ms}$ (devido a limitações do hardware). Este tempo deve ser mínimo de forma que o maior número de rastreamentos possa ser efetuado em um intervalo de tempo e assim mais informação esteja disponível para o sistema de localização. Uma espera de 10ms é cerca de 13 vezes mais do que o necessário para o pior caso descrito no parágrafo anterior, o que indica que não deve haver qualquer problema, e os rastreamentos devem sempre ser bem sucedidos.

Não obstante essas considerações serem corretas considerando uma rede com baixo tráfego e baixa taxa de erros, o panorama fica um pouco diferente quando se mudam as premissas. Imagine uma rede onde existe um dispositivo que esteja transmitindo dezenas de Kbytes de dados (o que é um caso bastante comum). Neste caso, para minimizar as sobrecargas dos cabeçalhos adicionados por cada camada, admite-se que os quadros transmitidos devem ter o tamanho máximo que, sem os adendos gerados pela PHY, é de 2344 bytes segundo a especificação. Um quadro desses transmitido a 11Mbits/s deve demorar cerca de $1.8 \mathrm{~ms}$. Suponha-se que as transmissões aconteçam intercaladas: 1 quadro de dados, 1 quadro de gerenciamento. Neste caso, o processo todo de troca de quadros de rastreamento, quando há apenas um PA no canal, deve levar cerca de $4 \mathrm{~ms}$. Se houver 2 PAs, cerca de 6ms, se houver 3 PAs, cerca de $8 \mathrm{~ms}$. Como a ordem dos quadros não é controlada por nenhum agente central, é estatisticamente esperado este tempo, vez ou outra, ultrapasse os $10 \mathrm{~ms}$.

Considere agora a possibilidade de haver 3 dispositivos transmitindo dados em um canal ao mesmo tempo. Usando o mesmo raciocínio de transmissões intercaladas de quadro, o processo de rastreamento desse canal, quando há apenas um PA, deve levar cerca de 11ms! E um detalhe é interessante de ser mencionado aqui: quanto mais redes sintonizadas num mesmo canal, maior a chance de mais dispositivos estarem transmitindo dados ao mesmo tempo.

Outra situação interessante é quando acontecem transmissões de dados simultâneas em canais adjacentes. Neste caso, é possível que a taxa de erro chegue a $50 \%$ ou mais. Se isso acontecer, o que levava $4 \mathrm{~ms}$ passa a levar $8 \mathrm{~ms}$. Logicamente, fica muito mais fácil atingir um nível de tráfego que faça o processo de rastreamento levar mais que 10ms.

Quando o processo de rastreamento de um canal leva mais que o tempo de espera (que está sendo considerado aqui para efeito de argumentação como sendo de $10 \mathrm{~ms}$ ), o dispositivo muda de canal antes da chegada do quadro de resposta, parecendo para ele que a rede não respondeu, ou seja, que seu sinal não estava presente. Assim, fica claro que a freqüência da presença do sinal de um determinado PA em rastreamentos feitos 
por um dispositivo numa posição fixa pode muito bem não ser constante no tempo e é dependente de fatores imprevisívies, como o aumento de tráfego no próprio canal do PA ou em canais adjacentes, ou como a ocorrência de colisões na transmissão simultânea feita por aparelhos que não se "sentem", como foi explicado no item A.2.2.1.

\section{A.3 Hardware e Drivers}

A implementação da especificação 802.11 é feita através de placas Wi-Fi e seus respectivos drivers. Os primeiros costumam corresponder à PHY (algumas vezes, somente à subcamada PMD), e os últimos, por sua vez, correspondem à sub-camada MAC, podendo conter a também a implementação da sub-camanda PLCP da PHY.

Duas são as características mais importantes para definir a qualidade de uma placa Wi-Fi de dispositivo móvel - e seu chipset - para ser usada em um serviço de localização: a exatidão das medidas de RSSI e a sensibilidade de recepção do sinal.

Como já foi dito neste trabalho, a potência de um determinado sinal tem um comportamento bastante imprevisível. Assim, é muito difícil medir a exatidão das medidas de RSSI de um determinado chipset. Além disso, essa informação não é particularmente relevante para o usuário comum e por isso ela é uma característica que nunca é descrita nas especificações técnicas.

A sensibilidade de recepção - que corresponde à mínima potência que deve ter um sinal ao chegar na antena receptora para que o chipset consiga identificá-lo - já é uma informação que se encontra em algumas das especificações, mas não em todas. Seria possível testar o desempenho de um conjunto de chipsets em relação a essa característica, mas para isso seria necessária uma disponibilidade de hardware e de tempo que excedia as condições deste trabalho. Para definir então a escolha do hardware a ser usado no desenvolvimento de experimentos seria necessário recorrer a outras referências.

Uma fonte que se pode usar são listas de dispositivos recomendados por empresas que comercializam serviços de localização Wi-Fi, como a Ekahau. Em sua lista, a Ekahau mostra uma preferência clara por chipsets Atheros, mas também são citados dispositivos compostos por chipsets Cisco, Centrino e Agere (EKAHAU, 2006).

Outra característica importante para a escolha de um hardware é a existência de um bom driver para Linux, o que abre a possibilidade de eventuais ajustes já que seu código fonte é aberto, e um bom driver para Windows que é o sistema operacional mais encontrado. A lista de Langfeldt (2007) mostra que tanto o Atheros quanto o Centrino 
têm boas opções de drivers para Linux. Em relação ao Windows, o próprio sistema operacional fornece drivers para praticamente todos os chipsets e placas disponíveis. No entanto, como veremos mais adiante, há indícios de que tais drivers não se adequam bem à localização Wi-Fi. Uma solução seria utilizar os drivers desenvolvidos pela Ekahau, o que remete novamente à lista de chipsets recomendados para seu produto.

Três questões que concernem à implementação da especificação 802.11 devem ser respondidas para uma melhor compreensão do problema de localização em redes Wi-Fi. Primeiro, qual a maior freqüência de rastreamento possível? Essa é uma pergunta de interesse geral para localização Wi-Fi, independentemente da arquitetura escolhida. Ela é importante pois se o intervalo entre observações for muito grande, a suposição de que se podem considerar possíveis apenas as transições correspondentes a arestas do mapa topológico (ver item 3.2) não se sustenta.

A segunda questão é relevante para um serviço de localização Wi-Fi com uma arquitetura distribuída: pode-se fazer um rastreamento de redes estando associado a alguma rede específica? Isso é importante porque, como se viu na seção anterior, para enviar mensagens à rede, um dispositivo tem que estar associado. A arquitetura distribuída discutida na primeira seção deste capítulo depende de que sejam intercaladas observações de RSSIs e trocas de mensagens entre o dispositivo móvel e um servidor. Como a idéia mais óbvia é usar o rastreamento como forma de obter as observações, essa é uma pergunta essencial.

A terceira pergunta é como se comporta o processo de rastreamento quando o dispositivo está em movimento? Nada disso está especificado e é dependente do funcionamento dos drivers. Por isso, uma série de análises foi feita para responder a essas questões e para isso utilizou-se um computador portátil Satelite 6500 que possui uma placa de rede com chipset Atheros RX5004G. Os testes foram feitos em um sistema operacional Windows XP e em um Linux 2.4.25. Uma breve discussão decorrente deste testes é apresentada a seguir. No fim dessa seção é ainda apresentada uma análise da sensibilidade do aparelho utilizado nos testes.

\section{A.3.1 A rede sem fio no Windows}

No Windows, o driver já vem instalado. O sistema operacional oferece uma interface de comunicação com ele chamada NDIS (Network Driver Interface Specification). Ela é na verdade uma interface que permite a comunicação com a LME dos drivers de cada uma das placas de rede instaladas numa determinada máquina. A forma de um processo se 
comunicar com uma determinada LME consiste em pedir à NDIS que estabeleça uma associação entre o processo e a LME desejada, e a partir de então todas as requisições feitas à NDIS são repassadas diretamente à LME associada ao processo. É um esquema versátil que permite que diferentes dispositivos de rede sejam gerenciados com uma mesma interface, mas ele tem um problema. Quando uma LME é relacionada a um processo, nenhum outro processo pode acessá-la enquanto este processo estiver ativo. No Windows $\mathrm{XP}$, há um daemon que se associa à LME do driver da rede sem fio, e ele deve ser terminado para que outro processo possa usá-lo, o que é um inconveniente.

Inconvenientes a parte, desenvolveu-se um programa que, através da NDIS, pede um rastreamento da rede e grava as respostas em um arquivo residente em outra máquina da rede. Isso provoca que, a cada iteração, o programa acesse a rede. O programa operou sem problemas, o que responde à segunda questão levantada no item anterior.

Quanto à primeira e à terceira questões, aparentemente neste caso, elas estão de certa forma relacionadas. É possível, através do programa descrito, que se façam dezenas de rastreamentos por segundo. Mas o que se nota quando isso é feito é que o menor intervalo durante o qual um valor observado de uma RSSI permanece constante é de 0,5 segundos. E ao se caminhar com o dispositivo enquanto ele realiza suas medidas de observação, percebe-se uma estranha latência na mudança do valor da RSSI. Essas informações foram obtidas depois da realização de horas de testes. Isso tudo leva a crer que o driver faz algum tipo de média das observações obtidas, ou que elimine RSSIs que pareçam estar fora de um intervalo esperado. Isso, sem dúvida, prejudica muito o desempenho de um serviço de localização Wi-Fi.

Buscou-se então uma alternativa que foi instalar um driver desenvolvido pela Ekahau. Com ele, o menor intervalo observado sem mudança foi 0,1 segundos e a latência diminui consideravelmente, mas uma comparação com testes realizados no Linux mostrou problemas que serão discutidos no final desta seção.

\section{A.3.2 A rede sem fio no Linux}

Para usar a placa de rede no Linux, foi necessário instalar um módulo contendo o driver. O driver utilizado é um projeto de fonte aberta chamado MadWifi (MADWIFI, 2006). Instalado o módulo, pode-se usar a interface que o sistema operacional oferece ou a interface própria do driver para configurá-lo.

Um programa semelhante ao descrito no item anterior foi desenvolvido também para 
o Linux e testes foram executados, mas o mesmo problema apresentado no Windows foi também observado. Para buscar uma melhor compreensão do que acontece, seguiu-se uma análise dos quadros de baixo nível que chegam à placa de rede.

Os acessos às placas de rede no Linux são feitos através de sockets. O socket é uma abstração que representa um repositório de dados a serem recebidos ou transmitidos através da rede. Ele pode representar uma porta TCP/IP ou de outro protocolo, assim como pode representar também uma interface de quadros de baixo nível. Esse último tipo de socket é chamado PF_PACKET. Um quadro que chega a um determinado PF_PACKET atrelado a uma placa Wi-Fi é composto pelo quadro MAC (que pode ser de dados, de gerenciamento ou de controle) e mais um cabeçalho que contém basicamente as informações passadas da PHY para a MAC (dentre as quais está a RSSI do quadro, como explicado na seção anterior).

Utilizando um socket do tipo PF_PACKET, simulou-se o que seria um rastreamento passivo e observou-se que a latência descrita no item anterior praticamente desapareceu. No entanto, essa solução apresenta dois problemas. O primeiro é que o acesso à rede fica obstruído pois o driver tem que ser colocado em um modo chamado "monitor", que não aceita transmissão de dados. O segundo problema é que um rastreamento ativo seria mais indicado para monitorar todos os canais.

Decidiu-se então que seria mais correto tentar uma alteração no driver. A análise do código mostrou que o programa original de fato faz com que os valores apresentados para as RSSIs de cada um dos PAs não se alterem com freqüência. A razão desse comportamento é que o driver retorna uma média ponderada entre cada novo valor observado e o último valor calculado da RSSI de cada PA, onde o peso do valor antigo é bastante maior que o do valor observado (9 vezes). Isso explica a latência observada e mencionada anteriormente. Modificou-se então este comportamento, fazendo com que, a cada pedido de rastreamento, o driver retornasse, para um determinado PA, o valor da RSSI observada no último quadro Beacon ou Probe Request recebido.

Além disso, para que possa analisar todos os canais, a cada pedido de rastreamento, o driver original faz com que a placa Wi-Fi fique "escutando" cada um deles por um tempo relativamente longo. Diminui-se esse tempo para cerca de $10 \mathrm{~ms}$, o que se aproxima do valor de um jiffie, ou seja, do tempo entre duas interrupções de clock do computador. Esse tempo é o limite mínimo dos temporizadores (ou, timers) do sistema operacional, e por isso é o limite do tempo de permanência em um canal durante o rastreamento. É interessante observar que a limitação aqui notada é imposta por uma parte do hardware 
que não tem relação direta com a placa Wi-Fi. Pelo que foi descrito no final da seção anterior, segundo a especificação 802.11 seria possível que o tempo de permanência em cada canal fosse ainda menor.

Com o tempo de permanência em cada canal de cerca de $10 \mathrm{~ms}$, os rastreamentos podem de ser feitos em intervalos de $130 \mathrm{~ms}$ a $140 \mathrm{~ms}$, que é o tempo necessário para rastrear 13 canais $^{1}$. Neste trabalho, utilizou-se um intervalo de $150 \mathrm{~ms}$ entre os rastrementos.

\section{A.3.3 Comparação entre plataformas para a realização de expe- rimentos}

A escolha do sistema operacional para a realização dos testes foi feita baseada na comparação do comportamento dos drivers para redes sem fio em cada um dos casos. No caso do Windows, como o desenvolvimento de drivers é relativamente mais complicado e o foco deste trabalho é o sistema de localização, concluiu-se que não haveria tempo necessário e optou-se por apenas utilizar drivers que já existissem e estivessem disponíveis. Como mencionado anteriormente, o driver desenvolvido pela Ekahau apresentou um comportamento melhor em relação ao driver original do sistema operacional. No entanto, comparando o comportamento de seqüências de RSSIs observadas com esse driver às seqüências obtidas com o driver modificado do Linux, o comportamento ainda mostrou não ser satisfatório. Para sustentar essa afirmação, a tabela A.1 mostra trechos de duas seqüências de RSSI observadas de um determinado PA, a primeira obtida no Windows, a segundo no Linux, com o computador na mesma posição.

Deve-se primeiro considerar que a seqüência obtida no Linux tem o comportamento que pode ser usado como referência para a análise, já que, com o driver modificado, cada RSSI da seqüência representa de fato a observação mais recente possível (como foi explicado no item anterior). Comparando-se os dois trechos apresentados, nota-se primeiro que as seqüências apresentam médias diferentes. Isso acontece porque um driver, ou mesmo o chipset da placa Wi-Fi, não fornece necessariamente a informação da potência calculada em dBms, mas um valor relacionado a essa potência segundo suas próprias especificações (BARDWELL, 2007). Isso não deve ter importante relevância como fator de escolha, já que o intervalo de RSSI escolhido não deve ter influência no desempenho do sistema da forma como ele foi apresentado - desde que o RSSI passado pelo driver tenha

\footnotetext{
${ }^{1}$ Como a requisição de rastreamento deve chegar no intervalo entre duas interrupções de clock, o temporizador que controla a "escuta" do primeiro canal a ser rastreado é configurado para gerar a interrupção dois jiffies a frente do tempo da máquina no momento da requisição. Por isso o rastreamento pode demorar até $140 \mathrm{~ms}$.
} 
Tabela A.1: Trechos de seqüências de RSSIs observadas no Linux e no Windows.

\begin{tabular}{|c|c|c|c|c|c|c|c|c|c|c|c|c|c|c|c|}
\hline & $t_{0}$ & $t_{1}$ & $t_{2}$ & $t_{3}$ & $t_{4}$ & $t_{5}$ & $t_{6}$ & $t_{7}$ & $t_{8}$ & $t_{9}$ & $t_{10}$ & $t_{11}$ & $t_{12}$ & $t_{13}$ & $t_{14}$ \\
\hline \hline Linux & -90 & -89 & -91 & -89 & -91 & -85 & -81 & -95 & -85 & -85 & -87 & -89 & -87 & -88 & -87 \\
\hline Windows & -78 & -78 & -78 & -78 & -78 & -78 & -77 & -77 & -77 & -77 & -75 & -75 & -75 & -75 & -76 \\
\hline
\end{tabular}

uma relação linear com a potência medida em dBms, dimensão na qual a distribuição da potência deve se aproximar de uma função gaussiana (HASHEMI, 1993).

Mas nota-se então que a seqüência do Windows apresenta um comportamento anômalo caracterizado pelos tamanhos das subseqüências cujo valor de RSSI que se observa é o mesmo. Na seqüência obtida no Linux, o caso mais comum é que o valor observado de RSSI em um determinado instante seja diferente da próxima observação da seqüência, sendo que se mostra rara a ocorrência de 3 ou mais valores iguais consecutivos. Na seqüência do Windows, no entanto, 3 ou mais valores de RSSI iguais em seqüência é, como se pode notar, o caso mais comum. Isso sugere que o driver ainda esteja interferindo de alguma forma nos valores observados na recepção dos quadros. Como isso potencialmente deve afetar os resultados dos experimentos, definiu-se que os experimentos seriam desenvolvidos apenas no Linux, utilizando-se o driver modificado e descrito no item anterior.

\section{A.3.4 Análise da sensibilidade do aparelho utilizado nos experi- mentos}

A sensibilidade de uma placa Wi-Fi corresponde à RSSI do sinal menos potente que ela consegue detectar. No caso da placa com chipset Atheros RX5004G que foi utilizada nos experimentos deste trabalho, a sensibilidade especificada é de -96dBm. No entanto, existe um outro parâmetro importante para caracterizar a sensibilidade do aparelho, parâmetro que está sendo chamado neste trabalho de Limiar de Sensibilidade Absoluta (LSA). O LSA corresponde a um valor de média de distribuição de RSSI, de forma que, se a distribuição de RSSI de um determinado sinal tiver média igual ou maior ao LSA do aparelho em um ambiente sem interferências, o sinal deve ser percebido aproximadamente $100 \%$ das vezes. A figura A.6 ilustra o que acontece.

Considerando que a distribuição da RSSI de um sinal em um determinado ponto é dada por uma gaussiana, e como uma gaussiana é uma função que representa uma distribuição entre $-\infty$ a $+\infty$, parte dos sinais pertencentes a essa distribuição deve ficar fora do intervalo de sensibilidade de cada aparelho (existe um valor máximo de sensibilidade também, que no caso do chipset Atheros RX5004G não é especificado, mas que deve ficar em torno de $-20 \mathrm{dBm}$ ). Mas se o intervalo entre a média das RSSIs subtraída pelo desvio 

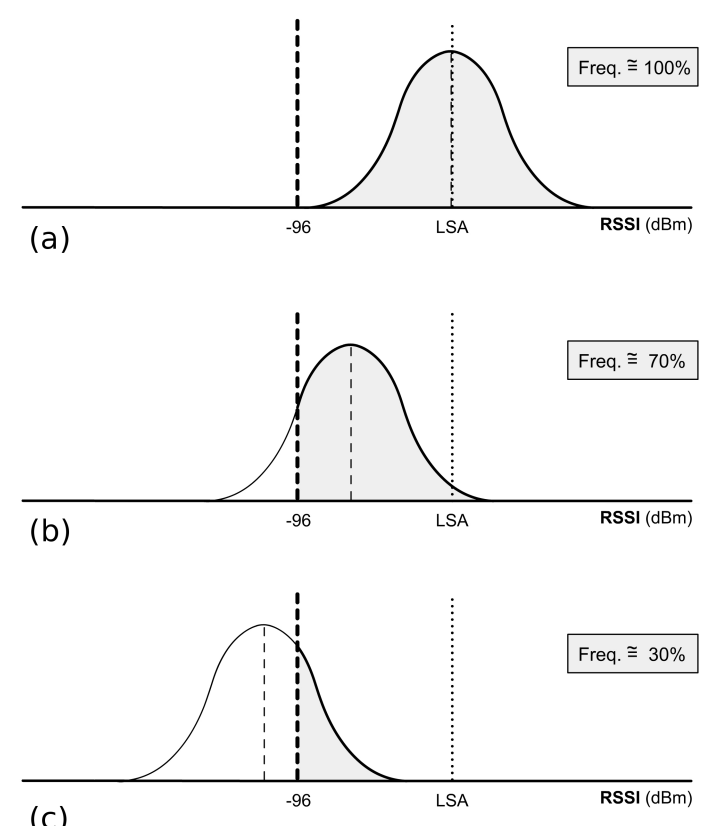

(c)

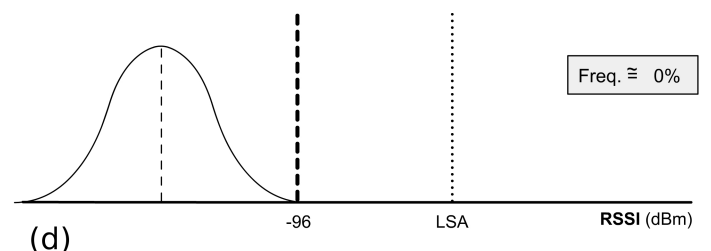

(d)

Figura A.6: Distribuições da RSSI de sinais que se aproximam da sensibilidade do aparelho. A área sombreada dividida pela área total da função corresponde à freqüência de presença do sinal.

multiplicado por três, e a média das RSSIs somada ao desvio multiplicado por três estiver contido no intervalo de sensibilidade do aparelho, a quantidade de sinais que não podem ser detectados é desprezível (aproximadamente 0,3\% para distribuições gaussianas). A figura A.6-a mostra uma distribuição de um sinal cuja média é igual ao LSA e verifica-se que o sinal é virtualmente sempre detectado (área hachurada). A figura A.6-b mostra uma distribuição de um sinal cuja média é menor que o LSA e verifica-se que o sinal é detectado cerca de $70 \%$ das vezes. A seqüência segue até a distribuição de um sinal que nunca é detectado pelo aparelho.

Para que pudesse ser utilizado na análise do ruído da informação recebida pelo sistema de localização (veja item 4.1.2), o LSA do aparelho utilizado foi determinado experimentalmente da seguinte forma. O aparelho foi posicionado em uma série de pontos de medida a diferentes distâncias de um PA em volta do qual não havia nem outros PAs nem trânsito de pessoas. Em cada ponto de medida foram realizadas 100 medições. Foi construído então um gráfico de pontos (figura A.7) onde cada ponto representa a média da RSSI em um ponto de medida - considerando apenas as medições em que o sinal estava presente 
- em função da freqüência de presença do sinal. Verifica-se que, a partir de $-85 \mathrm{dBm}$ de média, a freqüência começa a cair e por isso esse foi o valor estabelecido como o LSA do aparelho.

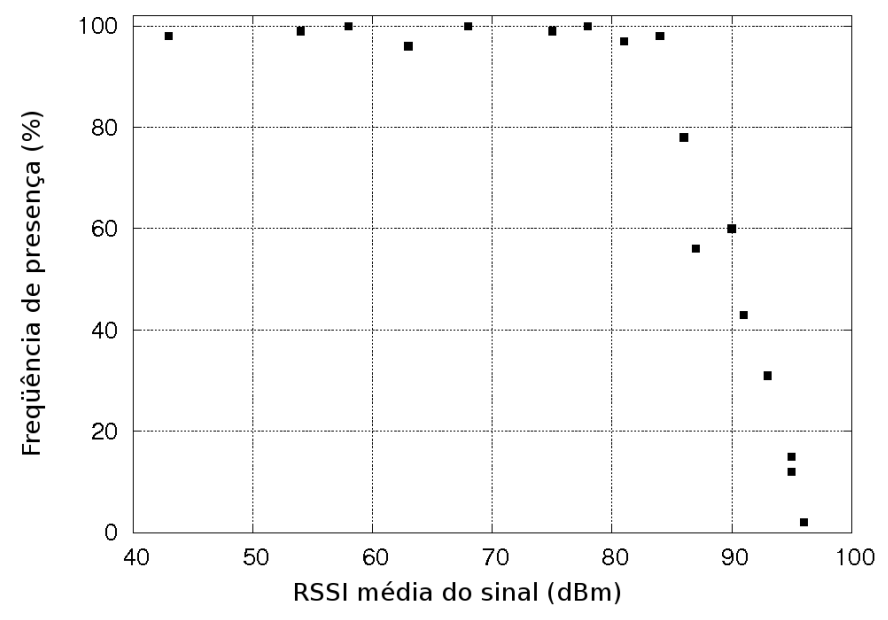

Figura A.7: Sensibilidade do aparelho usado nos experimentos. 


\section{Apêndice B - Resultados completos dos experimentos realizados}

Diversas medidas servem para avaliar o desempenho de um sistema de localização. Nos experimentos realizados neste trabalho, as medidas utilizadas foram: o erro médio das estimativas, a raiz do erro quadrático médio, a porcentagem de estimativas incorretas de célula de localização e o coeficiente de incerteza das estimativas (NEHMZOW, 2003). No capítulo 5 foram apresentados os resultados apenas em termos do erro médio das estimativas. Aqui são apresentados os resultados em função das outras medidas. 


\section{B.1 Testes preliminares}

Os resultados dos testes preliminares são apresentados nos 3 gráficos da figura B.1.
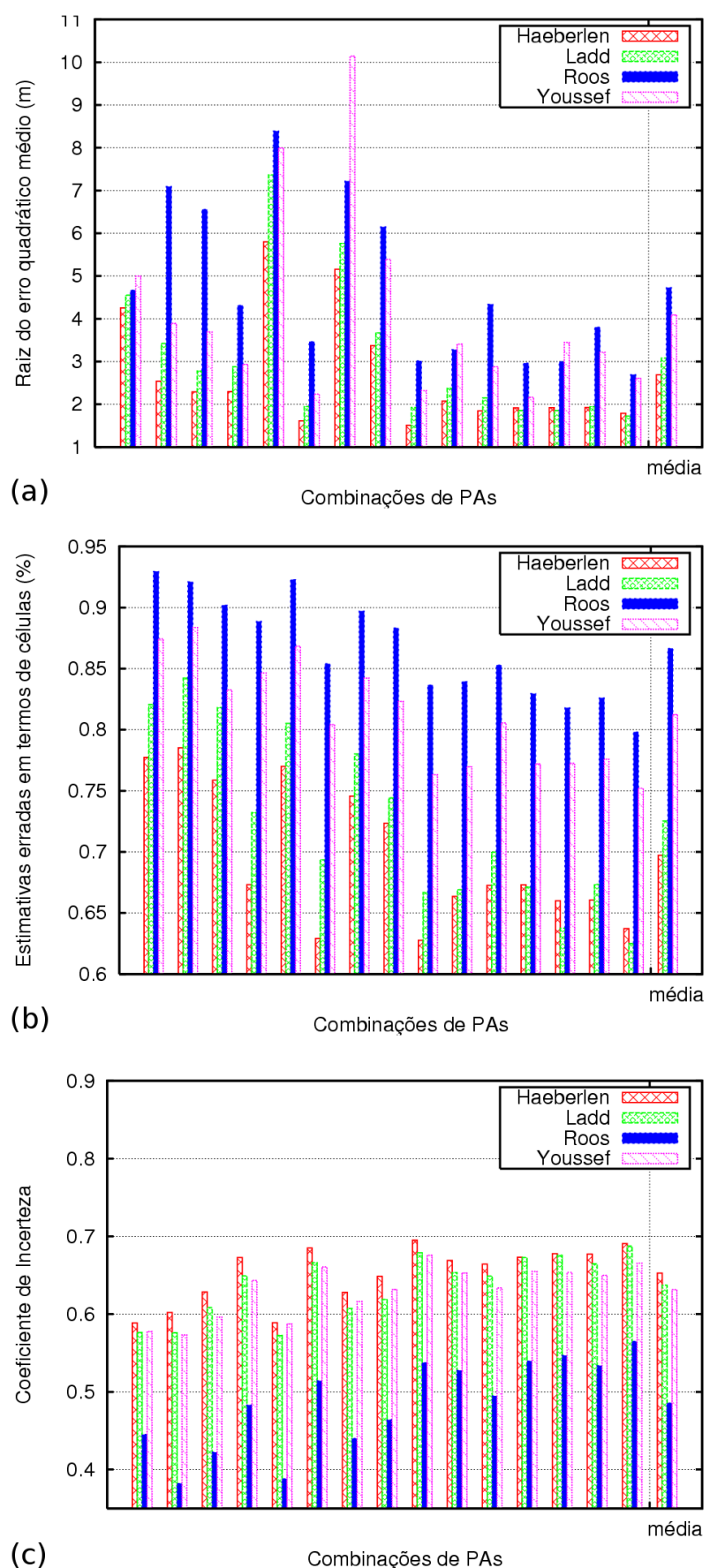

Figura B.1: Comparação de desempenho entre sistemas propostos na literatura em função de diferentes medidas: (a) raiz do erro quadrático médio; (b) porcentagem de estimativas incorretas de célula; e (c) coeficiente de incerteza. 


\section{B.2 Experimentos com dados simulados}

Os resultados dos experimentos com dados simulados são apresentados nas figura B.2 a B.6.
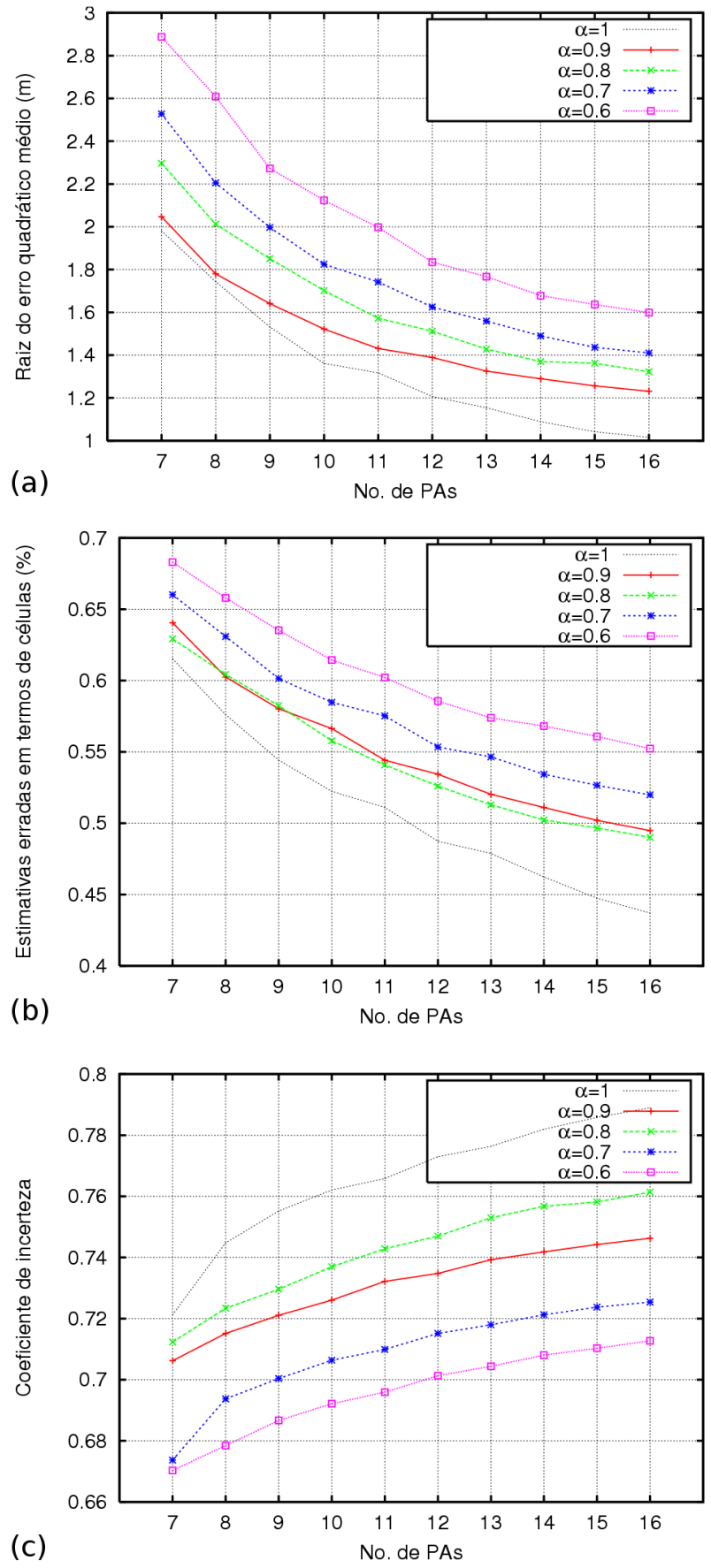

Figura B.2: Desempenho do sistema básico com dados simulados variando o coeficiente de correlação $\alpha$ em função de diferentes medidas: (a) raiz do erro quadrático médio; (b) porcentagem de estimativas incorretas de célula; e (c) coeficiente de incerteza. 

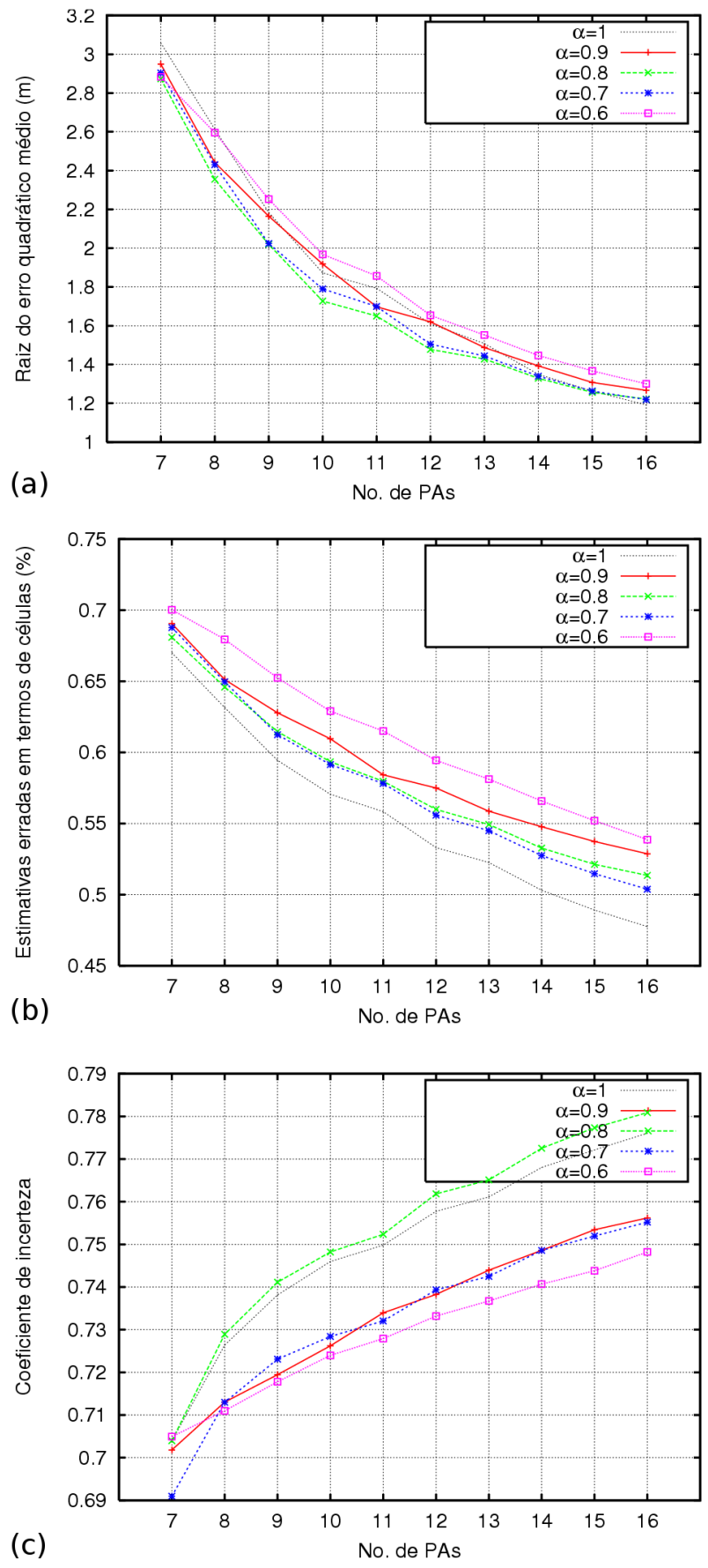

Figura B.3: Desempenho do WBLS com dados simulados variando o coeficiente de correlação $\alpha$ em função de diferentes medidas: (a) raiz do erro quadrático médio; (b) porcentagem de estimativas incorretas de célula; e (c) coeficiente de incerteza. 

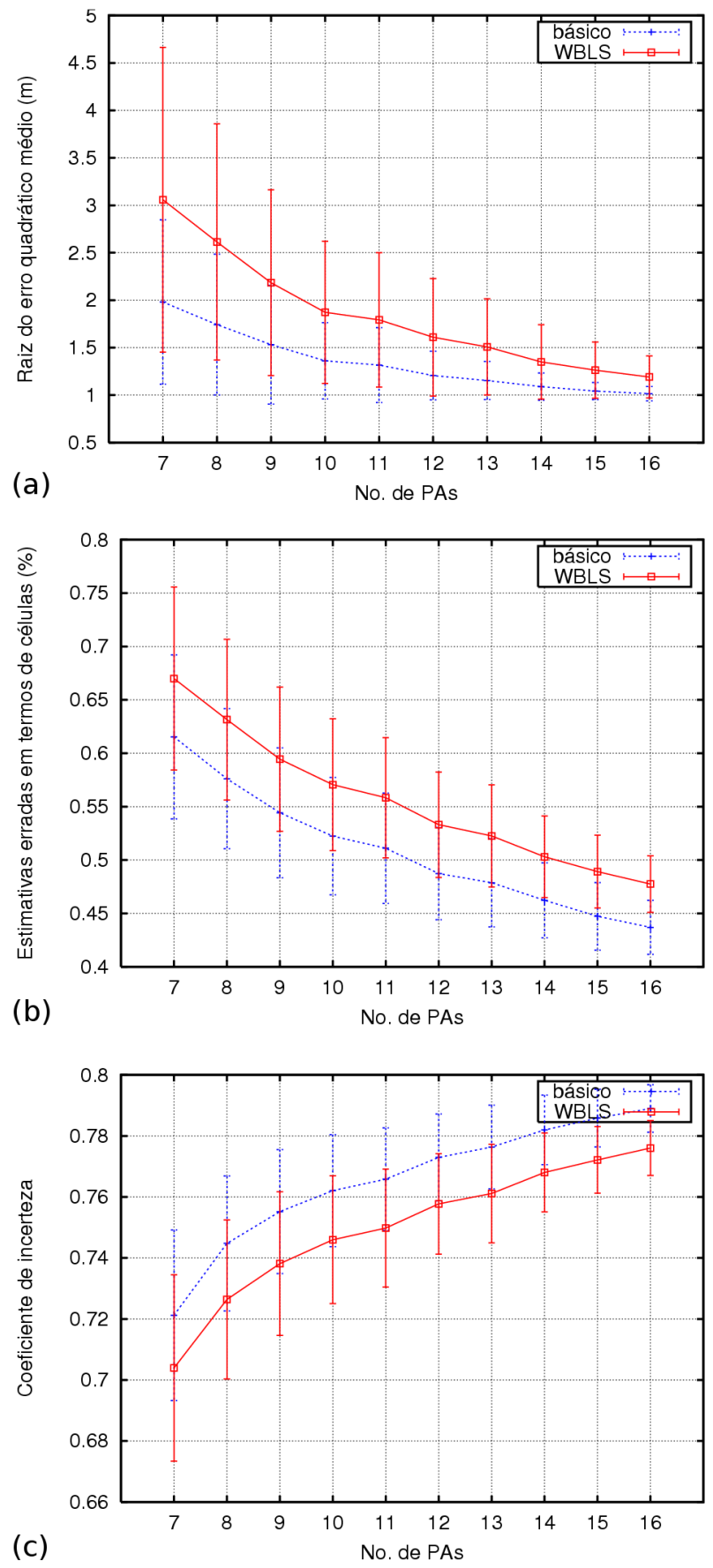

Figura B.4: Comparação de desempenho entre o WBLS e o sistema básico em caminhadas simuladas com $\alpha=1$, em função de diferentes medidas: (a) raiz do erro quadrático médio; (b) porcentagem de estimativas incorretas de célula; e (c) coeficiente de incerteza. 

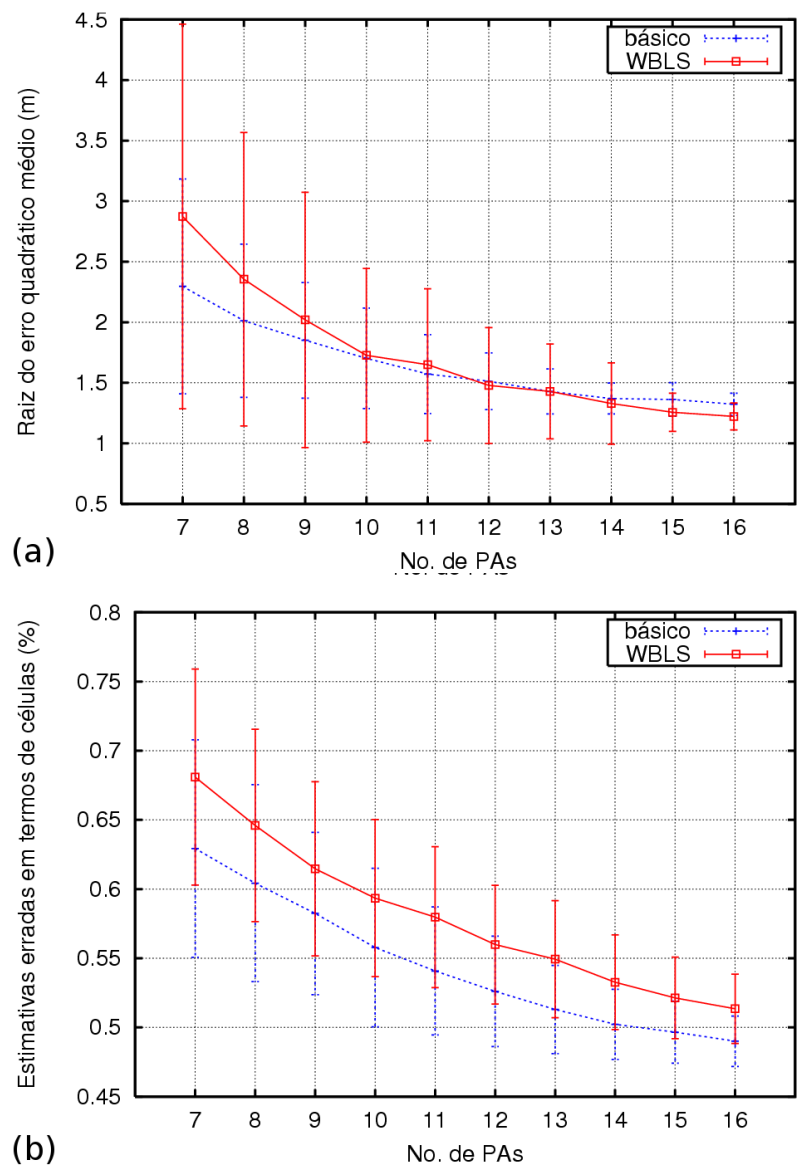

(b)

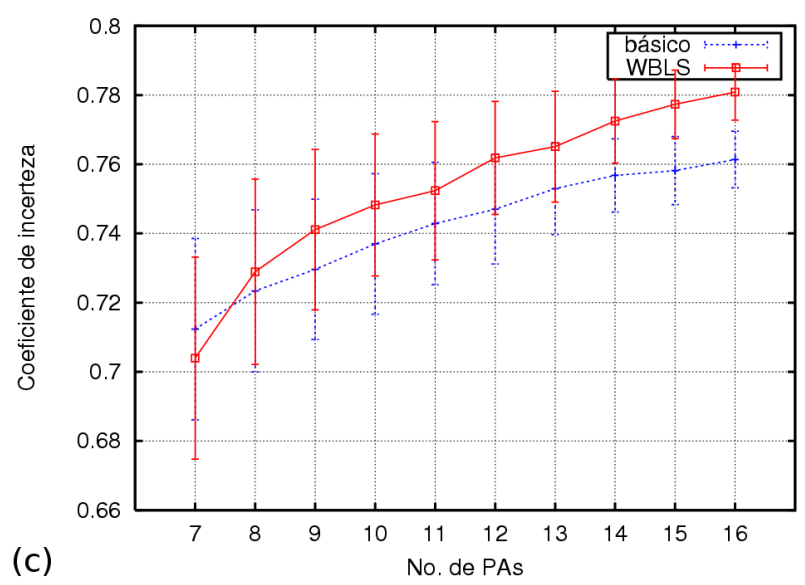

Figura B.5: Comparação de desempenho entre o WBLS e o sistema básico em caminhadas simuladas com $\alpha=0,85$, em função de diferentes medidas: (a) raiz do erro quadrático médio; (b) porcentagem de estimativas incorretas de célula; e (c) coeficiente de incerteza. 

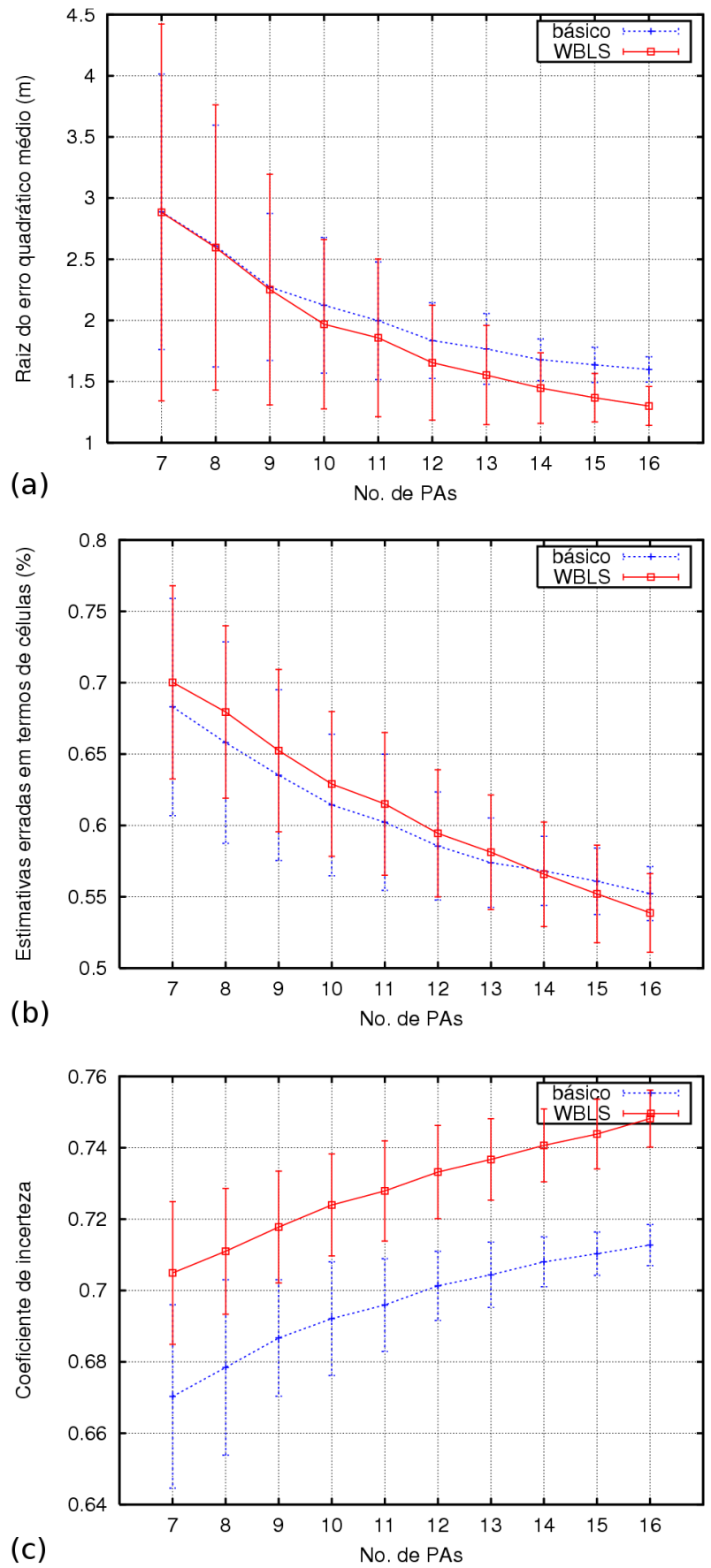

Figura B.6: Comparação de desempenho entre o WBLS e o sistema básico em caminhadas simuladas com $\alpha=0,75$, em função de diferentes medidas: (a) raiz do erro quadrático médio; (b) porcentagem de estimativas incorretas de célula; e (c) coeficiente de incerteza. 


\section{B.3 Experimentos em ambiente real}

Os resultados dos experimentos em ambiente real são apresentados nas figuras B.7 e B.8.
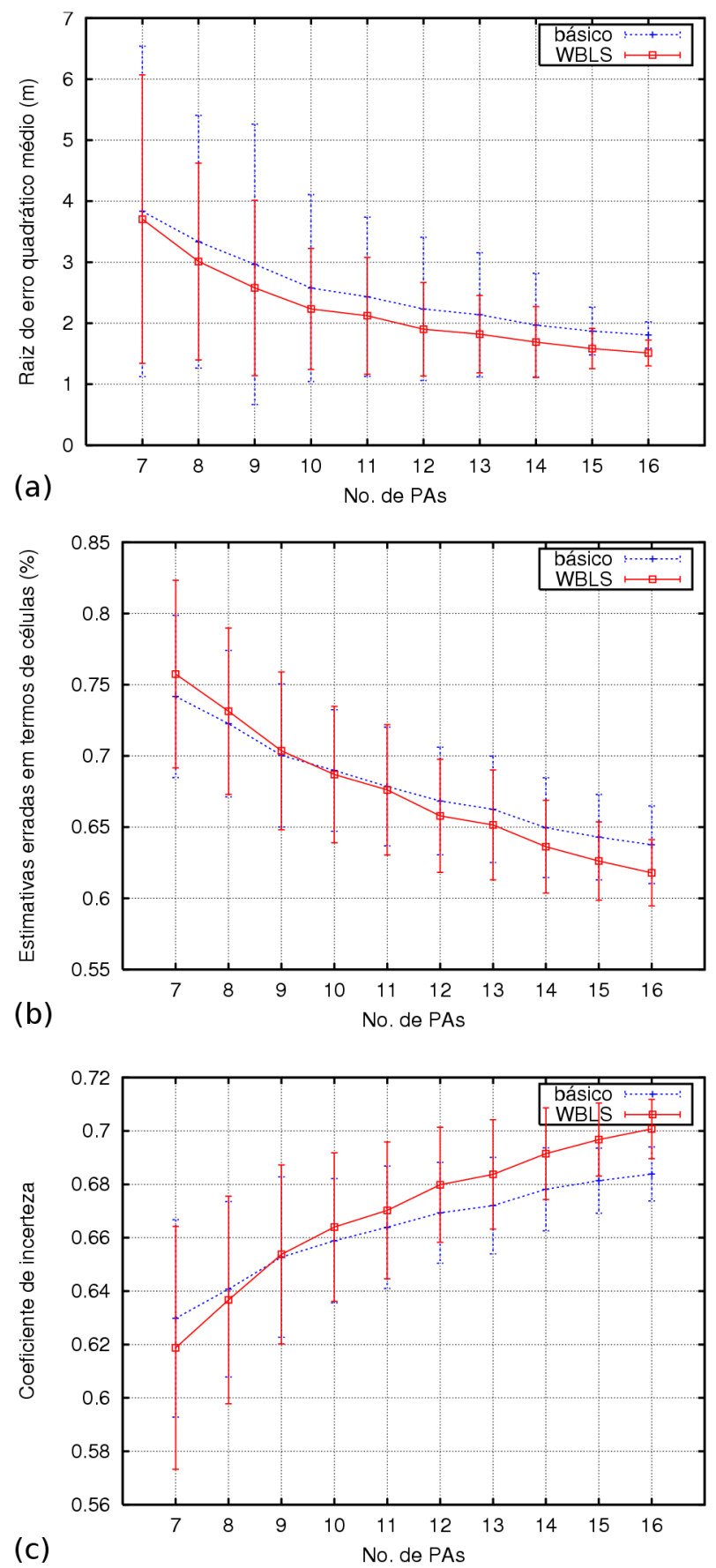

Figura B.7: Comparação de desempenho entre o WBLS e o sistema básico com dados de percursos realizados em ambiente real, em função de diferentes medidas: (a) raiz do erro quadrático médio; (b) porcentagem de estimativas incorretas de célula; e (c) coeficiente de incerteza. 

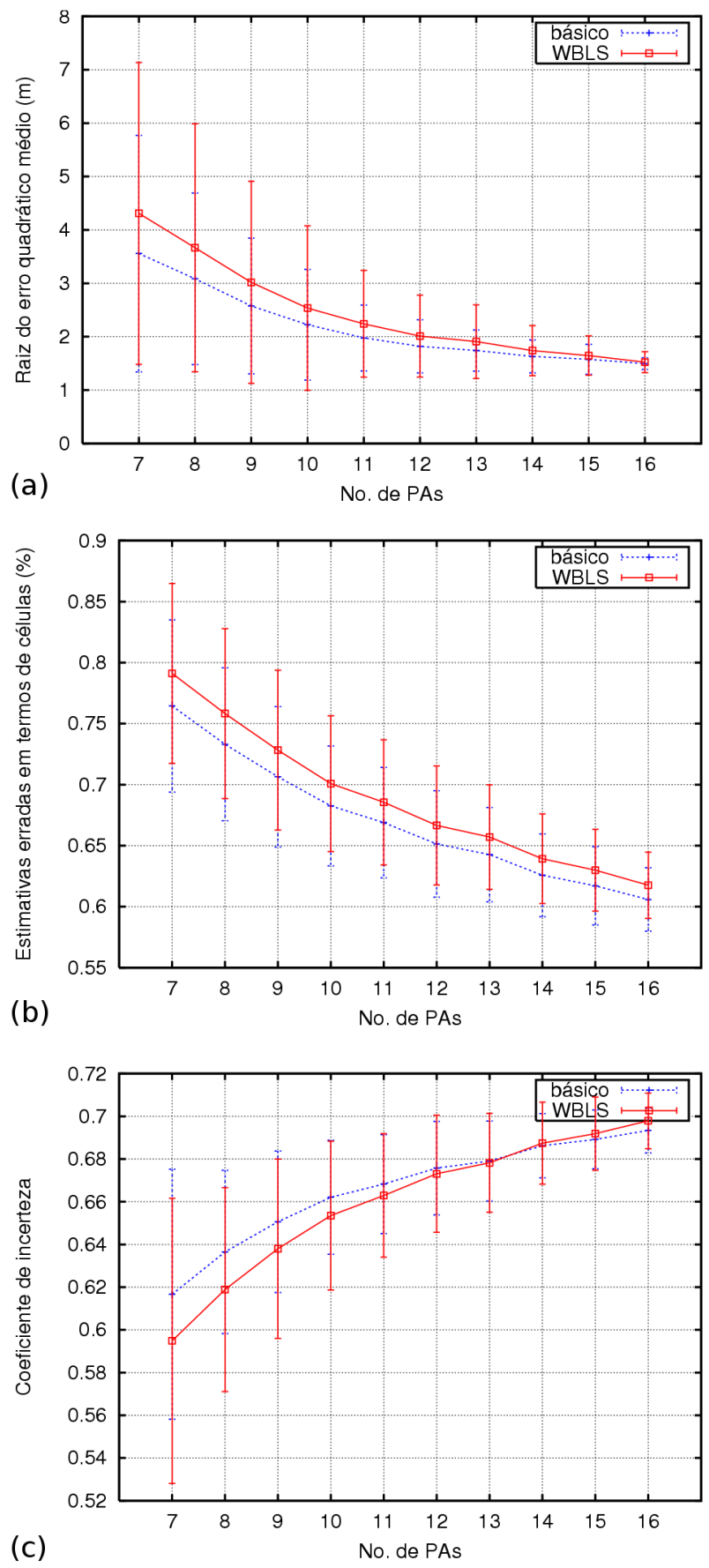

Figura B.8: Comparação de desempenho entre o WBLS e o sistema básico desconsiderando PA com falha, em função de diferentes medidas: (a) raiz do erro quadrático médio; (b) porcentagem de estimativas incorretas de célula; e (c) coeficiente de incerteza. 


\section{B.4 Experimentos com perda de sinal}

Os resultados dos experimentos com perda de sinal são apresentados nas figuras B.9, B.10 e B.11.
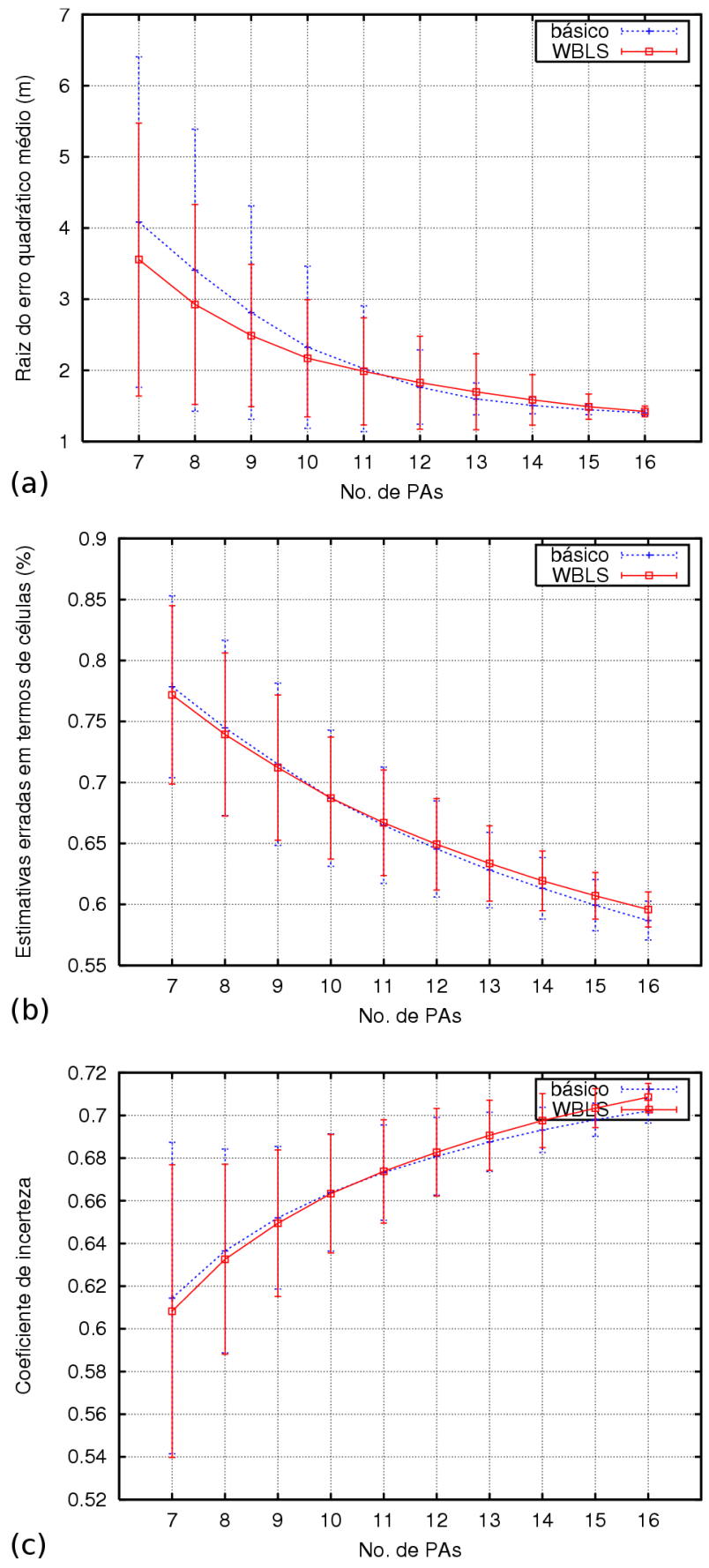

Figura B.9: Comparação de desempenho entre o WBLS e o sistema básico com simulação do desligamento de um PA com baixa presença na fase de treinamento, em função de diferentes medidas: (a) raiz do erro quadrático médio; (b) porcentagem de estimativas incorretas de célula; e (c) coeficiente de incerteza. 

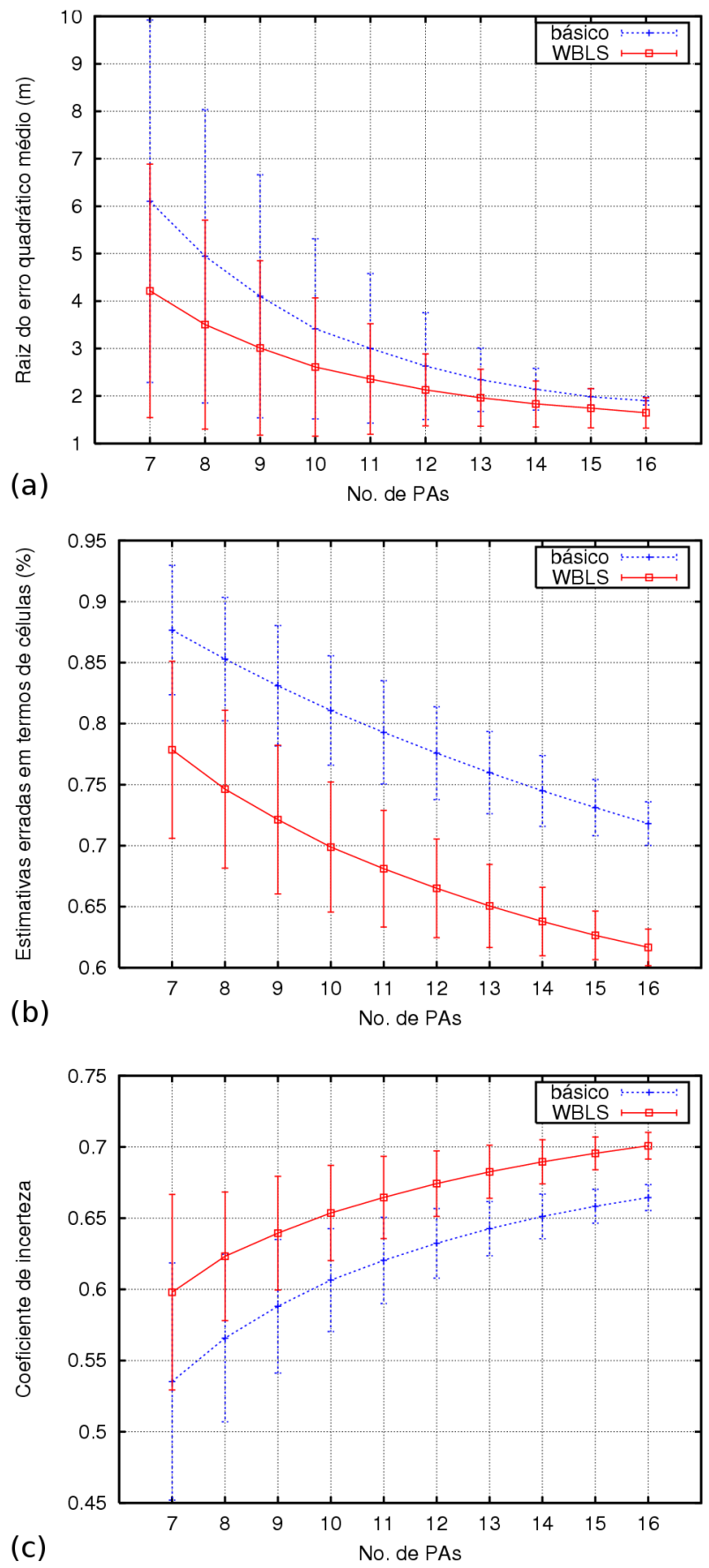

Figura B.10: Comparação de desempenho entre o WBLS e o sistema básico com simulação do desligamento de um PA com alta presença na fase de treinamento, em função de diferentes medidas: (a) raiz do erro quadrático médio; (b) porcentagem de estimativas incorretas de célula; e (c) coeficiente de incerteza. 

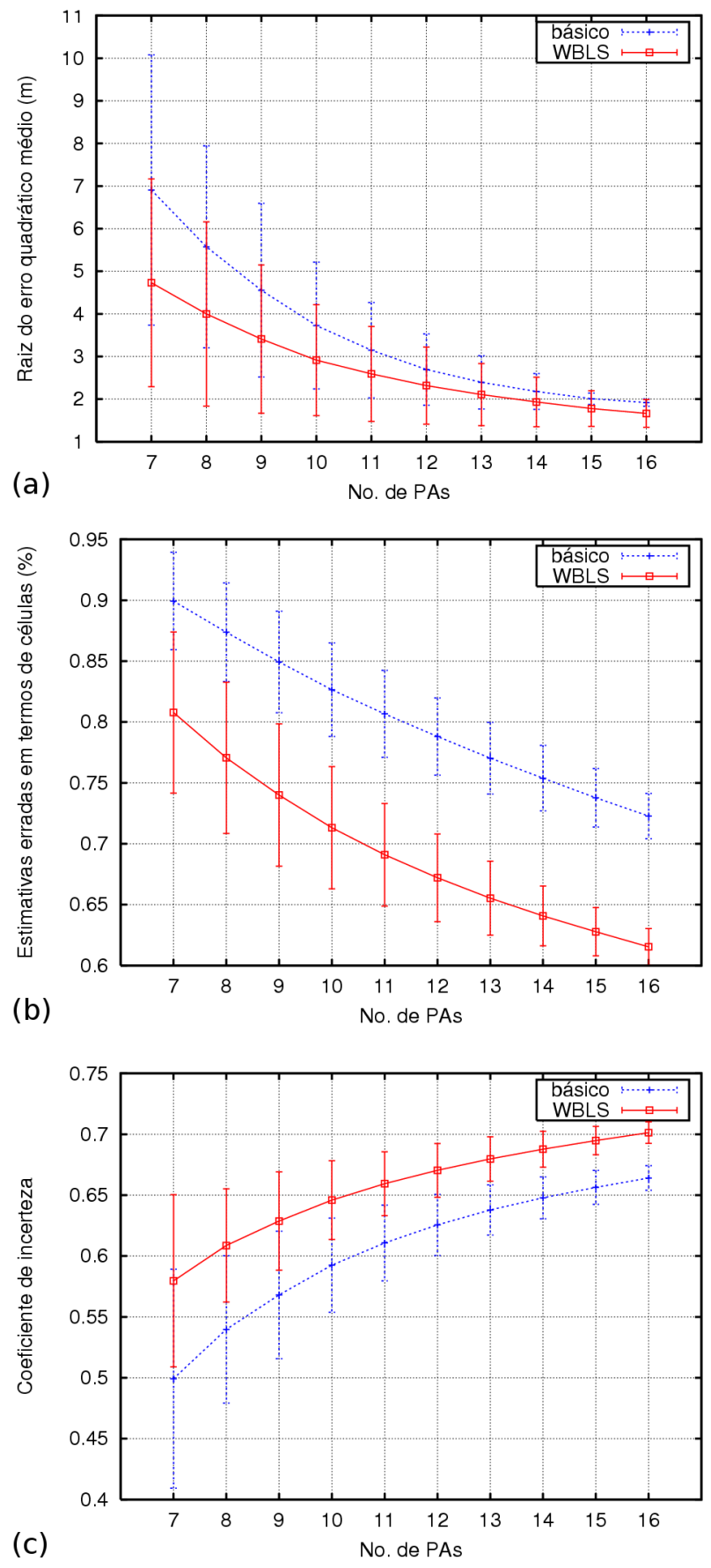

Figura B.11: Comparação de desempenho entre o WBLS e o sistema básico com simulação de desligamento de dois PAs, em função de diferentes medidas: (a) raiz do erro quadrático médio; (b) porcentagem de estimativas incorretas de célula; e (c) coeficiente de incerteza. 